Portland State University

PDXScholar

Summer 8-1-2014

\title{
Calcium Transport Inhibition, Stimulation, and Light Dependent Modulation of the Skeletal Calcium Release Channel (RyR1) by the Prototropic Forms of Pelargonidin
}

Thomas Joseph Dornan

Portland State University

Follow this and additional works at: https://pdxscholar.library.pdx.edu/open_access_etds

Part of the Biophysics Commons

Let us know how access to this document benefits you.

\section{Recommended Citation}

Dornan, Thomas Joseph, "Calcium Transport Inhibition, Stimulation, and Light Dependent Modulation of the Skeletal Calcium Release Channel (RyR1) by the Prototropic Forms of Pelargonidin" (2014).

Dissertations and Theses. Paper 1931.

https://doi.org/10.15760/etd.1930

This Dissertation is brought to you for free and open access. It has been accepted for inclusion in Dissertations and Theses by an authorized administrator of PDXScholar. Please contact us if we can make this document more accessible: pdxscholar@pdx.edu. 
Calcium Transport Inhibition, Stimulation, and Light Dependent Modulation of the Skeletal Calcium Release Channel (RyR1) by the Prototropic Forms of Pelargonidin

by

Thomas J. Dornan

A dissertation submitted in partial fulfillment of the requirements for the degree of

Doctor of Philosophy

in

Applied Physics

Dissertation Committee:

Jonathan Abramson, Chair

Gwen Shusterman

Reuben Simoyi

Robert Strongin

Portland State University

2014 
(c) 2014 Thomas J. Dornan 


\begin{abstract}
The principle calcium regulator in the muscle cell is the calcium ion release channel (RyR). Improper calcium homeostasis in the muscle cell is the foundation of many pathological states and has been targeted as a contributing factor to ventricular tachycardia, which is known to precede sudden cardiac arrest.
\end{abstract}

Numerous endogenous and exogenous compounds can affect the way RyR regulates calcium. In this study the anthocyanidin Pelargonidin $(\mathrm{Pg})$, an important natural colorant and dietary antioxidant, is evaluated for its effect on regulating the transport of calcium through the RyR1 of skeletal muscle sarcoplasmic reticulum. Pelargonidin undergoes time dependent structural changes in aqueous solutions at physiological $\mathrm{pH}$ and a mixture of up to seven forms of Pelargonidin are present in solution simultaneously. Pelargonidin is a unique RyR1 modulator. It can both stimulate and inhibit the RyR1 depending on the experimental conditions. In addition, when Pelargonidin is irradiated with white light, its inhibition properties on the RyR1 are essentially nullified. Proposed mechanisms include excited state charge shift within RyR1-Pg complexes. 


\section{Acknowledgements}

A sincere appreciation is extended to my advisor Jon Abramson for all of his time and support with regards to the completion of this project. The importance of Jon's mentoring and eagerness to share his extensive knowledge of the SR field cannot be overstated.

Financial support was partially provided by the award of teaching assistantships by the Department of Physics.

A large majority of cost of this degree was shouldered by my love and wife Laurie. Her emotional and financial support of our family during the all too long duration and cost of this work was more than ever could be expected. Laurie, thank you for your patience and your love. 


\section{Table of Contents}

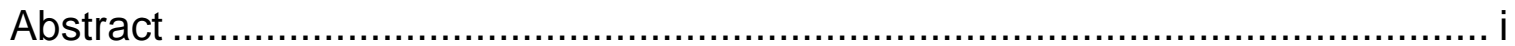

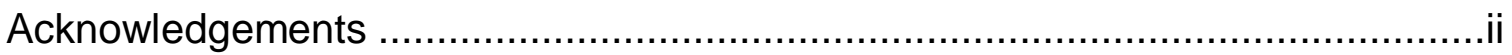

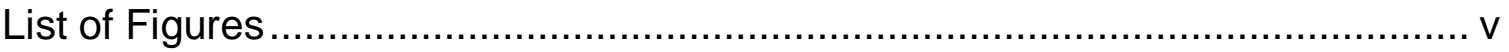

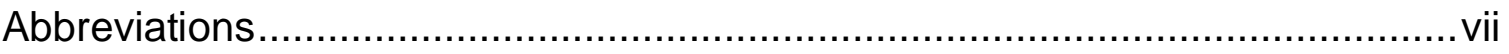

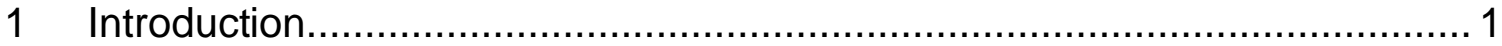

1.1 Oxidative Stress and Disease ................................................ 4

1.2 Oxidative Stress and Calcium Homeostasis in Muscle ......................... 5

1.3 CRC Modulation by Electron Donors and Acceptors.......................... 9

1.4 The Flavonoid Antioxidant - Calcium Homeostasis Connection ........... 12

1.4.1 Quercetin ................................................................... 12

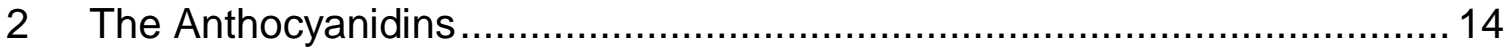

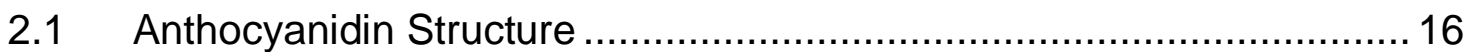

2.2 Anthocyanidin Structural Equilibrium ....................................... 18

2.3 Anthocyanidin Chemical and Physical Properties .......................... 20

2.3.1 Antioxidant Properties ....................................................... 20

2.3.2 Prooxidant Activity........................................................... 22

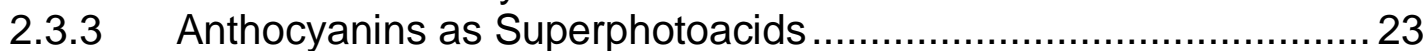

2.3.4 Anthcyanin Copigmentation and Self-Association...................... 24

2.3.5 Anthocyanin Excited State Redox Activity............................... 26

2.3.6 Photochromism ............................................................. 26

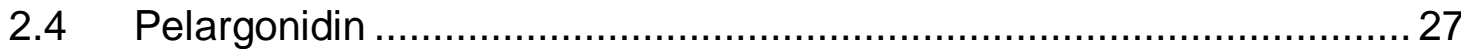

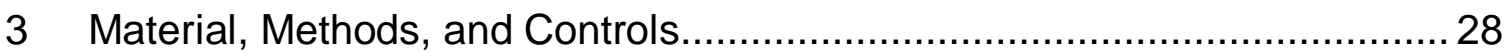

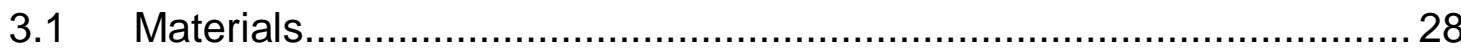

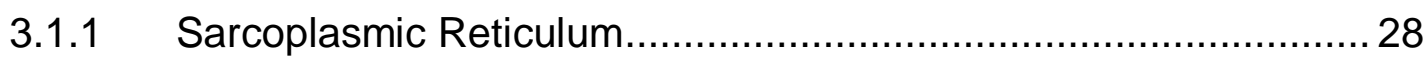

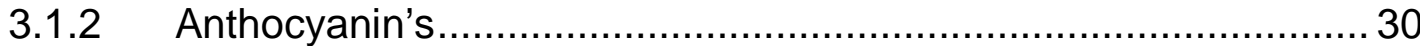

3.1.3 Miscellaneous Materials ..................................................... 30

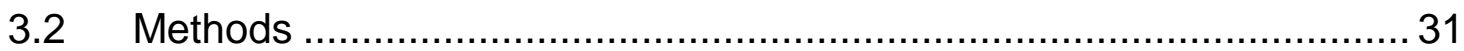

3.2.1 Active Efflux Experiments ............................................. 31

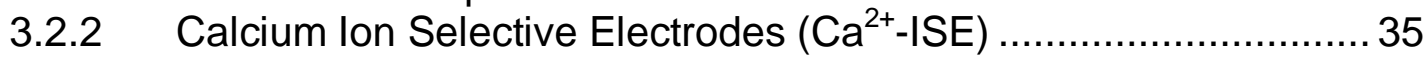

3.2.3 ATP Hydrolysis Measurements .......................................... 44

3.2.4 Anthocyanidin Preparations .............................................. 44

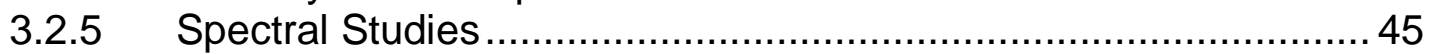

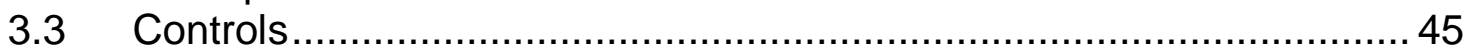

3.3.1 MeOH effects on calcium release rate .................................. 45

3.3.2 Pg, Cy, Dp do not inhibit the $\mathrm{Ca}^{2+}$-ATPase of the SSR ...............48

3.3.3 Pelargonidin Hydration Kinetics ............................................ 50

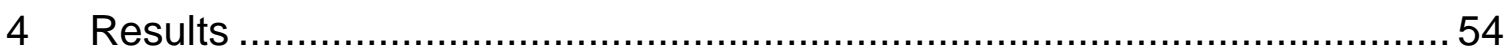


4.1 Concentration Dependent Modulation of the Initial Rate of $\mathrm{Ca}^{2+}$ Efflux from SSR by Varying Concentrations of Pg.

4.2 Concentration Dependent Modulation of the CMCR Rate of $\mathrm{Ca}^{2+}$ Efflux from SSR by Varying Concentrations of Pg .........................................5 57

4.3 Modulation of Efflux from sSR by Pelargonidin vs Time of Dilution......59

4.3.1 Initial Rate of $\mathrm{Ca}^{2+}$ Efflux by $30 \mu \mathrm{M}$ Pg Pre-buffered at $\mathrm{pH} 5.8$ vs Time of Dilution 59

4.3.2 CMCR Efflux by $30 \mu \mathrm{M}$ Pg Pre-buffered at pH 5.8 vs Time of

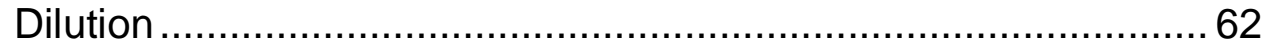

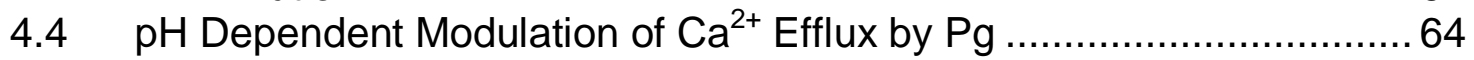

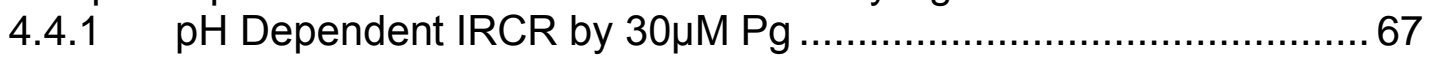

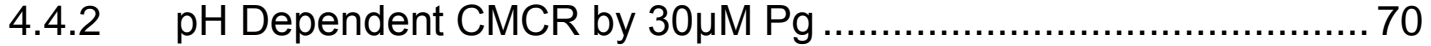

4.4.3 Comparison of Pg Effects on CMCR Efflux and the Relative Calculated Concentration of the Prototropic Forms of Pg ............. 76

4.5 Light Dependent Modulation of $\mathrm{Ca}^{2+}$ Efflux from SSR by Pg ............... 79

4.5.1 Light Dependent IRCR vs pH............................................... 79

4.5.2 Light Dependent CMCR Rate of $\mathrm{Ca}^{2+}$ Efflux vs $\mathrm{pH}$..................... 82

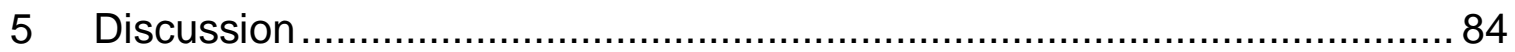

5.1 Proposed Mechanisms of Stimulation and Inhibition ......................... 88

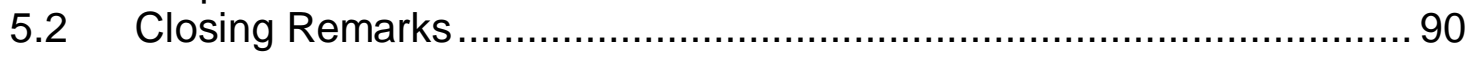

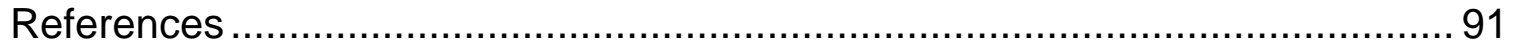




\section{List of Figures}

Figure 1.1 The Calcium Homeostasis Connection.......................................... 1

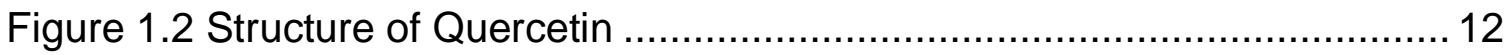

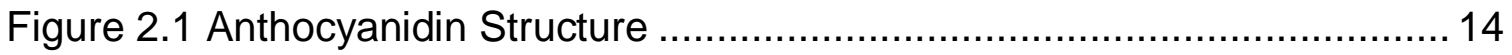

Figure 2.2 Pelargonidin (top), Cyanidin (middle), Delphinidin (bottom) ............. 15

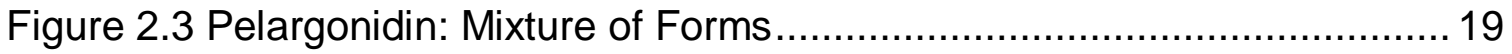

Figure 2.4 Molecular Structure of Pelargonidin Cation ................................... 27

Figure 3.1 Phases and Analysis Points of a Typical Active Ca ${ }^{2+}$ Efflux

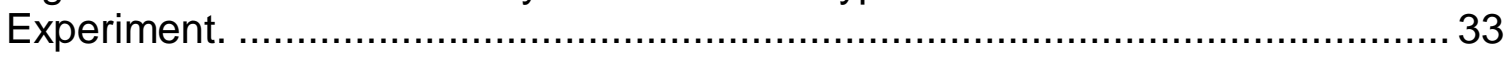

Figure 3.2 Excel Worksheet for the Determination of $\mathrm{Ca}^{2+}$-ISE Linearity, $\mathrm{mV}$ to $\left[\mathrm{Ca}^{2+}\right]$ Transform Equation, and Predicted Buffer $\left[\mathrm{Ca}^{2+}\right]$ Excel Worksheet ........ 43

Figure $3.3 \quad \mathrm{IRCR}$ and CMCR Effux Rates for Control vs $0.5 \% \mathrm{MeOH}$ vs $0.5 \% \mathrm{MeOH}+\mathrm{h} v$

Figure 3.4 Rate of A23187 Dependent NADH oxidation rate by SSR is not altered significantly by the addition of $20 \mu \mathrm{M} \mathrm{Pg}, \mathrm{Cy}$, or $\mathrm{Dp}$............................ 49

Figure 3.5 Pg Hydration Kinetics at pH 5.8............................................... 51

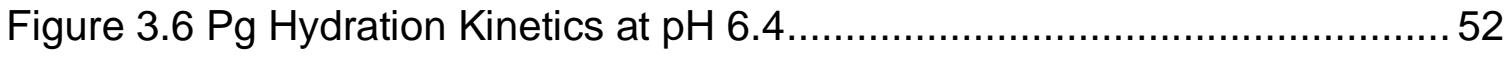

Figure 3.7 Pg Hydration Kinetics at pH 7.4 ................................................ 53

Figure 4.1 Pelargonidin Stimulates IRCR and Inhibits CMCR in a Concentration Dependent Manner (Experimental Trace Examples) ..................................... 55

Figure 4.2 Pelargonidin Stimulates IRCR from sSR at pH 7.4 in a

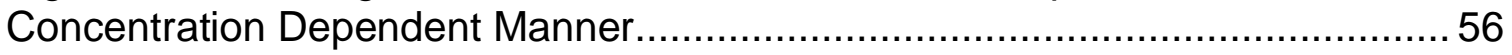

Figure 4.3 Pelargonidin Inhibits CMCR Rate from SSR at pH 7.4 in a Concentration Dependent Manner

Figure 4.4 IRCR Stimulation by $30 \mu \mathrm{M}$ Pg Decreases with Respect to Time when Pre-diluted in a pH 5.8 Efflux Buffer.

Figure 4.5 CMCR Inhibition by $30 \mu \mathrm{M}$ Pg Decreases with Respect to Time when Pre-diluted in a pH 5.8 Efflux Buffer 
Figure 4.6 Reference Chart of the Mole Fractions of the Prototropic Forms of

$\mathrm{Pg}$ vs $\mathrm{pH}$ Immediately After Dilution into an Aqueous Buffer 65

Figure 4.7 Calculated Mole Fractions of the Prototropic Forms of Pg vs pH Immediately After Dilution into an Aqueous Buffer 66

Figure 4.8 The Uptake and Efflux Kinetics of sSR Active Efflux Experiments are $\mathrm{pH}$ Dependent 68

Figure 4.9 IRCR Stimulation of $\mathrm{Ca}^{2+}$ Efflux by $30 \mu \mathrm{M} \mathrm{Pg}$ and $0.5 \mathrm{mM}$ Caffeine vs $\mathrm{pH} \quad 71$

Figure 4.10 Control Normalized IRCR by $30 \mu \mathrm{M}$ Pg vs pH .......................... 72

Figure $4.11 \mathrm{CMCR}$ Modulation of $\mathrm{Ca}^{2+}$ Efflux by $30 \mu \mathrm{M} \mathrm{Pg}$ and $0.5 \mathrm{mM}$ Caffeine vs $\mathrm{pH}$ 74

Figure $4.12 \%$ Difference of $30 \mu \mathrm{M}$ Pg Modulation of the CMCR Rate of $\mathrm{Ca}^{2+}$ Efflux with Respect to the $0.5 \% \mathrm{MeOH}$ control vs $\mathrm{pH}$.

Figure 4.13 Time Adjusted Concentration of the Pg Prototropic Forms at $\operatorname{CMCR}(\Delta \mathrm{t})$ vs $\mathrm{pH}$.

Figure 4.14 Irradiation with White Light Removes CMCR Inhibition by $30 \mu \mathrm{M} \mathrm{Pg}$ (Example Trace) 80

Figure 4.15 IRCR Modulation of Active $\mathrm{Ca}^{2+}$ Efflux by $30 \mu \mathrm{M} \mathrm{Pg}$ with and without Irradiation by White Light.

Figure 4.16 CMCR Modulation of Active $\mathrm{Ca}^{2+}$ Efflux by $30 \mu \mathrm{M} \mathrm{Pg}$ with and without Irradiation by White Light.

Figure 5.1 Anthocyanidin Form vs. Proposed Modulator Type..... 87 


\section{Abbreviations}

\begin{tabular}{|c|c|}
\hline$\left[\mathrm{Ca}^{2+}\right]$ & Calcium ion concentration \\
\hline$\left[\mathrm{Ca}^{2+}\right]_{\text {buf }}$ & Calcium ion concentration in buffer \\
\hline$\left[\mathrm{Ca}^{2+}\right]_{\text {high }}$ & Calcium ion concentration higher than that in buffer \\
\hline$\left[\mathrm{Ca}^{2+}\right]_{\text {low }}$ & Calcium ion concentration lower than that in buffer \\
\hline$[\mathrm{Pg}]$ & Pelargonidin concentration \\
\hline [Pg-initial] & Initial added concentration of pelargonidin \\
\hline$A^{-}$ & Anionic quinoidal base form of anthocyanidin \\
\hline A & Quinoidal base form of anthocyanidin \\
\hline ABTS $^{\cdot+}$ & 2,2'-azino-bis(3-ethylbenzothiazoline-6-sulphonic acid \\
\hline ADP & Adenosine diphosphate \\
\hline $\mathrm{AH}^{+}$ & Cationic form of anthocyanidin \\
\hline ATP & Adenosine triphosphate \\
\hline B & Hemiketal form of anthocyanidin \\
\hline $\mathrm{B}^{-}$ & Ionized hemiketal form of anthocyanidin \\
\hline BDE & Bond-dissociation energy \\
\hline C3 & Carbon 3 on $\mathrm{C}$ ring of anthocyanidin \\
\hline C3' & Carbon 3' on B ring of anthocyanidin \\
\hline C4' & Carbon 4' on B ring of anthocyanidin \\
\hline C5 & Carbon 5 on $A$ ring of anthocyanidin \\
\hline C5' & Carbon 5 ' on B ring of anthocyanidin \\
\hline C7 & Carbon 7 on $A$ ring of anthocyanidin \\
\hline $\mathrm{Ca}^{2+}$ & Calcium ion \\
\hline $\mathrm{Ca}^{2+}$-ATPase & Calcium ion pump or SERCA \\
\hline $\mathrm{Ca}^{2+}-\mathrm{ISE}$ & Calcium ion selective electrode \\
\hline $\mathrm{CaCl}_{2}$ & Calcium chloride \\
\hline Cc & cis-Chalcone isomer \\
\hline $\mathrm{Cc}^{-}$ & Ionized cis-Chalcone isomer \\
\hline $\mathrm{CHF}$ & Congestive heart failure \\
\hline CMCR & Calcium modulated calcium release \\
\hline $\operatorname{CMCR}(\Delta \mathrm{t})$ & Time to reach calcium modulated calcium release point \\
\hline $\mathrm{CRC}$ & Calcium release channel (aka Ryanodine receptor) \\
\hline $\mathrm{Ct}^{-}$ & Ionized trans-Chalcone isomer \\
\hline $\mathrm{Ct}$ & trans-Chalcone isomer \\
\hline $\mathrm{Cu}$ & Copper \\
\hline CVD & Cardiac vascular disease \\
\hline Су & Cyanidin \\
\hline DMSO & Dimethyl sulfoxide \\
\hline $\mathrm{Dp}$ & Delphinidin \\
\hline $\mathrm{DPPH}$ & 1,1-Diphenyl-2-Picrylhydrazyl radical \\
\hline $\mathrm{e}^{-}$ & Electron \\
\hline $\mathrm{EC}_{50}$ & Half maximal effective concentration \\
\hline EGTA & Ethylene glycol tetraacetic acid \\
\hline
\end{tabular}




\begin{tabular}{|c|c|}
\hline $\mathrm{EtOH}$ & Ethanol \\
\hline EtOH-HCl & Ethanol plus $0.1 \% \mathrm{HCl}$ \\
\hline $\mathrm{eV}$ & Electron volts \\
\hline GPx & Glutathione peroxidase \\
\hline GSH & Glutathione \\
\hline GSSG & Glutathione disulfide \\
\hline $\mathrm{H}$ & Hydrogen atom \\
\hline$+h v$ & Irradiated with white light \\
\hline$-h v$ & Absence of light \\
\hline $\mathrm{H}_{2} \mathrm{O}_{2}$ & Hydrogen peroxide \\
\hline $\mathrm{HCl}$ & Hydrochloric acid \\
\hline HEPES & Buffer: 4-(2-hydroxyethyl)-1-piperazineethanesulfonic acid \\
\hline HF & Heart failure \\
\hline $\begin{array}{l}\mathrm{IC}_{50} \\
\mathrm{IP}\end{array}$ & $\begin{array}{l}\text { Half maximal inhibitory concentration } \\
\text { lonization potential }\end{array}$ \\
\hline IRCR & Initial rate of calcium release \\
\hline LD & Lactate dehydrogenase \\
\hline LDL & Low-density lipoprotein \\
\hline LOD & Limit of detection \\
\hline MeLo & Methyl Linoleate \\
\hline $\mathrm{MeOH}$ & Methanol \\
\hline $\mathrm{MeOH}-\mathrm{HCl}$ & Methanol plus $0.1 \% \mathrm{HCl}$ \\
\hline $\mathrm{Mg}^{2+}$ & Magnesium ion \\
\hline $\mathrm{Mg}^{2+}$-ATP & Magnesium-ATP complex \\
\hline $\mathrm{MgCl}_{2}$ & Magnesium cholide \\
\hline $\mathrm{mM}$ & millimolar \\
\hline $\mathrm{mV}$ & millivolts \\
\hline $\mathrm{NAD}^{+}$ & Nicotinamide adenine dinucleotide \\
\hline $\mathrm{NADH}$ & Reduced form of nicotinamide adenine dinucleotide \\
\hline NADPH & Nicotinamide adenine dinucleotide phosphate \\
\hline $\mathrm{nM}$ & nanomolar \\
\hline $0^{\circ-}$ & Superoxide \\
\hline $\mathrm{p}\left[\mathrm{Ca}^{2+}\right]$ & $-\log _{10}\left[\mathrm{Ca}^{2+}\right]$ \\
\hline PEP & Phosphoenol pyruvate \\
\hline $\mathrm{Pg}$ & Pelargonidin \\
\hline PIPES & Buffer: piperazine- $\mathrm{N}, \mathrm{N}^{\prime}$-bis(2-ethanesulfonic acid \\
\hline PK & Pyruvate kinase \\
\hline $\mathrm{pK}_{\mathrm{a}}$ & Acid dissociation constant \\
\hline $\mathrm{pK}_{\mathrm{a} 1}$ & First acid dissociation constant \\
\hline $\mathrm{pK}_{\mathrm{a} 2}$ & Second acid dissociation constant \\
\hline PVC & Polyvinyl chloride \\
\hline QSAR & Quantitative structure activity relationship \\
\hline ROS & Reactive oxygen species \\
\hline
\end{tabular}




$\begin{array}{ll}\text { RyR } & \text { Ryanodine receptor (aka calcium release channel) } \\ \text { RyR1 } & \text { Ryanodine receptor type 1 - skeletal muscle isoform } \\ \text { RyR2 } & \text { Ryanodine receptor type } 2 \text { - cardiac muscle isoform } \\ \text { SCD } & \text { Sudden cardiac death } \\ \text { Sec } & \text { seconds } \\ \text { SOD } & \text { Superoxide Dismustase } \\ \text { SR } & \text { Sarcoplasmic reticulum } \\ \text { SSR } & \text { Skeletal muscle sarcoplasmic reticulum } \\ \text { StdDev } & \text { Standard deviation } \\ \text { TEAC } & \text { Trolox equivalent antioxidant capacity } \\ \text { TOD } & \text { Dilution duration time of anthocyanidin in aqueous buffer } \\ \text { VT } & \text { Ventricular tachyarrhythmia } \\ \mu M & \text { micromolar } \\ \text { XTT } & \text { 2,3-Bis(2-methoxy-4-nitro-5-sulfophenyl)-2H-tetrazolium-5- } \\ & \text { carboxanilide }\end{array}$




\section{Introduction}

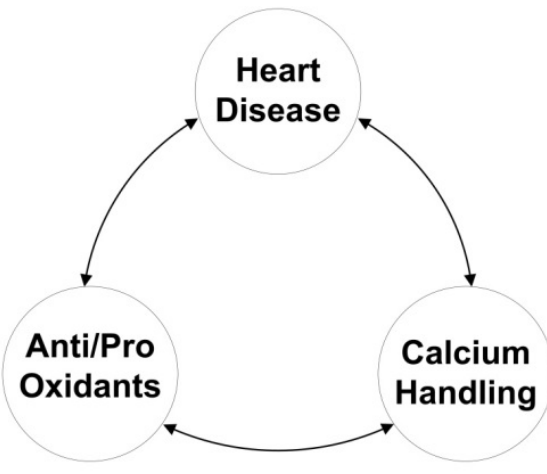

Figure 1.1 The Calcium Homeostasis Connection

Cardio vascular disease (CVD) causes more deaths than any other disease on the globe (World Health Organization). Although CVD encompasses numerous distinct pathological mechanisms, sudden cardiac death (SCD), the abrupt loss of heart function, is estimated to account for approximately 50\% of CVD related deaths. A majority of the SCD fatalities is attributed to ventricular tachyarrythmias (VT) (Huikuri, Castellanos, and Myerburg 2001). In an effort to improve the quality of life for non-fatal CVD victims, reduce CVD deaths, and minimize the enormous economic costs associated with CVD, extensive epidemiological studies and laboratory research continue to be funded and performed in hopes to better explain the pathological molecular mechanisms of CVD.

Non-behavioral risk factors of CVD include increasing age, male gender, and heredity related factors (children of people with heart disease and race related 
increased risks). Behavioral risk factors (ones that we can change) account for over $90 \%$ of the risk of heart failures (HF). These factors include cigarette smoking, abnormal blood lipid levels (high cholesterol), hypertension (high blood pressure related), diabetes, abdominal obesity, a lack of physical activity, low daily fruit and vegetable consumption, alcohol over consumption, and psychosocial factors. (AHA-Heart and Stroke Update 4/2009 referenced Lancet. 2004;364:937-952).

Interestingly, a subsequent epidemiological study found an exception to that rule, the people of southern France consume more fat and smoke more cigarettes than other countries with a similar incidence of CVD deaths. Additional studies revealed that the same population also had a slightly different diet which included higher intakes of vegetables, fruits, and wine. The lower incidence of CVD was quickly attributed to the constituents of those foods which were abundant in flavonoid antioxidant compounds. Since then, research has been conducted on almost every conceivable natural antioxidant to be found in those foods. Extensive quantitative-structure activity relationship (QSAR) studies have characterized those compounds for their antioxidant properties. Naturally, those compounds that exhibited the highest level of antioxidant activity in vitro were perceived as the 'best of the best'. These compounds have been studied extensively in the literature. If antioxidants are the 'cure', then it follows that oxidants may be the cause. Researchers targeted native reactive oxidant species (ROS) and studied their effects on the proliferation of CVD biomarkers in vitro. 
The results all seem to imply that ROS cause severe damage to biological processes and can be attributed to increased incidence of several CVD pathologies. In addition to the ROS connection, recent studies (Lehnart et al. 2004; A. Belevych et al. 2007; A. E. Belevych et al. 2008; A. E. Belevych et al. 2009; A. Belevych and Terentyev 2010) related to ventricular tachyarrythmias, a significant contributor to sudden heart failure, have shown a connection between VT and increased levels (overload) of calcium $\left(\mathrm{Ca}^{2+}\right)$ in the heart muscle cell via 'leaky' calcium release ion channels (ryanodine receptor). The ryanodine receptor (RyR) is known to have reactive thiol residues that are extremely sensitive to the oxidation by ROS and numerous other compounds. Oxidation of these thiols can causes increased channel activity and $\mathrm{Ca}^{2+}$ conductance (J.J. Abramson and Salama 1988; Jonathan J. Abramson and Salama 1989; J. J. Abramson et al. 1988; J. J Abramson, Cronin, and Salama 1988).

There may indeed be a connection between increased oxidative stress in the cell (oxidative stress) and abnormal calcium handling by the RyR (calcium overload) in cardiac myocytes, and deaths by ventricular tachyarrythmias. Dietary antioxidants that play a part in reducing ROS in the cell may also have a part to play in the decreased incidence of CVD deaths of those populations engaged in higher risk behaviors (disease related). However, numerous studies have shown that antioxidant compounds, especially the good ones, can also act as prooxidants. These antioxidant compounds have also been shown to bind to proteins and protective enzymes impacting their function (Graziani et al. 1982; 
Kaldas et al. 2005). The intention of the investigation of various dietary antioxidants is to characterize that compound for its potential beneficial properties and its potential damaging properties so that fully informed and educated decisions can be made as to whether or not their benefits outweigh their risks. Due to the possible prooxidant activity of flavonoid antioxidants, it is clear that before recommendations can be made regarding their dietary inclusion, any impact that they may have on other biological systems must be understood. Given the importance of $\mathrm{Ca}^{2+}$ homeostasis in both skeletal and cardiac muscle, the interaction of these compounds need to be evaluated with regards to their possible modulation effects on the RyR.

\subsection{Oxidative Stress and Disease}

It is now well accepted that elevated ROS levels are associated with numerous bodily disease states including cardio vascular diseases, including but not limited to, atherosclerosis pathology (Khatri et al. 2004), cardiac hypertrophy (Higuchi et al. 2002), and myocardial lipotoxicity (Sharma et al. 2004). Abnormal ROS levels are also connected with a variety of cancers, Alzheimer's Disease, inflammatory diseases (Hidalgo and Donoso 2008; Zima and Blatter 2006; A. E. Belevych et al. 2009) as well as skeletal muscle fatigue and failure (Moopanar and Allen 2005). Lipid peroxidation and sulfhydryl group oxidation during ischemia-reperfusion can lead to abnormally high cell $\mathrm{Ca}^{2+}$ levels and contractile dysfunction (Dhalla et al. 1999). Improper $\mathrm{Ca}^{2+}$ handling in the heart muscle has been connected to atrial arrhythmogenesis and contractile dysfunction in dogs with congestive heart 
failure (CHF) (Yeh et al. 2008). Evidence has shown that reactive oxygen species (ROS) alter calcium pump function (Kourie 1998; Kaplan et al. 2003), alter calcium current reduction in L-type calcium channels (Guerra et al. 1996), and decrease contractility via altered calcium handling (He et al. 2003) in cardiac myocytes. Recently, there have been numerous studies pointing to $\mathrm{Ca}^{2+}$ overload via improper $\mathrm{Ca}^{2+}$ handling by the RyR as an underling cause of arrhythmias and sudden cardiac death (A. Belevych et al. 2007; A. E. Belevych et al. 2009).

\subsection{Oxidative Stress and Calcium Homeostasis in Muscle}

Calcium can signal and activate biological processes via dynamic variations in its concentration within cells. The concentration of free $\mathrm{Ca}^{2+}$ is generally controlled by its transport in and out of the cytoplasm of cells by ion channel proteins located in the membrane of the endoplasmic/sarcoplasmic reticulum organelles within the cell. This $\mathrm{Ca}^{2+}$ movement alters the cytoplasmic (intra-cellular) $\mathrm{Ca}^{2+}$ concentration which in turn impacts $\mathrm{Ca}^{2+}$ binding to various biological substrates. An important example of $\mathrm{Ca}^{2+}$ signaling is the binding of $\mathrm{Ca}^{2+}$ to specific muscle cell proteins. This interaction is mandatory for our muscles to contract and it also controls how much force is generated during the contraction. Indeed, without $\mathrm{Ca}^{2+}$ signaling, our muscles would cease to function and we would die. Improper functioning of the $\mathrm{Ca}^{2+}$ regulatory proteins can lead to pathological $\mathrm{Ca}^{2+}$ homeostasis conditions that can severely decrease the quality of human life and 
also lead to eventual death. The importance of knowing how the $\mathrm{Ca}^{2+}$ level in muscle cells is regulated and knowing what causes changes in that regulation cannot be overstated. Studies to determine why muscles malfunction, fatigue, and fail have consumed researchers for many decades. Although the normal functioning of the muscle is the result of synergistic cooperation from numerous proteins that reside in the muscle cell, the main regulatory protein, the one that controls the fast $\mathrm{Ca}^{2+}$ transient signals within the cell, is called the ryanodine receptor (RyR). The RyR is, simply put, the valve that opens and closes controlling the concentration of $\mathrm{Ca}^{2+}$ within the cell. Increased $\mathrm{Ca}^{2+}$ levels allow for $\mathrm{Ca}^{2+}$-protein interactions that allow the contractile process of the muscle to occur. The RyR is very sensitive to the environment within the cell. It is sensitive to $\mathrm{Ca}^{2+}$ concentrations, the redox environment, binding of other closely associated proteins, and numerous other endogenous and exogenous compounds. All of these can have an effect on the way the RyR manages the $\mathrm{Ca}^{2+}$ level in the cell. This is of utmost importance because too much, or too little, $\mathrm{Ca}^{2+}$ can cause the concert of cooperation between the cellular proteins to breakdown which may lead to various pathological conditions and even death. It has been shown that one of the most important cellular conditions, with regards to proper $\mathrm{Ca}^{2+}$ homeostasis regulation by the $\mathrm{RyR}$, is the redox environment within the cell (Jonathan J. Abramson and Salama 1989; Jonathan J. Abramson and Salama 1988; Trimm, Salama, and Abramson 1986). The redox potential in the cell is related to the relative ease by which the constituents in the cell 
environment can reduce (donate electrons to) the RyR or oxidize (accept electrons from) the RyR. The RyR is a large homotetrameric membrane protein containing four subunits of $\sim 5000$ amino acids and $\sim 565 \mathrm{kDa}$ each totaling an approximate total molecular mass of 2.3 megadaltons (Du et al. 2002). The protein contains approximately 320-400 cytoplasmic, oxidation sensitive, cysteine residues (Xu et al. 1998). Many of these cysteines have thiol side chains that are very sensitive to oxidization. When the thiols are oxidized, intra-molecular cystines or cysteine-oxidizer adducts can be formed. It has been shown that some of the thiols on the RyR activate the channel when they are exposed to oxidizing conditions and that some of the thiols inhibit the channel when oxidized. (Jonathan J. Abramson and Salama 1988; Jonathan J. Abramson and Salama 1989; Dulhunty et al. 2000). To maintain proper cell function, the redox potential of the muscle cell environment is kept in a tightly controlled and reduced state by the relative ratios (redox couple) of a few important endogenous compounds capable of cyclic redox states. The redox state of the cellular environment can be impacted by all of the cellular redox couples present with each couple contributing via an additive effect. However, due to its high concentration and respective reducing capacity, the glutathione disulfide/glutathione (GSSG/2GSH) couple is considered to be the main redox buffer of the cell and the state (value) of this couple alone is typically used as an indication of the state of the redox environment of the cell (Schafer and Buettner 2001). The relative concentration of GSH present in the cell, and consequently, the redox environment is impacted 
by the invasion of oxidative species. The main endogenous oxidative species are derivatives of either oxygen or nitrogen. In particular, oxidative free radical compounds, hydrogen peroxide, and derivatives of nitric oxide. These are commonly referred to as reactive oxygen species (ROS) or reactive nitrogen species (RNS). ROS are natively generated and released from the oxidative phosphorylation processes of the mitochondria in the cell and by other mechanisms such as xanthine oxidase $(\mathrm{XO})$ and $\mathrm{NAD}(\mathrm{P}) \mathrm{H}$ oxidases. ROS can impart their damage by further increasing ROS levels via autoxidation reactions that further increase the levels of oxidants by directly attacking and altering (taking or donating electrons) cellular membranes and proteins causing altered function (Sen and Packer 2000). Increased levels of ROS can be generated during increased levels of exercise, exposure to environmental pollutants, and consumption of pro-oxidant compounds in food and beverages. In order to keep the redox environment tightly controlled (and in a reduced state), the body has a host of endogenous antioxidant defenses against these oxidants. Antioxidants are tasked with neutralizing the ROS by donating or accepting electrons or hydrogens to or from the ROS minimizing or nullifying its reactivity before the ROS reaches critical cellular substrates. In doing so, the antioxidant generally becomes a radical species itself but one that is more stable and relatively unreactive as compared to the original ROS. The main endogenous antioxidant compounds of the cell are glutathione (GSH), the glutathione peroxidase system, CoEnzyme Q, superoxide dismustase (SOD), and catalase. This defense 
network is effective at protecting against various ROS under normal cell conditions but high levels of oxidants, generated during times of high oxygen consumption (strenuous exercise) or as a result of prooxidant intake (air pollutants or high fat diets), can overwhelm the endogenous defenses. These increased levels of oxidant compounds can easily overwhelm the endogenous antioxidants inducing a state of oxidative stress in the cell (M. J. Davies and Dean 1997; Fridovich 1978; K. J. Davies et al. 1982).

\subsection{CRC Modulation by Electron Donors and Acceptors}

Although redox control of the thiol-disulfide balance of the calcium release channel (CRC) is a well-established and accepted modulating mechanism of the $\mathrm{CRC}$, the modulation by non-thiol compounds is less understood. The Abramson group has been accumulating evidence that non-thiol CRC modulators may work on the CRC via an electron donation or withdrawing mechanism (Marinov et al. 2007; Ye et al. 2012). Through a patented free radical scavenging assay (Jonathan J. Abramson and Marinov 2012) involving the manipulation of dye radical (Methylene Blue) life-times and the resulting formation and measurement of superoxide reactive compounds (XTT), the relative electron donor and acceptor characteristics can be indirectly compared. They observed that well known CRC stimulators such as caffeine, doxorubicin, and mitoanthrone all exhibit electron accepting characteristics and that known CRC inhibitors, 
tetracaine and procaine, exhibit electron donor characteristics. The modulation by caffeine and tetracaine, on ryanodine binding on the CRC indicated a competitive interaction. If the method of modulation of the CRC is indeed by an electron donation and accepting mechanism, the results imply that there is a common mutual site involved. Additionally, they looked at the affect that caffeine and tetracaine have on the redox potential of the skeletal muscle RyR (RyR1) and found that addition of caffeine, an electron acceptor, shifted the redox potential of the reactive thiols on RyR1 to more negative values, favoring thiol oxidation and a resulting channel open state. In contrast, tetracaine (an electron donor), shifted the redox potential to more positive values, favoring the thiol's reduced state and a resulting shift to a more closed state of the channel. An additional assay performed utilizing the thiol labeling, florescent indicator CPM (7-diethylamino-3-(4'-maleimidylphenyl)-4-methylcoumarin), showed that the number RyR1 thiols increased when in presence of the electron donor tetracaine $(5 \mu \mathrm{M})$ and decreased when in the presence of the electron acceptor caffeine (2mM). In all, the results established a correlation between non-thiol RyR1 modulating compounds and their electron accepting and donating characteristics. RyR1 activators that shifted the redox potential to more negative values were also electron acceptors and RyR1 inhibitors that shifted the redox potential to more positive values are electron donors. The implications proposed are that these compounds act via a weak redox mechanism where the binding of these compounds results in a charge transfer complex that shifts electron density to or 
away from the RyR1 which then allosterically influences the thiol-disulfide balance (Marinov et al. 2007).

Also supporting this redox theory as a mechanism of RyR1 modulation, the Abramson group and Strongin groups chemically modified known RyR1 modulating compounds by replacement or alteration of the compound's functional groups. They modified the known RyR1 activator 4-CmC (an electron acceptor as measured by the dye scavenging radical assay previously mentioned) by replacing the chlorine group with a methoxy group they transformed $4-\mathrm{CmC}$ from an electron acceptor to 4-MmC, an electron donor. At the same time, the known stimulating effects of $4-\mathrm{CmC}$ on the RyR1 were transformed into inhibitory effects (lowering of single channel open probability) by 4-MmC. They also enhanced the electron donating properties of the antiarrhythmic drug K201 by substitution of a carboxy group for a methoxy group and the addition of dioxyl moiety to the compound. Again, the increased electron donating properties of the compound coincided with increased single channel inhibition effects (Ye et al. 2012).

The results thus far for the theory of charge transfer as an underlying mechanism for weak redox control of the CRC is promising and is applicable to the modulating mechanisms proposed for the effects that anthocyanidins have on the CRC as discussed in the following sections. 


\subsection{The Flavonoid Antioxidant - Calcium Homeostasis Connection}

\subsubsection{Quercetin}<smiles>O=c1c(O)c(-c2ccc(O)c(O)c2)oc2cc(O)cc(O)c12</smiles>

Figure 1.2 Structure of Quercetin

Studies on the interaction of flavonoids with SR or the RyR are sparse. However, one popular flavonoid antioxidant, quercetin, has been shown to activate $\mathrm{Ca}^{2+}$ release from the SR skeletal muscle (Kim, Ohnishi, and Ikemoto 1983). Quercetin is a popular dietary antioxidant found in numerous vegetables, fruits, nuts, and teas. It has been extensively studied due to its excellent antioxidant properties and inclusion in numerous foods. Lee et. al. (Lee, Meissner, and Kim 2002) showed that quercetin activates single RyR channel open probability $\left(E_{50}\right.$ of $91.0+/-15 \mu \mathrm{M}$ at $10 \mu \mathrm{M} \mathrm{Ca}^{2+}$ ) more effectively than the well-known RyR activator caffeine $\left(\mathrm{EC}_{50}\right.$ of $\sim 2.93 \mathrm{mM}$ at $\left.10 \mu \mathrm{M} \mathrm{Ca}^{2+}\right)$. Quercetin also exhibited a higher maximal open probability $\left(P_{0}=0.89\right.$ at $\left.250 \mu \mathrm{M}\right)$ as compared to caffeine $\left(P_{0}=0.66\right.$ at $\left.9 \mathrm{mM}\right)$. With regards to the redox sensitivity of the RyR, further tests were conducted to assay the effects of quercetin in the presence of the reduced and oxidized forms of glutathione (a cellular redox couple and as well as an 
endogenous antioxidant). The results showed that the effects of 5mM GSSG (a RyR1 stimulant) plus $0.3 \mathrm{mM}$ quercetin on the RyR1 were not reversed by $5 \mathrm{mM}$ GSH (a RyR1 inhibitor). This may indicate that quercetin does not work via a redox dependent pathway. However, GSSG $\left(\mathrm{EC}_{50} \sim 0.09 \mathrm{mM}\right)$ has been shown to be a much more potent stimulator in single channel experiments than GSH is an inhibitor ( $\left.\mathrm{IC}_{50} \sim 2.4 \mathrm{mM}\right)$ (Zable, Favero, and Abramson 1997) and therefore the amounts of GSH and GSSG used by Lee et. al. may have played a part in the lack of inhibitory response by GSH. Lee et. al. also showed that the known stimulatory effects of $\mathrm{K}^{+}$-ATP on the RyR partially inhibited the stimulation by quercetin indicating that they may share the same binding site or that the effects of ATP on the channel may allosterically affect quercetin binding. These results are interesting from the stand point that quercetin appears to have a direct effect on the RyR yet not via a redox pathway. This is surprising since quercetin has a catechol group (ortho hydroxyls) on its B-ring which is notorious for being oxidized to semiquinone radicals and quinones which have prooxidant properties and directly react with protein thiols (Metodiewa et al. 1999; Boots et al. 2003). 


\section{The Anthocyanidins}

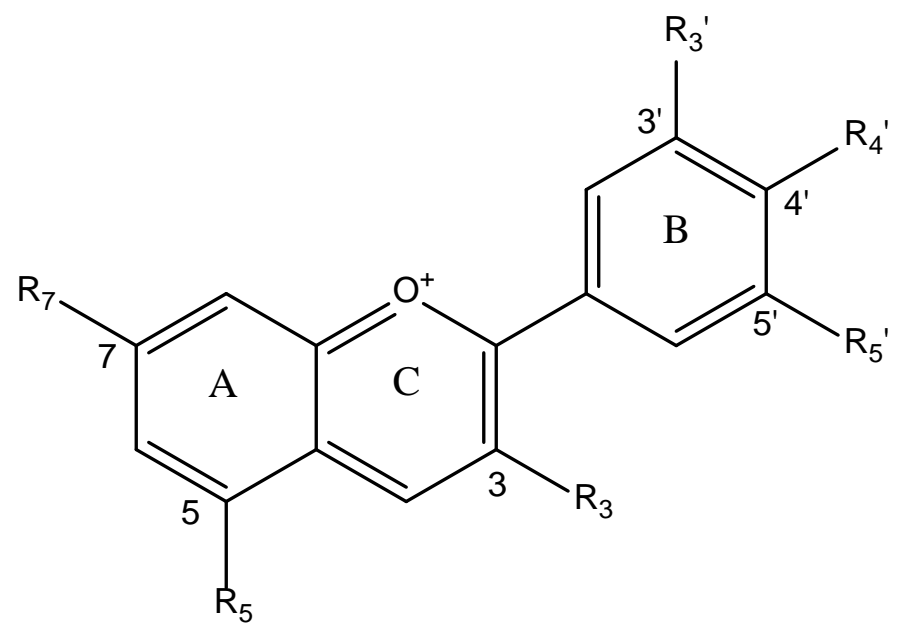

Figure 2.1 Anthocyanidin Structure

Anthocyanidins are a subclass of flavonoids and are best known for the beautiful colors they impart to nature. They are responsible for most of the intense orange, red, blue, and purple colors exhibited in leaves, flowers, and fruits (Harborne, Mabry, and Mabry 1975). The chemical and biological properties of these compounds are very complex. Unlike other flavonoids, anthocyanidins are structurally unstable in weakly acidic to alkaline solutions. Upon exposure to these conditions, they will immediately start to transform into several different structural forms each with distinct chemical properties. The relative proportions of these forms is dependent on the $\mathrm{pH}$ of the solution and the 
<smiles>Oc1ccc(-c2[o+]c3cc(O)cc(O)c3cc2O)cc1</smiles><smiles>Oc1cc(O)c2cc(O)c(-c3ccc(O)c(O)c3)[o+]c2c1</smiles><smiles>Oc1cc(O)c2cc(O)c(-c3cc(O)c(O)c(O)c3)[o+]c2c1</smiles>

Figure 2.2 Pelargonidin (top), Cyanidin (middle), Delphinidin (bottom) 
specific functionalization of the compound (Brouillard and Delaporte 1977;

Brouillard and Dubois 1977; Brouillard, Iacobucci, and Sweeny 1982; Jurd 1963; Jurd and Geissman 1963; Jurd 1964; Jurd and Waiss 1965). Anthocyanidins are compounds of broad and intense interest due to their commercial value as potential food colorants, food preservatives (antioxidants), and, as of more recently, their potential health benefits.

\subsection{Anthocyanidin Structure}

Anthocyanidins are one of the six sub-classes of Flavonoids (itself being a subclass of polyphenols). They are compounds of the plant kingdom that have the general structure of a flavylium cation (2-phenylchromenylium) with a $\mathrm{C}_{6} \mathrm{C}_{3} \mathrm{C}_{6}$ skeleton and with functionalization occurring at specific locations on the structure (see Figure 2.1). Functional groups are typically referred to by the number of the carbon to which it is attached (e.g. The C4' hydroxyl or the 4'-OH). Additionally, the compound is also characterized by its rings A, B, and C. Anthocyanidins are salts and usually are identified along with a chloride counter ion. The counter ion dissociates with the main molecule in solution which leave a positive charge on the compound. Anthocyanidins provide most of the red to purple colors observed in flowers, leaves, fruits, and vegetables. They share a common function in the phyto-kingdom as pigments used to attract insects for pollination, cellular signaling molecules, anti-fungal protection, and UV light protection. Specific anthocyanidins are identified by how the base structure is functionalized with hydrogens, hydroxyl, methoxy, and sugar groups and the amount and type of 
substitution contributes greatly to the color properties of the molecule. There are 23 known anthocyanidins (Andersen and Markham 2006). Anthocyanidins have poor solubility in aqueous solutions but when sugar groups are attached (anthocyanins), they become more soluble and as such, that is the form that is found most in nature with more than 500 known anthocyanins documented. Although anthocyanins are the more prevalent, the functional properties of those compounds are typically attributed to the aglycon form (anthocyanidin) (Estevez and Mosquera 2008; Harborne, Mabry, and Mabry 1975).

Six anthocyanidins that are considered to be the most important mainly due to their widespread distribution in nature are pelargonidin, cyanidin, delphinidin, petunidin, peonidin, and malvidin. Three of these six are considered to be the principle anthocyanidins due to their minimal substituent groups: delphinidin (Dp), cyanidin (Cy), and pelargonidin (Pg) (Figure 2.2). These three all have the same hydroxyl functionality on the 3,5 , and 7 carbons of the $A$ and $C$ rings. They differ in the amount of hydroxyl groups on the B-ring. The addition of hydroxyl groups to the B-ring ( 1 for pelargonidin, 2 for cyanidin, and 3 for delphinidin) causes a bathochromic (red) shift in their absorption spectrum. They have absorbance maxima at 530nm, 545nm, and 556nm (respectively) when prepared in acidified ethanol (Cabrita, Fossen, and Andersen 2000b). 


\subsection{Anthocyanidin Structural Equilibrium}

Anthocyanidins are native to the acidic conditions of the plant cell. Under these conditions, the anthocyanidins predominately exist in the 'flavylium cation' form as shown in Figure 2.2. Upon placing them in a more alkaline aqueous environment, they become unstable and their structure is altered in various ways depending mainly on the $\mathrm{pH}$ but temperature and light can also play a role. At very acidic $\mathrm{pH}$, anthocyanidins exist almost exclusively in the flavylium cationic form $\left(\mathrm{AH}^{+}\right)$(see Figure 2.3). When subjected to higher $\mathrm{pH}(\sim 5)$, anthocyanidins exhibit three distinct chemical reactions involving proton transfers, hydration, and tautormerization. Upon a $\mathrm{pH}$ jump to $\sim 5$, deprotonation immediately occurs on the hydrogen (or hydrogens) of the flavylium cation with the lowest bond disassociation enthalpy (BDE) resulting in the quinoidal base form $(A)$ or the quinoidal base anion form $\left(\mathrm{A}^{-}\right)$. The flavylium cation $\left(\mathrm{AH}^{+}\right)$and the quinoidal base (A) quickly (<1 sec) come to an equilibrium. On a slower time scale (minutes to hours), $\mathrm{AH}^{+}$undergoes hydration to obtain a mixture of the hemiketal $\left(\mathrm{B} / \mathrm{B}^{-}\right)$and the cis and trans-chalcone isomers with mole fractions dependent on the specific anthocyanidin as well as the $\mathrm{pH}$, temperature, and irradiation conditions. (Brouillard and Delaporte 1977; Brouillard and Dubois 1977). 

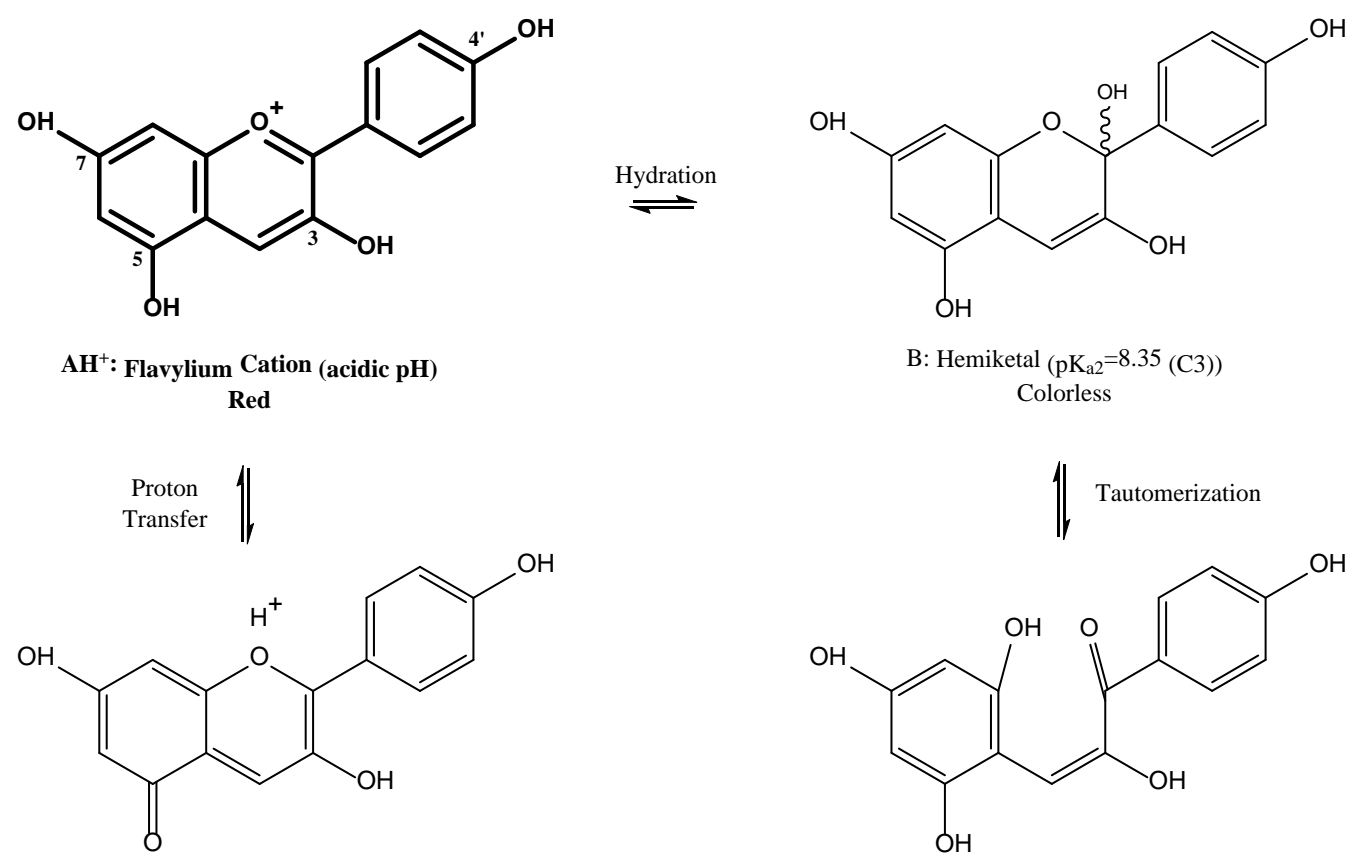

A: Quinoidal Base $\left(\mathrm{pK}_{\mathrm{a} 1}=5.79(\mathrm{C} 5)\right)$
Purple

$$
\begin{gathered}
\text { Cc: } \text { cis-Chalcone }\left(\mathrm{pK}_{\mathrm{a} 2}=6.73\left(\mathrm{C}^{\prime}\right)\right) \\
\text { Pale Yellow }
\end{gathered}
$$
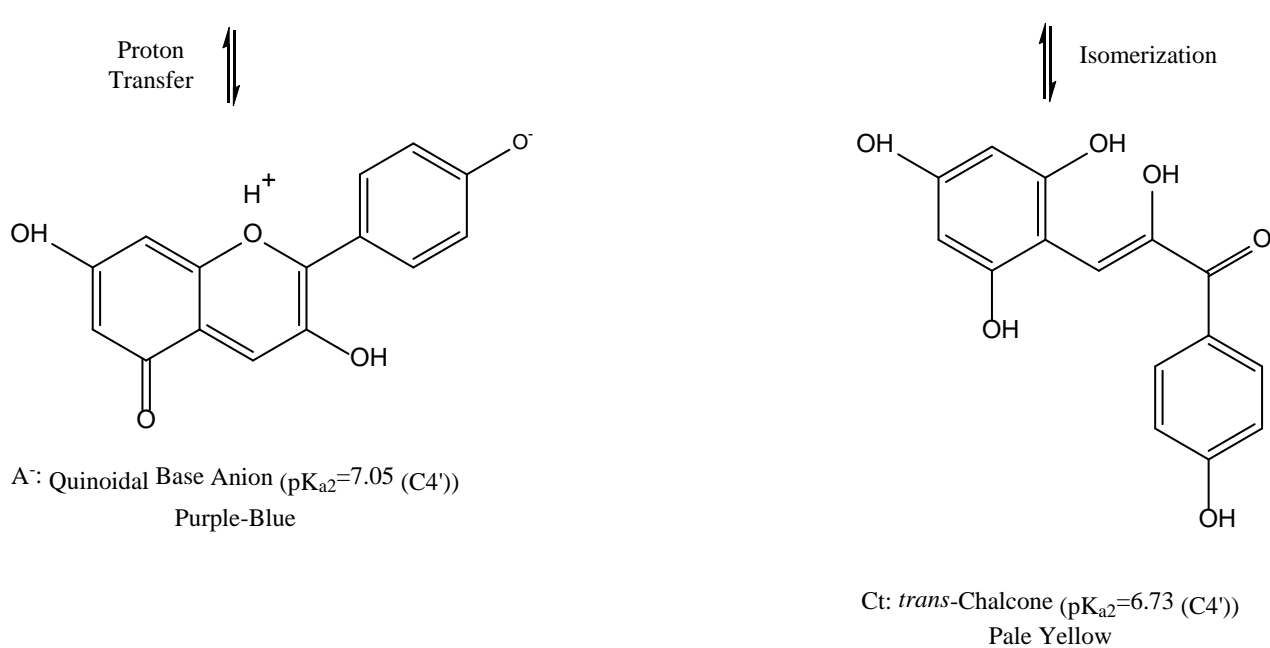

$\mathrm{A}^{*}$ : Quinoidal Base Anion $\left(\mathrm{pK}_{\mathrm{a} 2}=7.05\left(\mathrm{C} 4^{\prime}\right)\right)$

$$
\text { Purple-Blue }
$$

Figure 2.3 Pelargonidin: Mixture of Forms 


\subsection{Anthocyanidin Chemical and Physical Properties}

\subsubsection{Antioxidant Properties}

Antioxidants are compounds that inhibit or delay oxidative processes. They are available in the body as enzymes (SOD, catalase, glutathione peroxidase), various proteins (albumin, transferrin, haptoglobin), and low molecular weight antioxidants (tocopherol, carotenoids, glutathione, ascorbic acid, and polyphenolics). The generally accepted mechanism of action is either electron donation (or hydrogen) to a free radical or quenching of reactive oxygen or nitrogen species initiators (Vaya and Aviram 2001). For anthocyanidins, the key structural substituent(s) contributing to their antioxidant ability is the number of hydroxyl groups in the B ring. One hydroxyl, as in Pelargonidin, does not seem to contribute greatly to antioxidant properties. Addition of a second hydroxyl in an catechol like structure (cyanidin) greatly enhances antioxidant activity. The addition of a third hydroxyl in a pyrogallo like structure (delphinidin) continues to increase antioxidant activity but only slightly over that of cyanidin (Rice-Evans, Miller, and Paganga 1996). The catechol groups are very easily oxidized and its mechanism of antioxidant action is probably by electron donation and formation of a semiquinone moiety. The donation of a second electron then will form a quinone. (Van Acker et al. 1996; A. Sekher Pannala et al. 2001). Pelargonidin only has a mono-hydroxyl B-ring and is a less effective antioxidant. Its mechanism of action is probably by donation of an electron and subsequent 
formation of a phenoxyl radical (Galati et al. 1999; Ananth Sekher Pannala et al. 2001).

Pelargonidin, cyanidin, and delphinidin all exhibit superoxide and hydroxyl scavenging activity and can inhibit hydrogen peroxide induced lipid peroxidation. In a study of pomegranate extract, a hypoxanthine-xanthine oxidase superoxide generating system where DMPO-OOH spin adducts (indicator of superoxide concentration) were measured by ESR, Pg, Cy, and Dp scavenged super oxide with $\mathrm{IC}_{50}$ values of $456 \mu \mathrm{M}, 22 \mu \mathrm{M}$, and $2.4 \mu \mathrm{M}$ respectively. It was noted that due to the mono-hydroxyl in $\mathrm{Pg}$, its mechanism of action may involve indirect rather than direct scavenging and possibly by more than one scavenging mechanism (Noda et al. 2002)

Dp and $\mathrm{Pg}$ also were shown to inhibit $\mathrm{H}_{2} \mathrm{O}_{2}$ induced lipid peroxidation in rat brain homogenate when $\mathrm{H}_{2} \mathrm{O}_{2}$ and $\mathrm{Pg}, \mathrm{Cy}$, and Dp were incubated together with the brain substrate for 60 minutes $\left(\mathrm{IC}_{50}=85 \mu \mathrm{M}, 3.5\right.$ and $0.7 \mu \mathrm{M}$ respectively) (Noda et al. 2002).

In a similar study (grape seed, etc), Pg, Cy and Dp also exhibited excellent scavenging properties for superoxide, hypochlorite ion, hydroxyl radical, and linolenic acid with the only exception being that $\mathrm{Pg}$ did not exhibit superoxide scavenging properties in this study (Wada et al. 2007).

The radical scavenging ability of anthocyanidins is strongly $\mathrm{pH}$ dependent. In a study by Borkowski et al., the Trolox Equivalent Antioxidant Capacity (TEAC) 
antioxidant assay was utilized to compare the antioxidant actions of different anthocyanins relative to a water soluble vitamin E analog (Trolox). The TEAC assay is based on the $\mathrm{ABTS}^{\circ+}\left(2,2^{\prime}\right.$-azino-bis(3-ethylbenzothiazoline-6-sulphonic acid) radical and the ability of the antioxidant to scavenge it and thus reduce its characteristic absorption spectrum. The results indicated that for these anthocyanidins, $\mathrm{ABTS}^{\circ+}$ scavenging activity increases with both the number of hydroxyl groups on the $\mathrm{B}$ ring (i.e. $-\mathrm{Dp}>\mathrm{Cy}>\mathrm{Pg}$ ) and with increasing $\mathrm{pH}$ (except not for $\mathrm{Pg}$ ). The $\mathrm{pH}$ dependent enhancement corresponded to the deprotonations of the C4' hydroxyl ( $\mathrm{pK}_{\mathrm{a} 1} \sim 5.3$ experimentally determined) and its $\mathrm{C} 5$ hydroxyl ( $\mathrm{pK}_{\mathrm{a} 2} \sim 6.3$ computationally predicted) of $\mathrm{Dp}$. The deprotonations of the C4' hydroxyl ( $\mathrm{pK}_{\mathrm{a} 1} \sim 5.48$ experimental) and its $\mathrm{C} 5$ hydroxyl ( $\mathrm{pK}_{\mathrm{a} 2} \sim 6.39$ computational) of Cy. Pg on the other hand had an activity similar to Trolox but did not show a significant increase in activity with the deprotonation of $\mathrm{C} 5\left(\mathrm{pK}_{\mathrm{a} 1} \sim 5.79\right.$ (experimental)) and the deprotonation at $\mathrm{C}^{\prime}\left(\mathrm{pK}_{\mathrm{a} 2} \sim 7.05\right.$ (computational)) (Borkowski et al. 2005). Addition of a sugar group at position C3 to Cy and Dp decreased the scavenging abilities by up to $50 \%$ at $\mathrm{pH}>\sim 6$.

\subsubsection{Prooxidant Activity}

To add to the complexity, under certain conditions, $\mathrm{Pg}, \mathrm{Cy}$, and Dp can exhibit prooxidant properties. Delphinidin's and Cyanidin's tri-hydroxy and di-hydroxy groups in the B-ring are highly oxidizable and autoxidation of these groups is possible at physiological $\mathrm{pH}$. Autoxidation is accompanied by generation of superoxide and hydrogen peroxide (Hodnick et al. 1986; Hodnick et al. 1988). 
This property may also be enhanced by their metal chelating ability which is also known to catalyze the autoxidation of (similarly oxidizable) catechol groups (dihydroxy group) (Vanacker et al. 1995; Canada et al. 1990; O. Dangles, Fargeix, and Dufour 2000).

Pelargonidin, with only a monohydroxyl group in the B-ring, does not exhibit autoxidation and doesn't chelate metals. Its reduction in hydrogen peroxide induced lipid peroxidation activity may be due to a different oxidation mechanism (Van Acker 1996). In one study, it was found that the phenoxyl radicals of similarly structured compounds with a mono-hydroxyl substituted B ring redox cycled and caused extensive GSH oxidation at $\mathrm{pH} \sim 7$ to form thiyl- radicals which reduced oxygen. Surprisingly, flavonoids containing a catechol B-ring did not show the same oxidative properties (Galati et al. 1999).

In a LDL (low-density lipoprotein) oxidation assay (Satue-Gracia, Heinonen, and Frankel 1997), both Dp and Pg act as prooxidants when $3 \mu \mathrm{M}$ copper is used as an oxidation initiator. Interestingly, when $10 \mu \mathrm{M}$ copper is used, $\mathrm{Pg}$ acts as an antioxidant and Dp continues to be prooxidant. It was noted that more work was needed to be able to propose a mechanism for why Pg changes its antioxidant/prooxidant activity with various copper concentrations.

\subsubsection{Anthocyanins as Superphotoacids}

Anthocyanins provide protection to plant tissues via an energy wasting mechanism that involves fast adiabatic proton transfer to water. This mechanism 
is also responsible for the typically weak fluorescence of the anthocyanin cation form. Laser pulse photolysis experiments have shown that when anthocyanin cations (low pH) of Pelargonin, Cyanin, Malvin, and Oenin are excited to their first excited single state, emission from both the excited cation and the excited quinoidal base is observed indicating ultra-fast excited state proton transfer (from the cation) to water. Proton transfer rate constants obtained were utilized to roughly calculate the pKa's which, upon excitation, decrease by approximately 4 pK units (4.44 to 0.14 for pelargonin) (Moreira et al. 2003). Hence, the anthocyanin cation form is a weak acid in the ground state but is a very strong acid in the excited state. The same trend may occur for the excited states of the quinoidal base and the ionized quinoidal base however the amount of pK shift has not been published to the best of my knowledge.

\subsubsection{Anthcyanin Copigmentation and Self-Association}

Anthocaynins can form complexes with colorless flavonoids copigments (polyphenols, flavonoids, alkaloids, and amino acids) which results in color enhancement and increased stability of the colored forms of the anthocyanidin (Brouillard et al. 1989; Asen, Stewart, and Norris 1972). Anthocyanidins can also self-associate as a mechanism to stabilize their color (Olivier Dangles, Saito, and Brouillard 1993) and self-associations between the cations, quinoidal base, and ionized quinoidal base forms as well as mixtures of these forms have been 
observed (Hoshino, Matsumoto, and Goto 1980; Hoshino, Matsumoto, and Goto 1981). The main driving force for complexation is proposed to be either hydrophobic solvent interactions (Robinson and Robinson 1931) (historical) or more recently proposed, a charge transfer complex (Ferreira da Silva et al. 2005). The (electron density) charge-transfer from the copigment (the electron donor) to the anthocyanidin (the electron acceptor) theoretically should decrease the positive charge at carbon 2 resulting in a reduction in the equilibrium constant for hydration. Additionally, charge density on the hydroxyl oxygens should increase decreasing the ease of deprotonation. This is consistent with the observed color enhancement and stability of these complexes (Ferreira da Silva et al. 2005; Quina et al. 2006). 


\subsubsection{Anthocyanin Excited State Redox Activity}

It has been reported that photo excitation of charge transfer complexes results in fluorescent quenching due to fast electron transfer from the copigment to the flavylium cation (Ferreira da Silva et al. 2004). The high efficiency of electron transfer results from the high oxidizing power in the excited state of the cation form. The authors also stated that as a consequence of the cations high reduction potential, the excited singlet state of the flavylium cation form should be capable of oxidizing most polyphenols as well as biomolecules such as tyrosine and tryptophan.

\subsubsection{Photochromism}

Photochromism is the transformation from one chemical species to another species by absorption of radiation. Within the flavylium network (Figure 2.3), there are two processes that will cause the transformation of color. Light absorption by the trans-chalcone allows it to overcome the isomerization barrier and (back) transform to the cis-chalcone species. Additional absorption of light by the cis-chalcone allows catalyzed ring closure to the hemiketal. Once the hemiketal is formed, acid catalyzed loss of water gives the cation and then the quinoidal base and ionized quinoidal base depending on $\mathrm{pH}$. When irradiation is removed, the system will revert back to the thermally favored forms (Pina et al. 1998). 


\subsection{Pelargonidin}

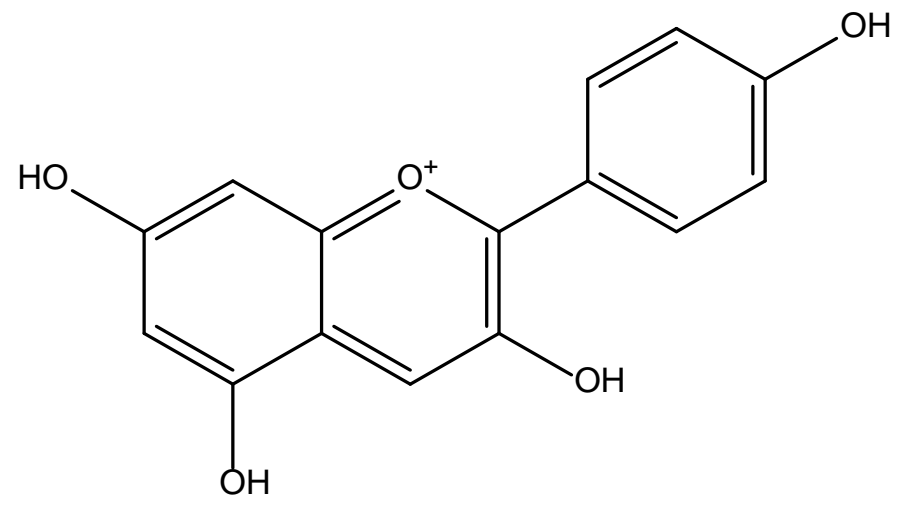

Figure 2.4 Molecular Structure of Pelargonidin Cation

Pelargonidin (Figure 3.4) was first obtained by Willstater and Bolton in 1914 by the hydrolysis of pelargonin of Pelargonium zonale. It has absorbance maxima in the 530nm (in EtOH-HCl). Pelargonidin is found in the skin of the red radish, strawberries, petals of geraniums, and the rose (among others). 22 glycosides of pelargonidin are known (Harborne 1967). Pelargonidin has hydroxyl (-OH) groups at the 3, 5, 7, and (para) 4' positions. The structural configurations of pelargonidin are shown in Figure 3.3. When exposed to increasing $\mathrm{pH}$ conditions, compounds with a monohydroxylated B ring (pelargonidin) exhibit a gradual bathochromic (red) shift up to $\mathrm{pH} \sim 6$, an extensive red shift from $\mathrm{pH} \sim 6$ to $\mathrm{pH} \sim 7.3$, and a stable $\lambda_{\max }$ from $\mathrm{pH} 7.3$ to $\mathrm{pH} \sim 10-11$ (Cabrita, Fossen, and Andersen 2000a). These color changes are caused by structural changes as mentioned in the previous sections. Although the first $\mathrm{pK}_{\mathrm{a}}\left(\mathrm{pK}_{\mathrm{a} 1}\right)$ can be determined 
experimentally, subsequent deprotonation $\mathrm{pK}_{\mathrm{a}}{ }^{\prime} \mathrm{s}$ ( $\mathrm{pK}_{\mathrm{a} 2}$ etc.) are difficult to determine experimentally due to the simultaneous existence of multiple forms of the compound in solution. Thus, to predict the $\mathrm{pK}_{\mathrm{a}}$ of subsequent deprotonations of each structural form, quantum mechanical calculations determining the disassociation energies of each hydrogen must be performed. The lowest computed bond-dissociation energy (BDE) based on the lowest energy structures are considered the first to deprotonated. In reality, there may be several similarly valued low energy structures and several hydrogens with similarly valued BDE which implies a mixture of compounds in solution at all times. When subjected to a neutral $\mathrm{pH}$ environment, pelargonidin rapidly deprotonates and changes from the flavylium cation from to its quinoidal base form. The first deprotonation is experimentally been shown to be at $\mathrm{pH}$ 5.79. The favored deprotonation site as calculated numerically is the $5-\mathrm{OH}$ group. The predicted $\mathrm{pK}_{\mathrm{a} 2}$ for the quinoidal base form is at pH 7.05 and located at the 4'-OH (Borkowski et al. 2005).

\section{Material, Methods, and Controls}

\subsection{Materials}

\subsubsection{Sarcoplasmic Reticulum}

Sarcoplasmic reticulum is isolated from fast twitch back and hind leg skeletal muscle extracted from 2-3 kg New Zealand white male rabbits according to protocols approved by Portland State University's Institutional Animal Care and Use Committee (IACUC) (also reference (MacLennan et al. 1973)). Live rabbits 
were euthanized and placed on ice. Removed muscle was also placed on ice. Fat and red muscle is trimmed from the fast twitch muscle and discarded. Fast twitch muscle is cut to approximately $1-2 \mathrm{~cm}^{3}$ peices and placed into a cold proteolysis inhibiting buffer of $120 \mathrm{mM} \mathrm{NaCl}, 10 \mathrm{mM}$ imidazole, $100 \mu \mathrm{M}$ DTT, $100 \mu \mathrm{M}$ EGTA, $0.2 \mu \mathrm{g} / \mathrm{ml}$ leupeptin, and 0.1mM PMSF at pH 7.4. Muscle is then homogenized with a common household blender (Waring) by a 4X repeating cycle of $15 \mathrm{sec}$ at low speed, $60 \mathrm{sec}$ high speed, and $30 \mathrm{sec}$ of no blending. Homogenate is then centrifuged at $1,600 \times \mathrm{g}$ for 10 minutes. Supernate is then filtered through four layers of cheesecloth to remove excess debris and fat. Remaining homogenate is adjusted to $\mathrm{pH} 7.4$ with imidazole and centrifuged at $10,000 \times \mathrm{g}$ for 15 minutes to remove mitochondria. Supernate is retained and centrifuged at $44,000 \times \mathrm{g}$ for an additional 70 minutes to collect SR. Supernatant is discarded and the remaining pellet is homogenized to approximately $10 \mathrm{mg} / \mathrm{ml}$ with a buffer of $120 \mathrm{mM} \mathrm{NaCl}, 10 \mathrm{mM}$ imidazole, $100 \mu \mathrm{M}$ DTT, and $50 \mu \mathrm{M}$ EGTA at $\mathrm{pH}$ 7.4. The resulting homogenate is then centrifuged at $7,500 \times \mathrm{g}$ for $10 \mathrm{~min}$ to remove remaining myosin. Supernatant is retained and centrifuged at $78,000 \times \mathrm{g}$ to obtain the SR pellet. The pellet is then homogenized to approximately $20 \mathrm{mg} / \mathrm{ml}$ in a buffer of $100 \mathrm{mM} \mathrm{KCl}$ and $20 \mathrm{mM}$ HEPES at pH 7.0. Aliquots of SR are put in cryo-storage tubes and stored in liquid $\mathrm{N}_{2}$ until needed. The protein concentration of the SR is then quantified by the method of Kalckar (Kalckar 1947) where the $280 \mathrm{~nm}$ absorbance of aromatic amino acids tyrosine and 
tryptophan combined with the $230 \mathrm{~nm}$ absorbance of the peptide backbone is utilized to determine the total protein concentration.

\subsubsection{Anthocyanin's}

Pelargonidin chloride (CAS\#134-04-3) and Cycnidn (CAS\#528-58-5) are purchased from Sigma Aldrich. Delphinidin chloride (CAS\#528-53-0) is purchased from Extrasynthese (France). $\mathrm{Ca}^{2+}$ Ion Selective Electrode $\left(\mathrm{Ca}^{2+}-\mathrm{ISE}\right)$ Materials

Materials (and supplier) for the fabrication of the $\mathrm{Ca}^{2+}-$ ISE are as follows. The POCO EDM3 Rod (Saturn Industries), stainless steel braid and abrasive paper were standard off the shelf, conductive glue (Radio Shack \#6400146), potassium tetrakis[3,5-bis(trifluoromethyl)phenyl]borate (CAS\#105580-52-9) (SIGMA), Tetrahydrofuran (CAS\#109-99-9) (freshly distilled) (PSU Chemistry Dept), Polyvinyl Chloride High Molecular Weight (CAS\#9002-86-2) (SIGMA), Fluka 2-Nitrophenyl octyl ether - Selectophore (CAS\#37682-29-4), Calcium Ionophore II -Selectophore (CAS\#74267-27-9) (SIGMA).

\subsubsection{Miscellaneous Materials}

Calium ionophore A23187 (SIGMA), EtOH is 95\% distilled by PSU Chemistry Department, $\mathrm{MeOH}$ is analytical grade anhydrous $>99.5 \%$, water is $18 \mathrm{Mohm}$ from a Mili-Q System (Millipore Co), EGTA (SIGMA), Lactate Dehydrogenase (SIGMA), NADH (SIGMA), Pyruvate Kinase (SIGMA), Phosphoenol pyruvate (SIGMA), SOD (SIGMA). Catalase (SIGMA), and all other reagents (HEPES and 
PIPES buffers, calcium, magnesium, salts, etc) were of typical laboratory grade unless noted.

\subsection{Methods}

\subsubsection{Active Efflux Experiments}

SR vesicles are suspended at typically $0.1-0.2 \mathrm{mg} / \mathrm{ml}$ final concentration in an efflux buffer of $100 \mathrm{mM} \mathrm{KCl}, 20 \mathrm{mM}$ HEPES or PIPES at the required $\mathrm{pH}$. The $\mathrm{Ca}^{2+}$-ATPase of the SR is activated by the addition of $20-200 \mu \mathrm{M}$ of $\mathrm{Mg}^{2+}$-ATP. $\mathrm{Ca}^{2+}$ is loaded into the SSR and allowed to leave the SSR through the CRC. The $\mathrm{Ca}^{2+}$ release rate is then measured and the relative degree of $\mathrm{CRC}$ modulation can be compared (Martonosi and Feretos 1964a; Martonosi and Feretos 1964b; Ogawa et al. 1971).

Figure 3.1-A shows a typical active efflux experimental trace of the $\mathrm{Ca}^{2+}$ electrode signal $(\mathrm{mV})$ versus time for both a control (no modulator) and a trace with a $30 \mu \mathrm{M} \mathrm{Pg}$ addition. First, SR and buffer (same buffer and $\mathrm{pH}$ as used in the experiment) are premixed (1:1) at approximately $10 \mathrm{mg} / \mathrm{ml}$ to $15 \mathrm{mg} / \mathrm{ml}$ [protein] depending on the stock SR concentration. Then approximately $250 \mu \mathrm{M} \mathrm{CaCl}_{2}$ is added to the SR premix. The SR-buffer premix is made to make the SR less viscous and allow for more repeatable pipetting. The $\mathrm{CaCl}_{2}$ is added to eliminate a pipetting step and to minimize variability. $\mathrm{MgCl}_{2}$ and ATP are premixed at a 2:1 $\mathrm{MgCl}_{2}$ : ATP ratio (again to minimize variability). However, it is common to add 
some or all of these compounds separately (not premixed) as well. The start of the active efflux experiment is the addition of the $\mathrm{SR} / \mathrm{CaCl}_{2}$ premix $(\sim 0.15 \mathrm{mg} / \mathrm{ml}$ I 5 $\mu \mathrm{M}$ final concentration) where the first large rise in the $\mathrm{Ca}^{2+}$-ISE signal is measured. To initiate the Uptake Phase, $\mathrm{Mg}^{2+}$-ATP $(60 \mu \mathrm{M} \mathrm{MgCl} 2: 30 \mu \mathrm{M}$ ATP) is added to activate the $\mathrm{Ca}^{2+}$-ATPase which will then pump $\mathrm{Ca}^{2+}$ into the SR. This results in a decrease in extra-vesicular $\left[\mathrm{Ca}^{2+}\right]$ and a corresponding decrease in the $\mathrm{Ca}^{2+}$-ISE signal. A pseudo steady state condition is achieved (Uptake Minimum) when the amount of $\mathrm{Ca}^{2+}$ being pumped into the lumen of the SR by the $\mathrm{Ca}^{2+}$-ATPase is equal to the amount of $\mathrm{Ca}^{2+}$ being released by the CRC. In the assay utilized for this work, the amount of $\mathrm{Mg}^{2+}$-ATP is optimized so that the steady state phase is short lived. As the extra-vesicular $\left[\mathrm{Ca}^{2+}\right]$ increases, the $\mathrm{CRC}$ becomes more stimulated by the $\left[\mathrm{Ca}^{2+}\right]$ which causes additional $\mathrm{Ca}^{2+}$ modulated stimulation. This process repeats itself in a positive feedback loop increasing the rate of $\mathrm{Ca}^{2+}$ efflux until the $\mathrm{Ca}^{2+}$ gradient across the SR is depleted and the efflux rate slows until equalized and net efflux is zero. This $\mathrm{Ca}^{2+}$ stimulated feedback loop is recognized as a sigmoid-like $\mathrm{Ca}^{2+}$ signal (Calcium Modulated Calcium Release -CMCR Phase). 

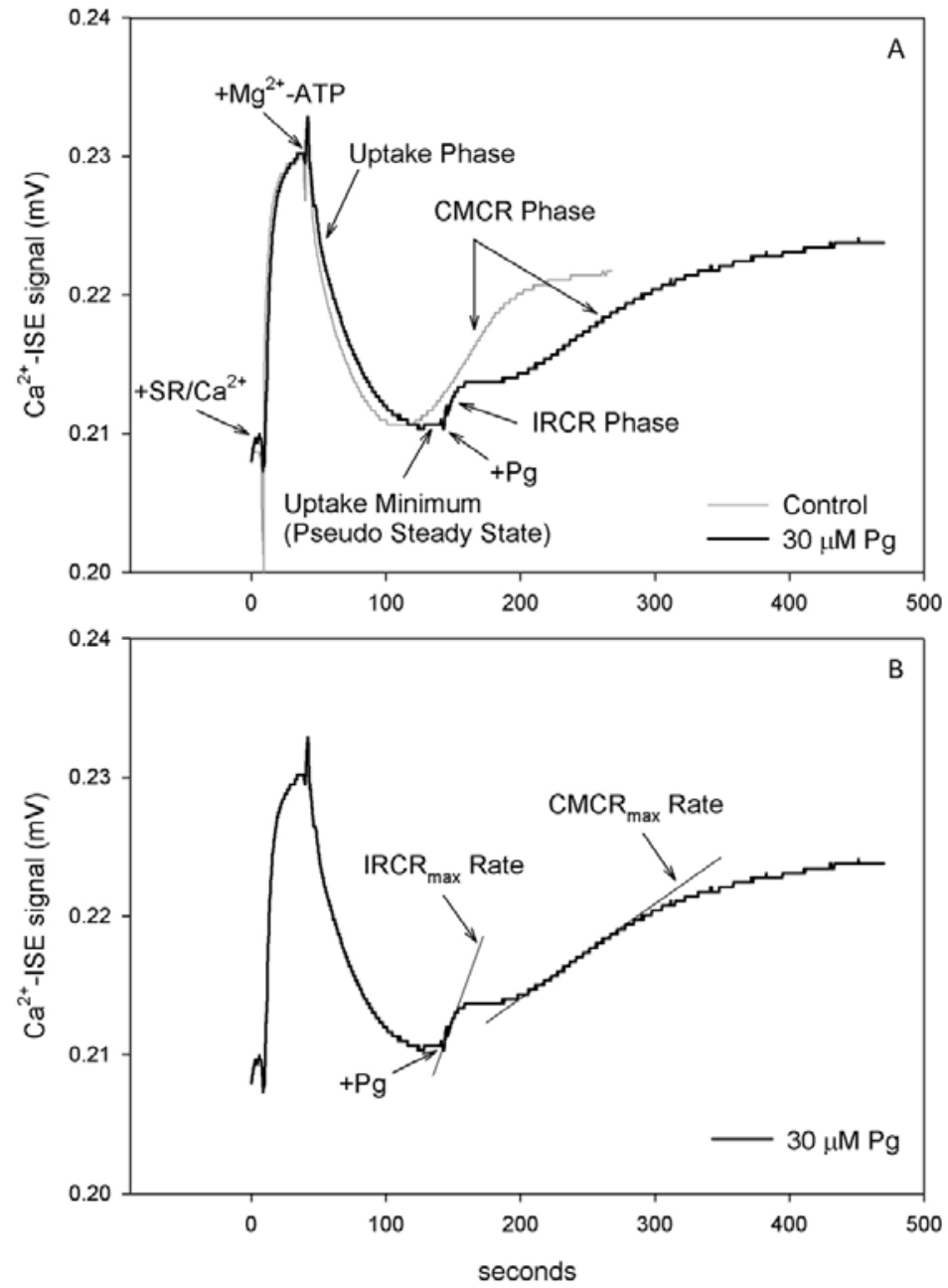

Figure 3.1 Phases and Analysis Points of a Typical Active $\mathrm{Ca}^{2+}$ Efflux Experiment.

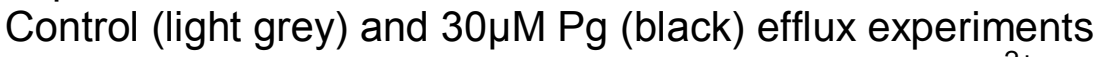

A. The seven main experimental phases: $+\mathrm{SR} / \mathrm{Ca}^{2+}$ (loading), $+\mathrm{Mg}^{2+}$-ATP (initiate uptake), Uptake Phase, Uptake Minimum (pseudo steady state), $+\mathrm{Pg}$ (modulator addition - none for control), Initial Rate of Ca2+ Release (IRCR), $\mathrm{Ca}^{2+}$ Modulated $\mathrm{Ca}^{2+}$ Release (CMCR) Phase.

B. Efflux Analysis Points: IRCR maximum (IRCR $\max )$ and $\mathrm{CMCR}$ rate maximum $\left(\mathrm{CMCR}_{\max }\right)$.

Experiments shown were performed in a $100 \mathrm{mM} \mathrm{KCl} 20 \mathrm{mM}$ PIPES efflux buffer at $\mathrm{pH}$ 7.4. $\sim 0.15 \mathrm{mg} / \mathrm{ml} \mathrm{sSR}+\sim 5 \mu \mathrm{M} \mathrm{CaCl}_{2}$ (premixed), $60 \mu \mathrm{M} \mathrm{MgCl}_{2}+30 \mu \mathrm{M} \mathrm{ATP}$ (premixed). At uptake minimum $\left[\mathrm{Ca}^{2+}\right] \sim 1 \mu \mathrm{M}$ 
If a CRC stimulator like $30 \mu \mathrm{M} \mathrm{Pg}$ is added at the Uptake Minimum (identified by an electrical spike artifact as a result of bringing the pipette close to the $\mathrm{Ca}^{2+}$ electrode), an increase in the extra-vesicular $\left[\mathrm{Ca}^{2+}\right]$ is observed (signal increase) as a result of an increased efflux of stored $\mathrm{Ca}^{2+}$ from within the SR. In this work, the maximum rate of $\mathrm{Ca}^{2+}$ release observed during this phase is noted as Initial Rate of Calcium Release - IRCR $\max$ (Figure 3.1-B). Similarly, the maximum rate during the $\mathrm{CMCR}$ phase will be denoted $\mathrm{CMCR}_{\max }$. The experimental instrumentation set-up consists of a grounded aluminum work enclosure ('Faraday Cage') approximately $0.3 \mathrm{~m} \times 0.3 \mathrm{~m} \times 0.3 \mathrm{~m}$ in size with a hinged door and a removable top. Inside the enclosure is a vertical aluminum rod with an attached adjustable electrode holder that allows the $\mathrm{Ca}^{2+}$ electrode and reference electrode (World Precision Instruments DRIREF-2) to be raised, lowered, and adjusted to the sample cuvette. Also included is a machined acrylic block fixed to the bottom of the chamber to allow for repeatable and easy positioning of the sample cuvette. The block also allows for the positioning of the two fiber optic light pipes (Dolan Jenner Fiber-Lite 180 with IR cutoff filters) for use in irradiation experiments. A magnetic stirring plate is positioned under the aluminum enclosure and provides constant mixing capability in the sample cuvette The $\mathrm{Ca}^{2+}$-ISE and reference electrode are connected to a Chemtrix Type 60A pH/mV meter with $\mathrm{mV}$ analog outputs. The $\mathrm{mV}$ outputs are connected to an AXON Instruments Mini-Digi 1A analog to digital converter. A computer running AXON 
Instruments AxoScope 9.0 is used to observe and record the signal. Data is analyzed in Excel 2010 or SigmaPlot 10.

\subsubsection{Calcium Ion Selective Electrodes ( $\left.\mathrm{Ca}^{2+}-\mathrm{ISE}\right)$}

The $\mathrm{Ca}^{2+}$-ISE used in this work are custom fabricated in this lab. The basic structure of the probes are based in part by the early works of Moody (Moody, Oke, and Thomas 1970) presenting on $\mathrm{Ca}^{2+}$ sensitive electrodes based on a liquid ion exchanger embedded in a polyvinyl chloride (PVC) membrane and of Ansaldi and Epstein (Ansaldi and Epstein 1973) reporting on a $\mathrm{Ca}^{2+}$-ISE in which a PVC membrane directly contacts a graphite rod. Further improvements in membrane formula (+ETH129) with regards to ion species selectivity and the limit of detection (LOD) of the membrane were presented by Schefer et al. (Schefer et al. 1986) and is also utilized here. General mixing and formulation procedures published by Baudet, hove-Madsen, and Bers were also considered. (Baudet, Hove-Madsen, and Bers 1994)

\subsubsection{ISE Theory}

The $\mathrm{Ca}^{2+}$-ISE fabricated and utilized in this work incorporates a PVC membrane partition that is functionalized with a mixture of compounds that allow $\mathrm{Ca}^{2+}$ to selectivity be transported through the membrane. The $\mathrm{Ca}^{2+}$ selective membrane is formed on the end of a solid state graphite rod that has its other surfaces encapsulated and insulated by a non-functionalized and impervious PVC sheath. When the functionalized membrane end is immersed into a solution with free 
$\mathrm{Ca}^{2+}$ ions, the $\mathrm{Ca}^{2+}$ ions diffuse into the membrane causing an internal positive charge within the membrane. Simultaneously, a negative charge builds up on the solution side of the membrane (due to the loss of positive $\mathrm{Ca}^{2+}$ ions) until eventually, the diffusion pressure and the electrostatic forces are balanced and the diffusion stops. The resulting difference in charge across the membrane is the membrane potential and when compared to a reference electrode in the solution without the functionalized membrane, the membrane potential can be measured by a high impedance electrical meter with $\mathrm{mV}$ capability. There are other junction potentials within the ISE system but those are constant and are manifested as a constant offset voltage.

\subsubsection{Nernst Relationship}

The electrical potential that develops across the membrane due to an inequality of active redox species can be characterized by application of the Nernst equation. The Nernst equation is formally used for measuring redox reactions and allows the determination of the relative activities of the ion being measured.

However, in the case of potentiomeric measurements with ion selective electrodes where there aren't any redox reactions occurring, the modified Nernst equation (Equation 3.1) is also applicable. 


$$
E=E^{0}-(R T / z F) \log \left[C a^{2+}\right]
$$

Where $E$ is the measured membrane potential, $E^{0}$ is the sum of the potentials on the electrode side of the membrane and any other junction potentials in the system. The $R T / z F$ term includes; $R$ the gas constant $\left(8.31 \mathrm{~J} / \mathrm{mol}^{\star} \mathrm{K}\right), T$ the temperature (295K), $z$ the species charge $\left(2\right.$ for $\left.\mathrm{Ca}^{2+}\right)$, and $F$ the Faraday constant $(96,485$ Coulomb/mol). The result of that term including a 2.3 factor for conversion to base $\log _{10}$, is 0.029 V. Substitution into Eq. 3.1 yields:

Equation 3.2

$$
E=E^{0}-29 * \log _{10}\left[\mathrm{Ca}^{2+}\right](m V)
$$

Where $E$ is the measured potential in $\mathrm{mV}$. This equation describes a line with a slope of $29 \mathrm{mV} /$ decade change of $\left[\mathrm{Ca}^{2+}\right]$.

\subsubsection{Probe Fabrication}

A $\sim 10 \mathrm{~cm}$ length of 0.0625 in or 0.125 in diameter graphite rod (Saturn Industries POCO EDM3 Rod) is cut and wiped well with a Kimwipe wetted with 200 pf EtOH and then dried with nitrogen gas. A length of a small diameter ( $\sim .125$ ID) shielded coax cable is cut and striped at each end leaving approximately $2 \mathrm{~cm}$ of braid showing. The center conductor plus insulation is pulled out and discarded. One end of the exposed braided shielding is cleaned with 200 pf EtOH and blown 
dry with nitrogen (repeated $3 x$ ). The cleaned end of the shielding is expanded with an awl as to allow insertion of the graphite rod. The expanded steel braid is then partially filled with a graphite based conductive glue (Radio Shack \#6400146). The electrode is then inserted into the braid and the braid is then pulled as to tighten it around the rod (like a Chinese finger trap). The exuding glue is spread evenly to coat the steel braid and carefully set aside and allowed to air dry overnight. The next day, a length of an appropriate diameter PVC heat shrinkable tubing (Insultab 30PVC) is cut to a length long enough to cover the graphite rod and the exposed coax shielding glued to the rod. The heat shrinkable tube is then applied by a hot air gun to securely fit the insulation to the electrode. To prepare the non-pigtailed end of the electrode for accepting the ion selective membrane, it must be sanded smooth and the PVC jacket must be level with the electrode rod. A majority of the (working) electrodes prepared for use in this work have been sanded to a visibly shiny surface in two dry steps with 600 then 1500 grit waterproof sandpaper. Finally, the exposed electrode surface is gently rubbed in a circular motion on a Kimwipe to clean off loose particles and then it is blown clean with a strong stream of nitrogen gas.

\subsubsection{Ion Selective Membrane Preparation and Application}

Prepare in advance the PVC-ionophore solution as described by Baudet et al. (Baudet, Hove-Madsen, and Bers 1994). With a small volume pipette, dispense between 5 and $10 \mu \mathrm{l}$ of the solution in the center of the watch glass and immediately discard the tip to minimize THF vapors from permeating the internals 
of the pipette. Immediately dip and swirl the end of the electrode into the solution and then remove and invert the electrode (dipped end up). Place in a holder for solvent to evaporate. The remaining solution on the watch glass will begin to dry and should be wiped away with a clean Kimwipe. Several more electrodes can be dipped while the previously dipped ones are drying. Typical dry times for this first membrane solution application process is approximately 15 minutes (other times not evaluated). Once the set of electrodes has been dipped once. Repeat process. Two dip applications of the membrane solution seems to be adequate for achieving a sufficiently functional membrane. Electrodes should be allowed to dry overnight to allow complete removal of any residual THF.

\subsubsection{ISE Conditioning}

The ISE should now be conditioned in an unstirred aqueous $\mathrm{CaCl}_{2}$ solution (no buffer) for 1 to 3 days as needed. This is a qualitative process as the degree of required conditioning can vary (possibly dependent on the thickness of the membrane). I have found that conditioning in $1 \mathrm{mM} \mathrm{CaCl}_{2}$ for 2 days usually produces a working electrode. However, I have also seen electrodes that show slow response times even after 2 days and a 3rd day of conditioning improved its performance dramatically. 


\subsubsection{6 $\mathrm{Ca}^{2+}$-ISE Calibration - Standard Addition}

When a new probe is put into use for the first time after fabrication and conditioning, it should be checked for its functionality. Specifically, its limit of detection and response time should be characterized.

The $\mathrm{Ca}^{2+}-$ ISE $\mathrm{mV}$ response to $\mathrm{p}\left[\mathrm{Ca}^{2+}\right]$ relationship should be verified to be linear and with a near Nernstian slope. ISEs with slopes that are not Nernstian, that is, not near the theoretical value of $29 \mathrm{mV} / \mathrm{p}\left[\mathrm{Ca}^{2+}\right]$, could technically be used as long as the sensitivity is adequate and the response is linear over the desired measurement range. However, a deviation from Nernstian characteristics can be an indication of a defect in the $\mathrm{Ca}^{2+}-$ ISE and therefore the user should proceed carefully. Approximately 1 in 5 probes fabricated were not functional probably due to membrane defects or leaks. Working electrodes had a typical response range of $\sim 27$ to $\sim 30 \mathrm{mV} / \mathrm{p}\left[\mathrm{Ca}^{2+}\right]$.

\subsubsection{7 $\mathrm{Ca}^{2+}$-ISE Calibration}

To calibrate the response of $\mathrm{a} \mathrm{Ca}^{2+}$-ISE and to determine the buffer $\mathrm{Ca}^{2+}$ concentration $\left(\left[\mathrm{Ca}^{2+}\right]\right.$ buf $)$, the method of standard addition can be used. The $\mathrm{Ca}^{2+}$ ISE response is linearly proportional to the $\mathrm{p}\left[\mathrm{Ca}^{2+}\right]$. Once a $\mathrm{Ca}^{2+}-\mathrm{ISE}$ is placed in the assay buffer and its signal verified to be sufficiently stable, successive additions of known $\left[\mathrm{Ca}^{2+}\right]$ additions are made and plotted. Preferably, the $\left[\mathrm{Ca}^{2+}\right]$ used for calibration should be in the same range of the $\left[\mathrm{Ca}^{2+}\right]$ present in a typical experiment. 
The calibration of a $\mathrm{Ca}^{2+}-\mathrm{ISE}$ can be separated into two $\left[\mathrm{Ca}^{2+}\right]$ ranges. A range higher than $\left[\mathrm{Ca}^{2+}\right]_{\text {buf }}$ and a range lower than $\left[\mathrm{Ca}^{2+}\right]_{\text {buf. }}$. To calibrate the $\mathrm{Ca}^{2+}-$ ISE in the higher than buffer range, one just needs to use the typical standard addition method by adding a known amount of $\mathrm{Ca}^{2+}$ and correlating the response. This is also effective for determining the $\left[\mathrm{Ca}^{2+}\right]_{\text {buf }}$ (assuming a linear response in that $\left[\mathrm{Ca}^{2+}\right]$ range). To calibrate the $\mathrm{Ca}^{2+}-\mathrm{ISE}$ in the $\left[\mathrm{Ca}^{2+}\right]$ range lower than $\left[\mathrm{Ca}^{2+}\right]$ buf , a $\mathrm{Ca}^{2+}$ chelator system must be used.

Once a linear (Nernstian) $\mathrm{Ca}^{2+}$-ISE response is confirmed, the $\mathrm{mV}$ signal from the ISE can easily be converted to $\left[\mathrm{Ca}^{2+}\right]$ which is desired for reporting efflux activity of the sSR.

\subsubsection{Calibration in the $\left[\mathrm{Ca}^{2+}\right]_{\text {high }}$ range (higher than $\left[\mathrm{Ca}^{2+}\right]_{\text {buf }}$ )}

Once a $\mathrm{Ca}^{2+}-$ ISE is placed in the assay buffer and its signal verified to be sufficiently stable, multiple additions of a known amount of $\mathrm{Ca}^{2+}$ are added. The signal of the $\mathrm{Ca}^{2+}$-ISE should be allowed to stabilize between successive additions. Once the desired number of data points are obtained, the $\mathrm{mV}$ signal vs the $\mathrm{p}\left[\mathrm{Ca}^{2+}\right]$ response should be plotted for analysis (Excel or other). Figure 3.2 shows a simple worksheet used for calibration analysis. The black unfilled circles are the known additions and the black unfilled square data point is the $\left[\mathrm{Ca}^{2+}\right]_{\text {buf }}$ 'fitted' value. The $\left[\mathrm{Ca}^{2+}\right]_{\text {buf }}$ value can be found by utilizing Excel's Solver function and having it solve for the best fit (highest $r^{2}$ ). To verify that the linearity of the probe response falls below the extrapolated value of the $\left[\mathrm{Ca}^{2+}\right]_{\text {buf, }}$ a calibration in 
the $\left[\mathrm{Ca}^{2+}\right]$ range that is lower than the buffer should be performed. For an acceptable $\mathrm{Ca}^{2+}$-ISE, the analysis should yield a slope in the range of 27 to 30 $\mathrm{mV} / \mathrm{p}\left[\mathrm{Ca}^{2+}\right]$.

\subsubsection{Calibration in the $\left[\mathrm{Ca}^{2+}\right]_{\text {low }}$ range (lower than $\left[\mathrm{Ca}^{2+}\right]_{\text {buf }}$ )}

Working in a $\left[\mathrm{Ca}^{2+}\right]$ range that is lower than the $\left[\mathrm{Ca}^{2+}\right]_{\text {buf }}$ generally requires a $\mathrm{Ca}^{2+}$ chelator to be used. The first objective is to produce a $\left[\mathrm{Ca}^{2+}\right]$ calibration curve in the $\left[\mathrm{Ca}^{2+}\right]$ high range that can also be used to confirm the expected linear $\mathrm{Ca}^{2+}-$ ISE response in the $\left[\mathrm{Ca}^{2+}\right]_{\text {low }}$ range. The main consideration is to obtain several chelating response steps in the same $\left[\mathrm{Ca}^{2+}\right]$ high range and, in addition, obtain a sufficient amount of data in the $\left[\mathrm{Ca}^{2+}\right]_{\text {low }}$ range (Figure 3.2 data marked with ' $x$ '). Chelating steps should be performed as needed to chelate the $\left[\mathrm{Ca}^{2+}\right]$ down well below the desired working $\left[\mathrm{Ca}^{2+}\right]$ range of the assay. This may be lower than the $\mathrm{Ca}^{2+}$-ISE's limit of detection (LOD) and out of the linear response range of the probe. Extreme diligence is then required to ensure accurate conversions from the $\mathrm{mV}$ signal of the probe to the desired calcium concentration. The range of calcium concentrations encountered in this work are relatively high (>2 orders of magnitude) as compared to the LOD of these probes and therefore the procedure for determining the LOD is not covered here. The typical LOD of the $\mathrm{Ca}^{2+}$-ISE fabricated for this work have LODs of less than 100nM. 


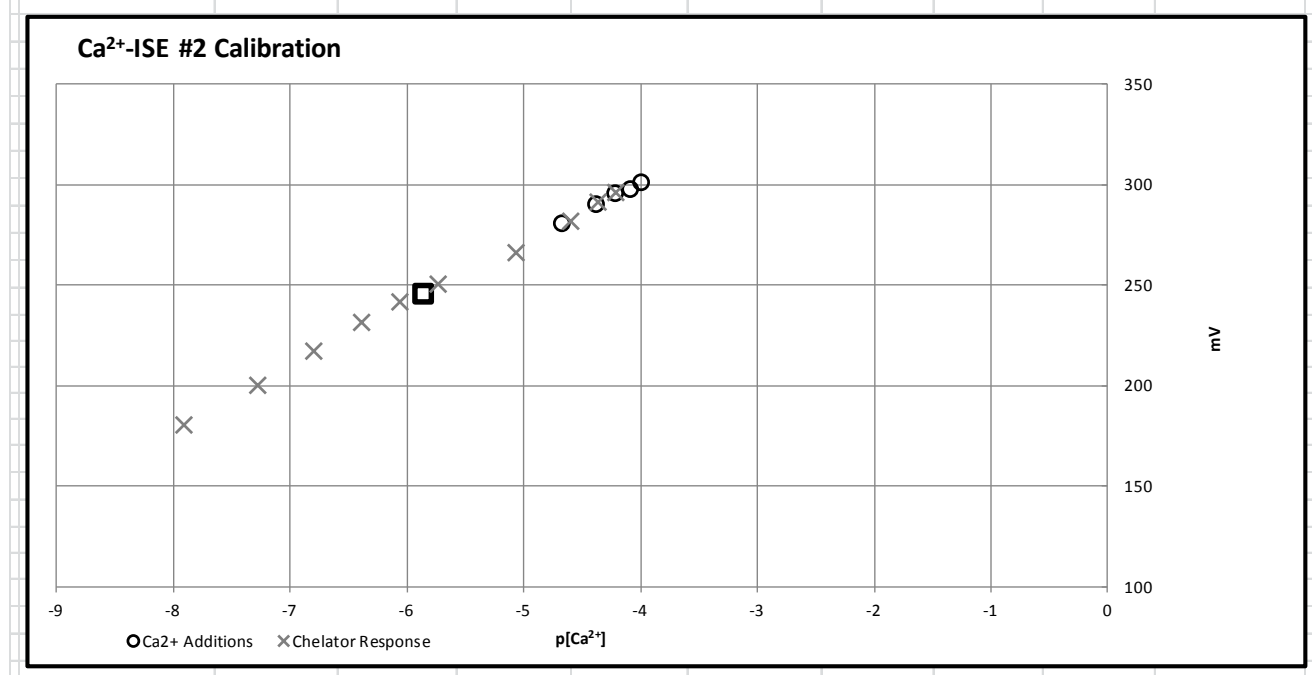

\begin{tabular}{|c|c|c|c|c|c|c|c|c|c|}
\hline Results & slope & $y$-intercept & $r^{2}$ & $\begin{array}{c}\text { Calculated } \\
{\left[\mathrm{Ca}^{2+}\right]_{\text {buf }}}\end{array}$ & & & & & \\
\hline$\left[\mathrm{Ca}^{2+}\right]_{\text {high }}$ Linear Fit & 30.0 & 421.2 & 0.999 & $1.4 \mathrm{E}-06$ & & & & & \\
\hline$\left[\mathrm{Ca}^{2+}\right]_{\text {low }}$ Linear Fit & 30.6 & 423.6 & 0.997 & & & & & & \\
\hline $\begin{array}{l}\text { Linear fit of all data } \\
{\left[\mathrm{Ca}^{2+}\right]_{\text {high }} \text { and }} \\
{\left[\mathrm{Ca}^{2+}\right]_{\text {low }}}\end{array}$ & 30.6 & 423.7 & 0.998 & & & & & & \\
\hline \multicolumn{2}{|c|}{ Enter values into green cells } & \multicolumn{3}{|c|}{ Everything else is calculated } & & & & & \\
\hline \multicolumn{10}{|c|}{ STEP $1:\left[\mathrm{Ca}^{2+}\right]_{\text {high }}$ Response } \\
\hline & $\begin{array}{l}\text { Total Sample } \\
\text { Volume (L) }\end{array}$ & $\begin{array}{c}\text { Stock Added } \\
\text { Ca2+ (L) }\end{array}$ & $\begin{array}{c}\text { Stock } \\
{[\mathrm{Ca} 2+](\mathrm{M})}\end{array}$ & $\begin{array}{c}\text { Added } \\
\text { moles of } \\
\mathrm{Ca}^{2+}\end{array}$ & $\begin{array}{l}\text { Cumulative } \\
\text { moles of } \mathrm{Ca}^{2+}\end{array}$ & $\begin{array}{l}\text { Sample } \\
{\left[\mathrm{Ca}^{2+}\right] \mathrm{M}}\end{array}$ & $\begin{array}{c}\text { Adjust for } \\
\text { best } r^{2}\end{array}$ & $\mathrm{p}\left[\mathrm{Ca}^{2+}\right]$ & $\begin{array}{c}\text { Electrode } \\
\text { Response }(\mathrm{mV})\end{array}$ \\
\hline Starting Volume & $5.000 \mathrm{E}-03$ & & & & $6.86 \mathrm{E}-09$ & $1.4 \mathrm{E}-06$ & $\longrightarrow$ & -5.86 & 245.4 \\
\hline Addition \#1 & $5.005 \mathrm{E}-03$ & 5.00E-06 & 0.02 & $1.00 \mathrm{E}-07$ & 1.07E-07 & $2.1 \mathrm{E}-05$ & & -4.67 & 280.6 \\
\hline Addition \#2 & $5.010 \mathrm{E}-03$ & 5.00E-06 & 0.02 & $1.00 \mathrm{E}-07$ & $2.07 \mathrm{E}-07$ & $4.1 \mathrm{E}-05$ & & -4.38 & 290.2 \\
\hline Addition \#3 & $5.015 \mathrm{E}-03$ & $5.00 \mathrm{E}-06$ & 0.02 & 1.00E-07 & 3.07E-07 & $6.1 \mathrm{E}-05$ & & -4.21 & 295.8 \\
\hline Addition \#4 & $5.020 \mathrm{E}-03$ & $5.00 \mathrm{E}-06$ & 0.02 & $1.00 \mathrm{E}-07$ & 4.07E-07 & $8.1 \mathrm{E}-05$ & & -4.09 & 298.0 \\
\hline Addition \#5 & $5.025 \mathrm{E}-03$ & $5.00 \mathrm{E}-06$ & 0.02 & $1.00 \mathrm{E}-07$ & $5.07 \mathrm{E}-07$ & $1.0 \mathrm{E}-04$ & & -4.00 & 301.0 \\
\hline \multicolumn{10}{|c|}{ STEP $2:\left[\mathrm{Ca}^{2+}\right]_{\text {low }}$ Response } \\
\hline & $\begin{array}{c}\text { Total Sample } \\
\text { Volume (L) }\end{array}$ & $\begin{array}{c}\text { Stock Added } \\
\text { EGTA (L) }\end{array}$ & $\begin{array}{c}\text { Stock } \\
{[\text { EGTA] M }}\end{array}$ & $\begin{array}{l}\text { Added } \\
\text { moles of } \\
\text { EGTA }\end{array}$ & $\begin{array}{c}\text { Cumulative } \\
\text { moles of } \\
\text { EGTA }\end{array}$ & $\begin{array}{c}\text { Sample } \\
\text { [EGTA] M }\end{array}$ & $\begin{array}{c}\text { BAD } \\
\text { Calculated } \\
{\left[\mathrm{Ca}^{2+}\right] \mathrm{M}}\end{array}$ & $\begin{array}{c}\text { Calculated } \\
\mathrm{p}\left[\mathrm{Ca}^{2+}\right]\end{array}$ & $\begin{array}{c}\text { Electrode } \\
\text { Response (mV) }\end{array}$ \\
\hline Starting Volume & $5.025 \mathrm{E}-03$ & & & & & & & & \\
\hline Addition \#1 & $5.035 \mathrm{E}-03$ & $1.00 \mathrm{E}-05$ & $1.93 \mathrm{E}-02$ & $1.93 \mathrm{E}-07$ & $1.93 \mathrm{E}-07$ & $3.84 \mathrm{E}-05$ & $6.30 \mathrm{E}-05$ & -4.20 & 295.4 \\
\hline Addition \#2 & $5.040 \mathrm{E}-03$ & $5.00 \mathrm{E}-06$ & $1.93 \mathrm{E}-02$ & 9.67E-08 & $2.90 \mathrm{E}-07$ & 5.76E-05 & $4.42 \mathrm{E}-05$ & -4.35 & 290.8 \\
\hline Addition \#3 & $5.045 \mathrm{E}-03$ & 5.00E-06 & $1.93 \mathrm{E}-02$ & 9.67E-08 & 3.87E-07 & 7.67E-05 & $2.56 \mathrm{E}-05$ & -4.59 & 281.6 \\
\hline Addition \#4 & $5.050 \mathrm{E}-03$ & $5.00 \mathrm{E}-06$ & $1.93 \mathrm{E}-02$ & 9.67E-08 & 4.84E-07 & 9.57E-05 & $8.73 \mathrm{E}-06$ & -5.06 & 265.6 \\
\hline Addition \#5 & $5.055 \mathrm{E}-03$ & $5.00 \mathrm{E}-06$ & $1.93 \mathrm{E}-02$ & 9.67E-08 & $5.80 \mathrm{E}-07$ & $1.15 \mathrm{E}-04$ & $1.90 \mathrm{E}-06$ & -5.72 & 250 \\
\hline Addition \#6 & $5.060 \mathrm{E}-03$ & $5.00 \mathrm{E}-06$ & $1.93 \mathrm{E}-02$ & 9.67E-08 & $6.77 \mathrm{E}-07$ & $1.34 \mathrm{E}-04$ & $8.86 \mathrm{E}-07$ & -6.05 & 241.6 \\
\hline Addition \#7 & $5.070 \mathrm{E}-03$ & $1.00 \mathrm{E}-05$ & $1.93 \mathrm{E}-02$ & 1.93E-07 & 8.70E-07 & $1.72 \mathrm{E}-04$ & 4.19E-07 & -6.38 & 231.2 \\
\hline Addition \#8 & $5.100 \mathrm{E}-03$ & $3.00 \mathrm{E}-05$ & $1.93 \mathrm{E}-02$ & $5.80 \mathrm{E}-07$ & $1.45 \mathrm{E}-06$ & $2.84 \mathrm{E}-04$ & $1.62 \mathrm{E}-07$ & -6.79 & 217 \\
\hline Addition \#9 & $5.200 \mathrm{E}-03$ & $1.00 \mathrm{E}-04$ & $1.93 \mathrm{E}-02$ & $1.93 \mathrm{E}-06$ & $3.38 \mathrm{E}-06$ & $6.51 \mathrm{E}-04$ & $5.42 \mathrm{E}-08$ & -7.27 & 200 \\
\hline Addition \#10 & $5.300 \mathrm{E}-03$ & $1.00 \mathrm{E}-04$ & $9.67 \mathrm{E}-02$ & $9.67 \mathrm{E}-06$ & $1.31 \mathrm{E}-05$ & $2.46 \mathrm{E}-03$ & $1.26 \mathrm{E}-08$ & -7.90 & 180 \\
\hline
\end{tabular}

Figure 3.2 Excel Worksheet for the Determination of $\mathrm{Ca}^{2+}$-ISE Linearity, $\mathrm{mV}$ to $\left[\mathrm{Ca}^{2+}\right]$ Transform Equation, and Predicted Buffer $\left[\mathrm{Ca}^{2+}\right]$ Excel Worksheet Chart at top shows the data points $\left[\mathrm{Ca}^{2+}\right]_{\text {high }}(\circ),\left[\mathrm{Ca}^{2+}\right]_{\text {buf predicted }}(\square)$, and $\left[\mathrm{Ca}^{2+}\right]_{\text {low }}$ $(\times)$. 


\subsubsection{ATP Hydrolysis Measurements}

The $\mathrm{Ca}^{2+}$-ATPase uses the hydrolysis of ATP (adenosine tri-phosphate) to drive $\mathrm{Ca}^{2+}$ into the SR against the $\mathrm{Ca}^{2+}$ gradient. The products of ATP hydrolysis are (adenosine di-phosphate) ADP and phosphate. ADP then reacts with phosphoenolpyruvate and the catalyst pyruvate kinase to regenerate ATP and pyruvate. Pyruvate (with lactate dehydrogenase (LD)) then oxidizes NADH to $\mathrm{NAD}^{+}$and lactate. NADH has a characteristic absorption at 340nm. Since the oxidation of one mole of NADH corresponds to the hydrolysis of one mole of ATP, the activity of the $\mathrm{Ca}^{2+}$ ATPase can be quantified by measuring NADH oxidation in a spectrophotometer. The rate of ATP hydrolysis can be modulated by increasing or decreasing resistance to the pumping of calcium. The $\mathrm{Ca}^{2+}$ ionophore A23187 eliminates the $\mathrm{Ca}^{2+}$ gradient between the inside and outside of the SR vesicles allowing the pump to run at full speed hydrolyzing ATP. Addition of EGTA to achieve sub- $\mu \mathrm{M}\left[\mathrm{Ca}^{2+}\right]$ will inhibit the $\mathrm{Ca}^{2+}$ dependent $\mathrm{Ca}^{2+}$ ATPase and inhibit hydrolysis of ATP.

\subsubsection{Anthocyanidin Preparations}

Anthocyanidin stock solutions are prepared by dissolving in EtOH at typical concentrations of $1 \mathrm{mM}$ to $10 \mathrm{mM}$. This stock is dispensed into $0.2 \mathrm{ml} \mathrm{PCR}$ tubes to obtain desired amount of the anthocyanidin. The tubes are left open and placed in a laboratory hood with warm air passed over them and the EtOH is allowed to evaporate (approximately 1 hour). Tubes are then closed and placed in a container with desiccant and stored in a lab freezer ( -10 C) until needed. 
On the day of use, the anthocyanidin is removed from freezer and allowed to come to room temperature. The required amount of acidified $\mathrm{MeOH}(+0.1 \% \mathrm{HCl})$ is added to the tube to obtain the desired stock concentration. The $\mathrm{HCl}$ is added to ensure the formation of only the flavylium cation in the stock solution.

References in this work to $\mathrm{MeOH}$ being utilized for anthocyanidin stock solutions and controls all have $0.1 \% \mathrm{HCl}$ included although it may not be specifically noted.

\subsubsection{Spectral Studies}

Spectral measurements are performed on either a HP 8452 or an Agilent 8453 diode array spectrophotometer. A disposable, $4.5 \mathrm{ml}$, sample cuvette is filled with $1 \mathrm{ml}-2 \mathrm{ml}$ of buffer or solvent at various pH's and anthocyanidin stock is pipetted into the cuvette. The cuvette is under constant stirring via an air driven magnetic stirring fixture in the spectrophotometer stage.

Concentration of anthocyanidin stock is determined by appropriate dilution and utilization of Beer's Law $(A=\varepsilon d c)$. The molar absorptivity coefficient was obtained from Extrasynthese. Pelargonidin $\left(\varepsilon_{523 n m}\right)=32400 \pm 1500$ (in $\mathrm{MeOH}+0.1 \% \mathrm{HCl})$.

\subsection{Controls}

\subsubsection{MeOH effects on calcium release rate}

Anthocyanidins are not appreciably soluble in water due to the lack of the sugar groups that the naturally occurring anthocyanins possess. To prepare the 
anthocyanidins in stock a concentration that is required for their practical use in these experiments, they were made up in $\mathrm{MeOH}+0.1 \% \mathrm{HCl}$. Although they are also soluble in EtOH and DMSO, those solvents were generally not used here (unless noted) due to their possible secondary effects seen in previous work (results not shown).

The anthocyanidin stock concentration used for these experiments ranged from approximately $1 \mathrm{mM}$ to $10 \mathrm{mM}$. The working concentrations obtained after dilution in the $2 \mathrm{ml}$ working buffer were generally in the range from $1 \mu \mathrm{M}$ to $50 \mu \mathrm{M}$. Using a $10 \mathrm{mM}$ stock solution of the anthocyanidin and a targeted final concentration of $50 \mu \mathrm{M}$, the final $\mathrm{MeOH}$ concentration in the working buffer is $0.5 \%$. The effect that $0.5 \% \mathrm{MeOH}+0.1 \% \mathrm{HCl}\left( \pm\right.$ irradiation) has on the modulation of $\mathrm{Ca}^{2+}$ efflux from the SR is measured. 


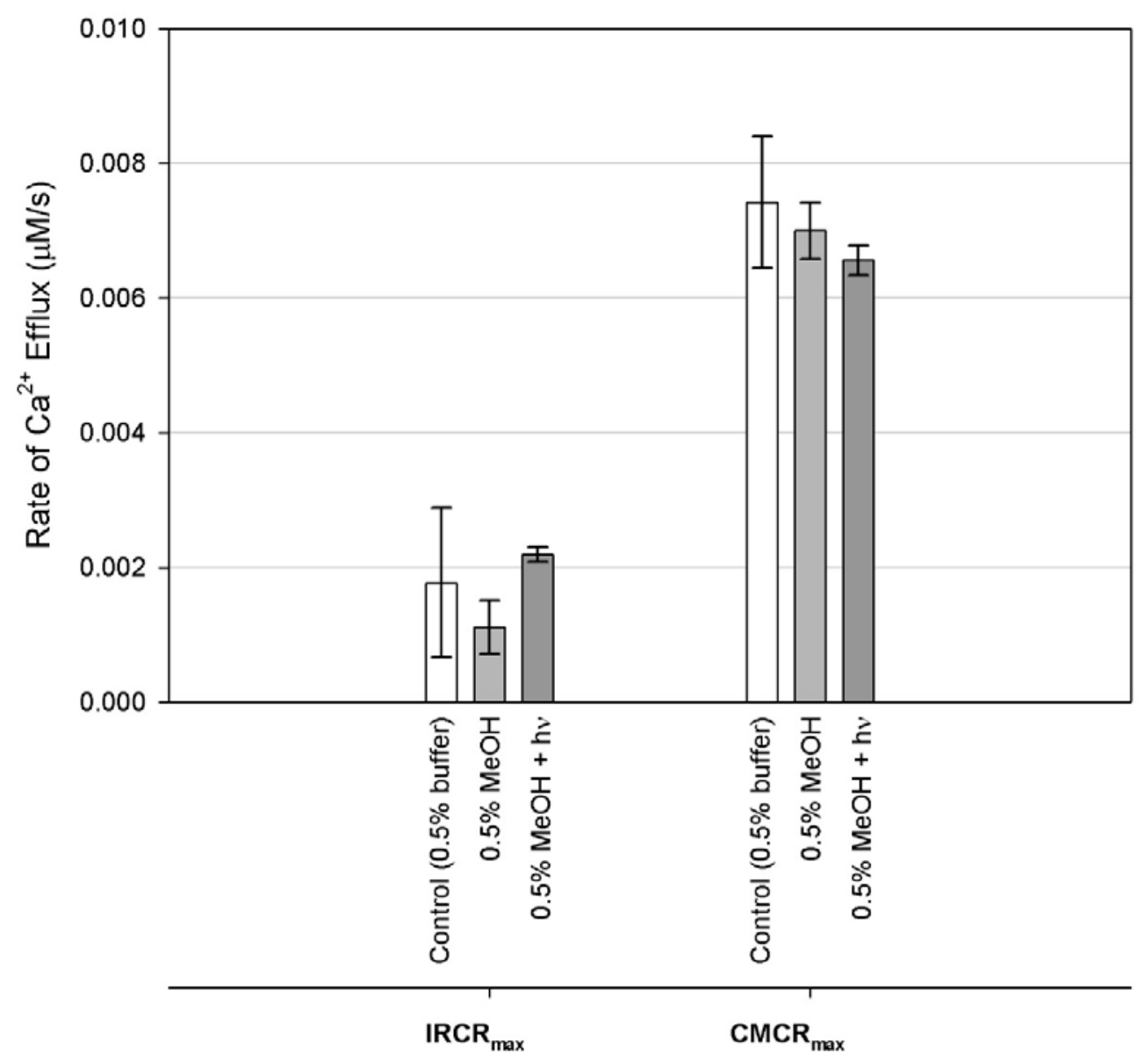

Figure 3.3 IRCR and CMCR Effux Rates for Control vs $0.5 \% \mathrm{MeOH}$ vs $0.5 \% \mathrm{MeOH}+\mathrm{h} v$

Experiments shown were performed in a $100 \mathrm{mM} \mathrm{KCl} 20 \mathrm{mM}$ PIPES efflux buffer at pH 7.4. $\sim 0.15 \mathrm{mg} / \mathrm{ml} \mathrm{sSR}+\sim 5 \mu \mathrm{M} \mathrm{CaCl}_{2}$ (premixed), $60 \mu \mathrm{M} \mathrm{MgCl}_{2}+30 \mu \mathrm{M} \mathrm{ATP}$ (premixed). At uptake minimum $\left[\mathrm{Ca}^{2+}\right] \sim 1 \mu \mathrm{M}$. Efflux initiated by either $0.5 \%$ buffer (Control), $0.5 \% \mathrm{MeOH}+0.1 \% \mathrm{HCL}, 0.5 \% \mathrm{MeOH}+0.1 \% \mathrm{HCL}$ plus irradiation $(+\mathrm{h} v)$ additions. IRCR [Control $=0.0018 \pm 0.0011 \mu \mathrm{M} / \mathrm{s}, 0.5 \% \mathrm{MeOH}+0.1 \% \mathrm{HCl}=$ $0.0011 \pm 0.0004 \mu \mathrm{M} / \mathrm{s}, 0.5 \% \mathrm{MeOH}+0.1 \% \mathrm{HCl}+\mathrm{h} v=0.0022 \pm 0.0001 \mu \mathrm{M} / \mathrm{s}]$ $\mathrm{CMCR}$ [Control $=0.0074 \pm 0.0010 \mu \mathrm{M} / \mathrm{s}, 0.5 \% \mathrm{MeOH}+0.1 \% \mathrm{HCl}=$ $0.0070 \pm 0.0004 \mu \mathrm{M} / \mathrm{s}, 0.5 \% \mathrm{MeOH}+0.1 \% \mathrm{HCl}+\mathrm{h} v=0.0066 \pm 0.0002 \mu \mathrm{M} / \mathrm{s}]$ Dual fiber light at $50 \%$ intensity during the release phase. $(n=3 \pm S D)$ 
The results (Figure 3.3) indicate that neither $\mathrm{MeOH}$ nor $\mathrm{MeOH}$ plus irradiation with white light modulate the efflux from the SR. Additional experiments with both lower and higher concentrations of $\mathrm{MeOH}(0.25 \%$ and $1 \%)$ have also shown a non-modulating effect (results not shown).

\subsubsection{Pg, Cy, Dp do not inhibit the $\mathrm{Ca}^{2+}$-ATPase of the sSR.}

Consistent $\mathrm{Ca}^{2+}$-ATPase activity of the SSR is critical to the accurate characterization of the CRC. Abrupt inhibition of the $\mathrm{Ca}^{2+}$-ATPase activity can manifest itself as a stimulation of $\mathrm{Ca}^{2+}$ efflux. Conversely, an abrupt enhancement of ATPase activity could be interpreted as an inhibition of the CRC.

To eliminate the possibility that the three anthocyanidins $\mathrm{Pg}, \mathrm{Cy}$, and $\mathrm{Dp}$ modulate the $\mathrm{Ca}^{2+}$-ATPase of the SSR and this effect alone or in part causes the apparent stimulated release from the SSR, an experiment measuring the activity of the $\mathrm{Ca}^{2+}$-ATPase of the SSR is conducted (Figure 3.4). The rate of NADH oxidation (and indirectly the rate of $\mathrm{Ca}^{2+}$-ATPase activity) is not affected by the presence of $20 \mu \mathrm{M}$ anthocyanidin. A23187 causes a significant increase in NADH oxidation rate but the addition of $20 \mu \mathrm{M}$ anthocyanidin does not significantly modulate the A23187 dependent rate. 10mM EGTA eliminates the effect of A23187 by chelating the free $\mathrm{Ca}^{2+}$ (the substrate for the ATPase) and thus preventing ATPase activity and NADH oxidation (results not shown). 


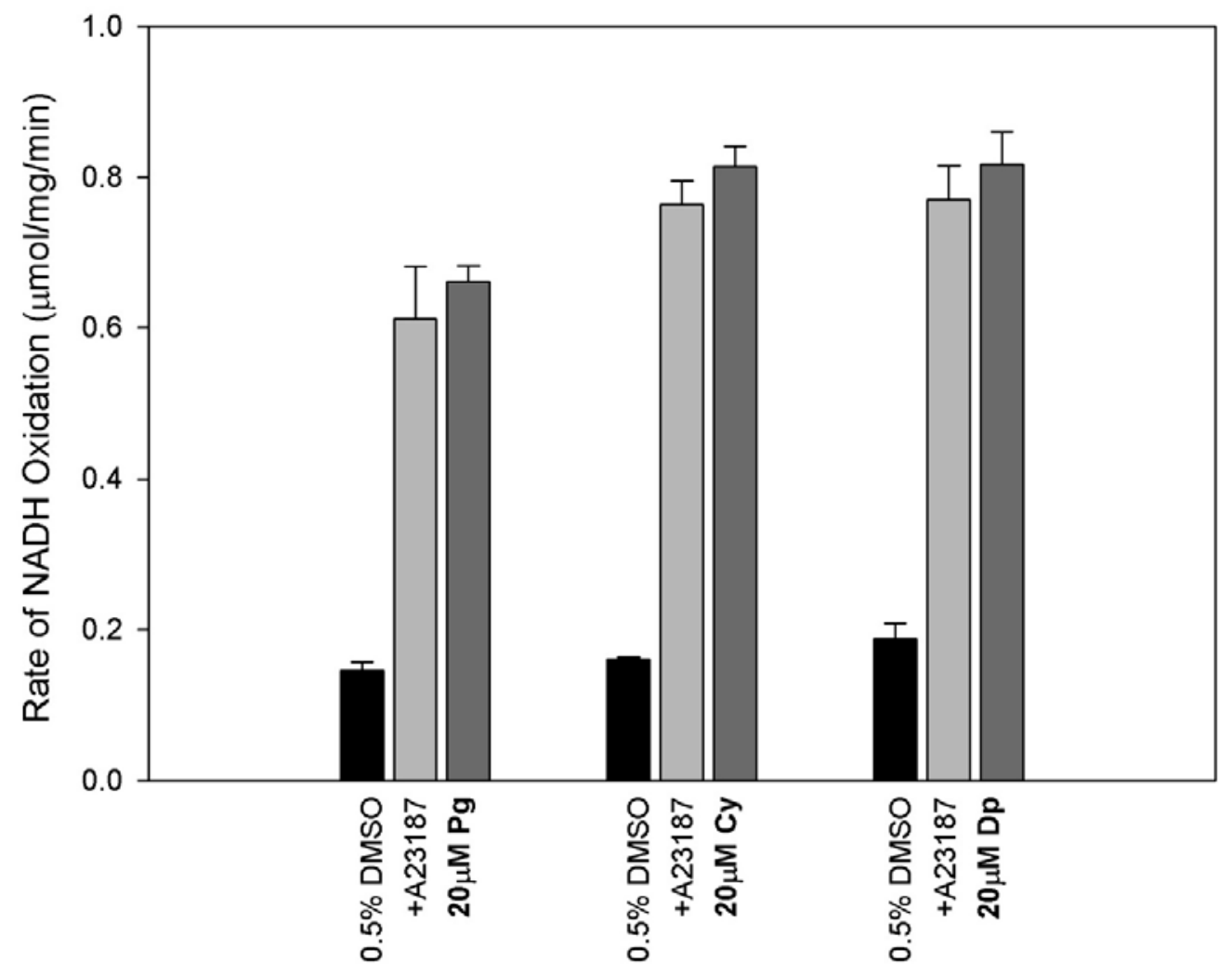

Figure 3.4 Rate of A23187 Dependent NADH oxidation rate by SSR is not altered significantly by the addition of $20 \mu \mathrm{M} \mathrm{Pg}, \mathrm{Cy}$, or Dp.

$100 \mathrm{mM} \mathrm{KCl}, 20 \mathrm{mM}$ MOPS $\mathrm{pH} 7,5 \mathrm{un} / \mathrm{ml}$ pyruvate kinase, $0.9 \mathrm{mM}$ phosphoenolpyruvate, $5 \mathrm{un} / \mathrm{ml}$ lactate dehydrogenase, $0.5 \mathrm{mM} \mathrm{Mg}^{2+}$ ATP, $0.125 \mathrm{mg} / \mathrm{ml} \mathrm{sSR}, 0.3 \mathrm{mM}$ NADH, $1 \mu \mathrm{M}$ A23187.

Following units in $(\mu \mathrm{mol} / \mathrm{mg} / \mathrm{min}) \mathrm{Pg}[0.5 \% \mathrm{DMSO}=0.15 \pm 0.01, \mathrm{~A} 23187=$ $0.61 \pm 0.07, \mathrm{Pg}=0.66 \pm 0.02]$ Cy $[0.5 \% \mathrm{DMSO}=0.16 \pm 0.00, \mathrm{~A} 23187=0.76 \pm 0.03$, Cy $=0.81 \pm 0.03]$ Dp $[0.5 \%$ DMSO $=0.19 \pm 0.02, A 23187=0.77 \pm 0.05, D p=$ $0.82 \pm 0.04](n=2 \pm S D)$ 


\subsubsection{Pelargonidin Hydration Kinetics}

Pelargonidin hydrates to its colorless forms (hemiketal and chalcones) in a similar time frame as the duration of time required for CMCR efflux to occur. Therefore, the change of $\mathrm{Pg}$ concentration during the course of the experiment is considered. To calculate the concentration of the prototropic colored forms of $[\mathrm{Pg}]$ that exist in the efflux assay at any given time point, the apparent kinetic constant of Pg hydration is measured and utilized.

Pelargonidin is made in $\mathrm{MeOH}-0.1 \% \mathrm{HCl}$ at $1 \mathrm{mM}-10 \mathrm{mM}$ stock concentrations and then diluted into buffers at $\mathrm{pH} 5.8,6.4$, and 7.4 under constant stirring at room temperature ( $22 \mathrm{C})$. The absorbance peak (at the tested $\mathrm{pH})$ is then followed and recorded vs time on a spectrophotometer (HP 8452). The data obtained is normalized and fit to a double exponential for use in concentration analysis as described in the results section. Normalization of the data to the first data point introduces error due to the delay from the actual time of $\mathrm{Pg}$ dilution and the time that the absorbance is recorded by the spectrophotometer, however these kinetics are only used to estimate $\mathrm{Pg}$ concentration and this error is acceptable in this case. The kinetics of hydration of $\mathrm{Pg}$ at $\mathrm{pH} 5.8, \mathrm{pH} 6.4$, and $\mathrm{pH}$ 7.4 are shown in Figure 3.5, Figure 3.6, and Figure 3.7 respectively. 


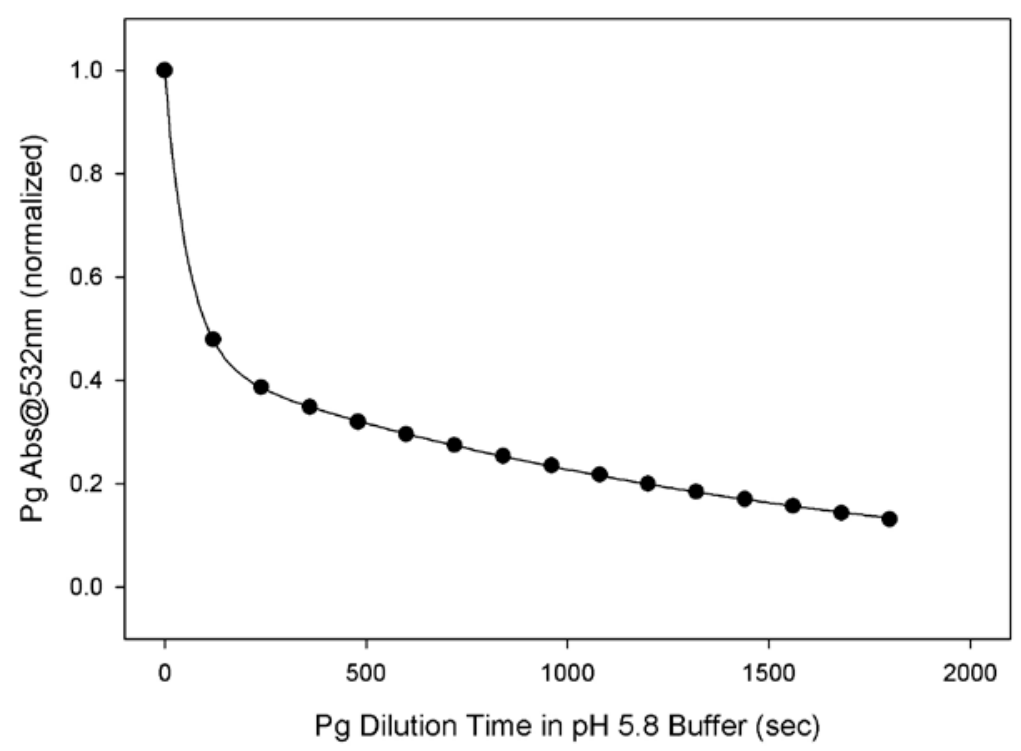

\begin{tabular}{|c|c|c|c|}
\hline \multicolumn{4}{|c|}{ Nonlinear Regression } \\
\hline \multicolumn{4}{|c|}{ Data Source: Pg spectrum kinetics pH5.8 } \\
\hline \multirow{2}{*}{\multicolumn{4}{|c|}{$\begin{array}{l}\text { Equation: Exponential Decay, Double, } 4 \text { Parameter } \\
f=a^{*} \exp \left(-b^{*} x\right)+c^{*} \exp \left(-d^{*} x\right)\end{array}$}} \\
\hline & & & \\
\hline $\mathrm{R}$ & Rsqr & Adj Rsqr & Standard Error of Estimate \\
\hline 1.00 & 1.00 & 1.00 & 0.00 \\
\hline \multicolumn{4}{|c|}{ Coefficient Std. Error } \\
\hline a & $5.58 \mathrm{E}-01$ & $1.80 \mathrm{E}-03$ & \\
\hline b & $1.71 \mathrm{E}-02$ & $1.90 \mathrm{E}-04$ & \\
\hline c & 4.42E-01 & $1.33 \mathrm{E}-03$ & \\
\hline$d$ & $6.64 \mathrm{E}-04$ & $3.00 \mathrm{E}-06$ & \\
\hline
\end{tabular}

Figure 3.5 Pg Hydration Kinetics at pH 5.8

A) Mole fraction of $\mathrm{Pg}$ prototropic forms vs time of dilution in an aqueous buffer at $\mathrm{pH}$ 5.8.

B) Resulting kinetic coefficients of data fit to a 4 parameter double exponential decay function.

Pelargonidin $(10 \mu \mathrm{M})$ is diluted from $\mathrm{MeOH}+0.1 \% \mathrm{HCl} 1 \mathrm{mM}$ stock solution into a stirred efflux buffer at the noted $\mathrm{pH}$. The hydration of $\mathrm{AH}^{+}$is monitored at $532 \mathrm{~nm}$, normalized to 1 , and fit to a 4 parameter double exponential decay function. 


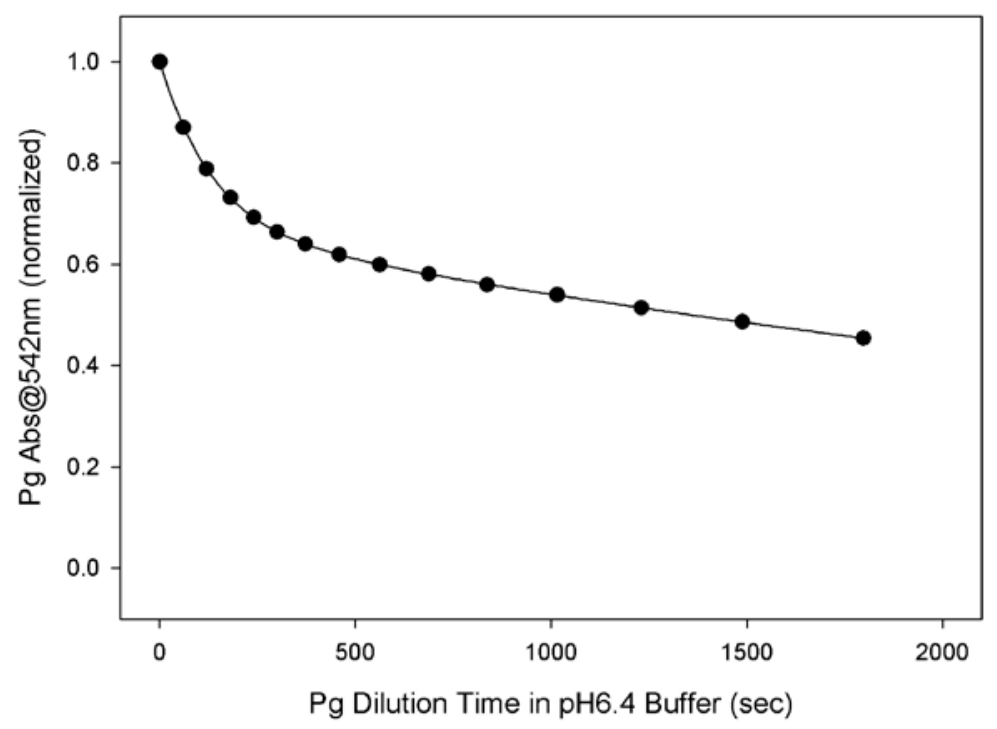

\begin{tabular}{|c|c|c|c|}
\hline \multicolumn{4}{|c|}{ Nonlinear Regression } \\
\hline \multicolumn{4}{|c|}{ Data Source: Pg spectrum kinetics pH6.4 } \\
\hline \multirow{2}{*}{\multicolumn{4}{|c|}{$\begin{array}{l}\text { Equation: Exponential Decay, Double, } 4 \text { Parameter } \\
f=a^{*} \exp \left(-b^{*} x\right)+c^{*} \exp \left(-d^{*} x\right)\end{array}$}} \\
\hline & & & \\
\hline $\mathrm{R}$ & Rsqr & Adj Rsqr & Standard Error of Estimate \\
\hline 1.00 & 1.00 & 1.00 & 0.00 \\
\hline \multicolumn{4}{|c|}{ Coefficient Std. Error } \\
\hline a & 3.31E-01 & $1.24 \mathrm{E}-03$ & \\
\hline b & 7.50E-03 & $6.00 \mathrm{E}-05$ & \\
\hline c & $6.73 \mathrm{E}-01$ & 1.09E-03 & \\
\hline d & $2.18 \mathrm{E}-04$ & 2.00E-06 & \\
\hline
\end{tabular}

Figure 3.6 Pg Hydration Kinetics at pH 6.4

A) Mole fraction of $\mathrm{Pg}$ prototropic forms vs time of dilution in an aqueous buffer at $\mathrm{pH} 6.4$.

B) Resulting kinetic coefficients of data fit to a 4 parameter double exponential decay function.

Pelargonidin $(10 \mu \mathrm{M})$ is diluted from $\mathrm{MeOH}+0.1 \% \mathrm{HCl} 1 \mathrm{mM}$ stock solution into a stirred efflux buffer at the noted $\mathrm{pH}$. The hydration of $\mathrm{AH}^{+}$is monitored at $542 \mathrm{~nm}$, normalized to 1 , and fit to a 4 parameter double exponential decay function. 


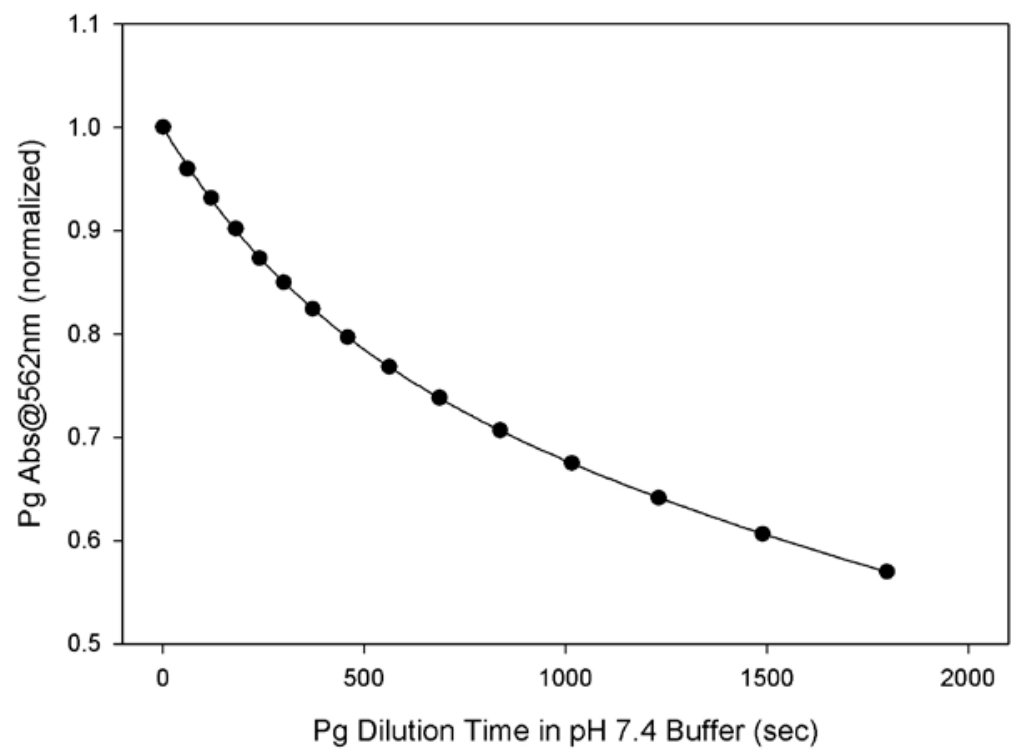

\begin{tabular}{|c|c|c|c|}
\hline \multicolumn{4}{|c|}{ Nonlinear Regression } \\
\hline \multicolumn{4}{|c|}{ Data Source: Pg spectrum kinetics pH7.4 } \\
\hline \multirow{2}{*}{\multicolumn{4}{|c|}{$\begin{array}{l}\text { Equation: Exponential Decay, Double, } 4 \text { Parameter } \\
f=a^{*} \exp \left(-b^{*} x\right)+c^{*} \exp \left(-d^{*} x\right)\end{array}$}} \\
\hline & & & \\
\hline $\mathrm{R}$ & Rsqr & Adj Rsqr & Standard Error of Estimate \\
\hline 1.00 & 1.00 & 1.00 & 0.00 \\
\hline \multicolumn{4}{|c|}{ Coefficient Std. Error } \\
\hline a & 2.01E-01 & 7.05E-03 & \\
\hline $\mathrm{b}$ & $2.46 \mathrm{E}-03$ & $9.50 \mathrm{E}-05$ & \\
\hline c & 7.99E-01 & $7.38 \mathrm{E}-03$ & \\
\hline d & $1.90 \mathrm{E}-04$ & $5.00 \mathrm{E}-06$ & \\
\hline
\end{tabular}

Figure 3.7 Pg Hydration Kinetics at $\mathrm{pH} 7.4$

A) Mole fraction of $\mathrm{Pg}$ prototropic forms vs time of dilution in an aqueous buffer at $\mathrm{pH}$ 7.4.

B) Resulting kinetic coefficients of data fit to a 4 parameter double exponential decay function.

Pelargonidin $(10 \mu \mathrm{M})$ is diluted from $\mathrm{MeOH}+0.1 \% \mathrm{HCl} 1 \mathrm{mM}$ stock solution into a stirred efflux buffer at the noted $\mathrm{pH}$. The hydration of $\mathrm{AH}^{+}$is monitored at $562 \mathrm{~nm}$, normalized to 1 , and fit to a 4 parameter double exponential decay function. 


\section{Results}

Pelargonidin is a complex natural compound with structural and chemical

characteristics that directly depend on its immediate environment as well as how long it has been subjected to that environment. This results section will show what effects Pg has on the modulation of efflux from sSR.

\subsection{Concentration Dependent Modulation of the Initial Rate of $\mathrm{Ca}^{2+}$ Efflux from SSR by Varying Concentrations of Pg.}

Pelargonidin is made in $\mathrm{MeOH}-0.1 \% \mathrm{HCL}$ stock solutions as described in the methods section at concentrations from $1 \mathrm{mM}$ to $10 \mathrm{mM}$. Additions are made to the sample cuvette containing an efflux buffer $(100 \mathrm{mM} \mathrm{KCl}, 20 \mathrm{mM}$ HEPES or PIPES) under constant stirring. After stock dilution, total $\mathrm{MeOH}$ is less $0.5 \%$. At low concentrations, the initial release is seen as a slight increase in efflux rate. At higher concentrations, the release can be characterized as a rapid transient release which quickly disappears to a pseudo steady state condition. Finally, release progresses in a way that is similar to a normal CMCR release curve (Figure 4.1) except that the CMCR rate is inhibited with respect to the control (discussed in the next section). Figure 4.2 shows the concentration dependent effect that Pelargonidin has on the IRCR at $\mathrm{pH}$ 7.4. The figure shows the results from two experimental sets (filled circles and unfilled circles). 


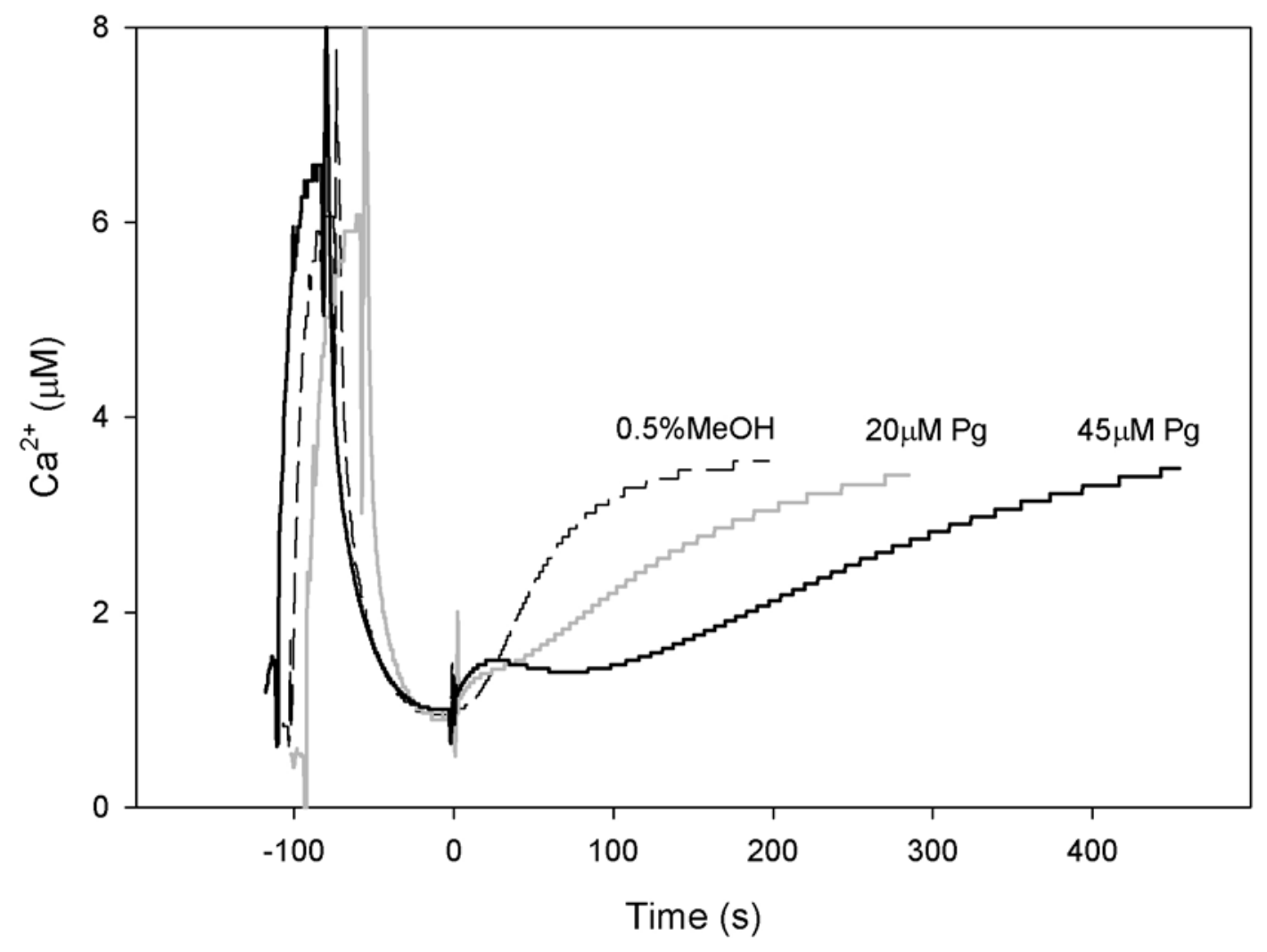

Figure 4.1 Pelargonidin Stimulates IRCR and Inhibits CMCR in a Concentration Dependent Manner (Experimental Trace Examples)

Active efflux experiments were performed in a $100 \mathrm{mM} \mathrm{KCl} 20 \mathrm{mM}$ PIPES efflux buffer at pH 7.4. $\sim 0.15 \mathrm{mg} / \mathrm{ml} \mathrm{sSR}+\sim 5 \mu \mathrm{M} \mathrm{CaCl}_{2}$ (premixed), $60 \mu \mathrm{M} \mathrm{MgCl}_{2}+$ $30 \mu \mathrm{M}$ ATP (premixed). At uptake minimum $\left[\mathrm{Ca}^{2+}\right] \sim 1 \mu \mathrm{M}$ the indicated amount of $[\mathrm{Pg}]$ was added to the assay. 


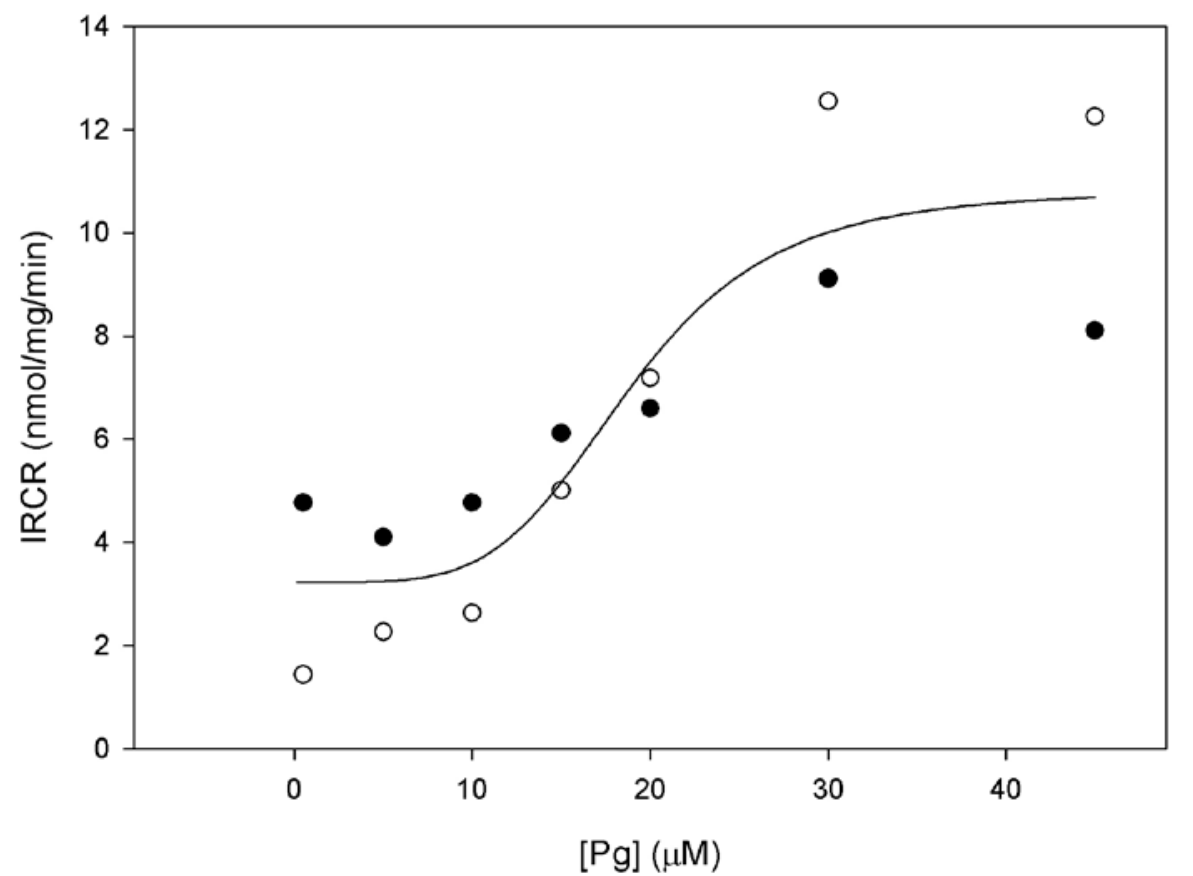

Figure 4.2 Pelargonidin Stimulates IRCR from SSR at pH 7.4 in a Concentration Dependent Manner.

Active efflux experiments were performed in a $100 \mathrm{mM} \mathrm{KCl} 20 \mathrm{mM}$ PIPES efflux buffer at pH 7.4. $\sim 0.15 \mathrm{mg} / \mathrm{ml} \mathrm{sSR}+\sim 5 \mu \mathrm{M} \mathrm{CaCl}_{2}$ (premixed), $60 \mu \mathrm{M} \mathrm{MgCl}_{2}+$ $30 \mu \mathrm{M}$ ATP (premixed). At uptake minimum $\left[\mathrm{Ca}^{2+}\right] \sim 1 \mu \mathrm{M}$ the indicated amount of $[\mathrm{Pg}]$ was added to the assay. $\mathrm{EC}_{50}=18.9 \pm 2.3 \underline{\mu \mathrm{M}}(\mathrm{n}=2 \pm \mathrm{SE})$. 
The results show that Pelargonidin stimulates IRCR from actively loaded SSR in a concentration dependent manner. Since the concentration of $\mathrm{Pg}$ is changing in solution with time (very minimal effect for initial rate calculations) and there are a mixture of $\mathrm{Pg}$ forms present, a typical dose-response analysis for $\mathrm{Pg}$ in general isn't very significant. However, when the data is fitted to a dose-response curve, a $\mathrm{EC}_{50}$ of $18.9 \mu \mathrm{M} \pm 2.3 \mu \mathrm{M}$ SE at $\mathrm{pH} 7.4$ is calculated.

\subsection{Concentration Dependent Modulation of the CMCR Rate of $\mathrm{Ca}^{2+}$ Efflux from sSR by Varying Concentrations of Pg.}

Pelargonidin inhibits the CMCR phase in a concentration dependent manner (Figure 4.3) It is a unique property for a CRC modulator to exhibit this type of dual modulating effect. Again, the fit of a dose-response curve has limited validity here especially for $\mathrm{CMCR}$ analysis where $\mathrm{Pg}$ is in a mixture of forms and the concentration of the specific forms are changing with respect to each other with time. However, when a fit is performed, an $\mathrm{IC}_{50}$ of $13.3 \mu \mathrm{M} \pm 0.5 \mu \mathrm{M}$ is calculated. More relevant $\mathrm{EC}_{50}$ and $\mathrm{IC}_{50}$ information will be presented in Sections Figure 4.4 and Figure 4.5 


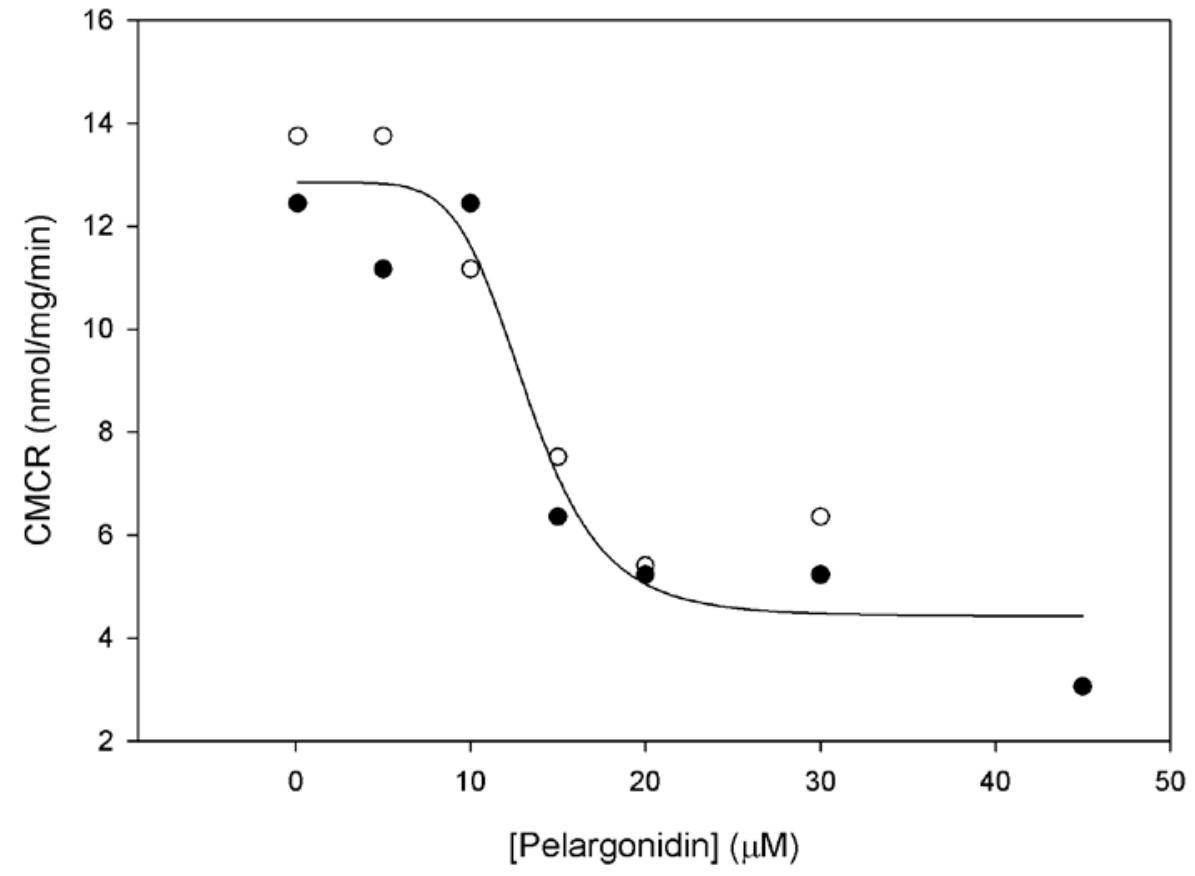

Figure 4.3 Pelargonidin Inhibits CMCR Rate from sSR at pH 7.4 in a Concentration Dependent Manner.

Active efflux experiments were performed in a $100 \mathrm{mM} \mathrm{KCl} 20 \mathrm{mM}$ PIPES efflux buffer at pH 7.4. $\sim 0.15 \mathrm{mg} / \mathrm{ml} \mathrm{sSR}+\sim 5 \mu \mathrm{M} \mathrm{CaCl}_{2}$ (premixed), $60 \mu \mathrm{M} \mathrm{MgCl}_{2}+$ $30 \mu \mathrm{M}$ ATP (premixed). At uptake minimum $\left[\mathrm{Ca}^{2+}\right] \sim 1 \mu \mathrm{M}$ the indicated amount of $[\mathrm{Pg}]$ was added to the assay. $\mathrm{IC}_{50}=13.3 \pm 0.5 \mu \mathrm{M}(\mathrm{n}=2 \pm \mathrm{SE})$ 


\subsection{Modulation of Efflux from sSR by Pelargonidin vs Time of Dilution.}

In an effort to elucidate what forms of Pg may be responsible for its effect on the SSR, the efflux rate verses the time of dilution (TOD) of $\mathrm{Pg}$ in an aqueous buffer is measured. As mentioned in chapter 2, upon dilution into an aqueous solution at greater than acidic $\mathrm{pH}, \mathrm{Pg}$ immediately transforms into a mixture of forms. The mole fraction of the forms that exist and the kinetics of transformation into other forms is dependent on the $\mathrm{pH}$ of the buffer. The transformation to the different forms can be roughly separated into two (time-domain) groups. The first group is the colored prototropic group is composed of the flavylium cation, the quinoidal base, and ionized quinoidal base. The prototropic form equilibrates in subseconds with the mole fraction of each form dependent on the $\mathrm{pH}$ of the dilution buffer. The prototropic forms then are more slowly (minutes to hours) transformed to the 'colorless' forms (hemiketal, cis-chalcone, and trans-chalcone) by hydration of the flavylium cation. In this experiment, Pelargonidin is pre-diluted into a pH 5.8 buffer and allowed to undergo its transformation to the colorless forms. During the transformation, samples of the diluted stock are taken and used in the active efflux assay.

\subsubsection{Initial Rate of $\mathrm{Ca}^{2+}$ Efflux by $30 \mu \mathrm{M}$ Pg Pre-buffered at pH 5.8 vs Time of Dilution}

Figure 4.4 shows the IRCR of $30 \mu \mathrm{M}$ Pg verse Time of Dilution (top). As the time of dilution is allowed to progress, the IRCR stimulation effect of Pg decreases indicating the loss of a IRCR stimulating form or forms. The IRCR is plotted 
against the calculated [Pg] (from Pg hydration kinetics) (bottom) that corresponds to the time of dilution. The fitted $\mathrm{EC}_{50}$ is $17.7 \mu \mathrm{M} \pm 3 \mu \mathrm{M}(\mathrm{SE})$. The time of dilution axis is included as a reference and estimate only. This result implies that the colored prototropic forms $\left(\mathrm{AH}^{+}, \mathrm{A}, \mathrm{A}^{-}\right)$which are decreasing in concentration with time, are responsible for the stimulated IRCR effect caused by Pelargonidin. 

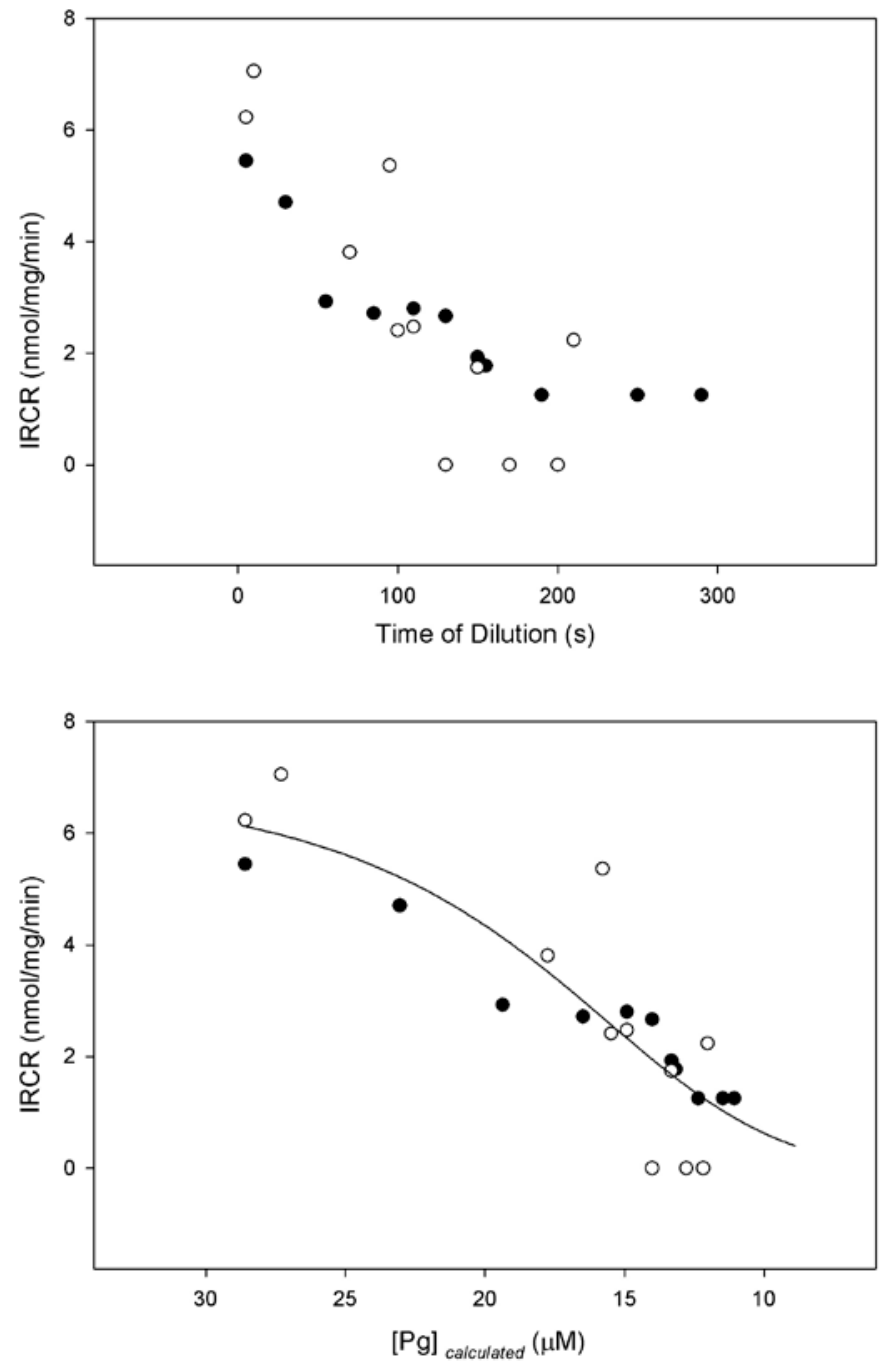

Figure 4.4 IRCR Stimulation by $30 \mu \mathrm{M}$ Pg Decreases with Respect to Time when Pre-diluted in a pH 5.8 Efflux Buffer

Top: IRCR vs TOD. Bottom: IRCR vs calculated [Pg] based on Pg's measured hydration kinetics (section 3.2.5). Data fit to a four parameter logistic curve - $\mathrm{EC}_{50}$ $=17.7 \mu \mathrm{M} \pm 3 \mu \mathrm{M} \mathrm{r}{ }^{2}=0.77$ (S.E. $n=2$ ). Experiments performed in a $100 \mathrm{mM} \mathrm{KCl}$ 20mM PIPES efflux buffer at pH 7.4. $\sim 0.15 \mathrm{mg} / \mathrm{ml} \mathrm{sSR}+\sim 5 \mu \mathrm{M} \mathrm{CaCl}_{2}$ (premixed), $60 \mu \mathrm{M} \mathrm{MgCl} 2+30 \mu \mathrm{M}$ ATP (premixed). At uptake minimum $\left[\mathrm{Ca}^{2+}\right] \sim 1 \mu \mathrm{M}$ the indicated amount of $[\mathrm{Pg}]$ was added to the assay. $\mathrm{Pg}$ was pre-diluted into a $\mathrm{pH}$ 5.8 efflux buffer at $2 \mathrm{mM}$ (time $=0$ ). $2 \mathrm{mM}$ aqueous stock was then added to efflux assay to obtain $30 \mu \mathrm{M} \mathrm{Pg}$. 


\subsubsection{CMCR Efflux by $30 \mu \mathrm{M}$ Pg Pre-buffered at pH 5.8 vs Time of Dilution}

This experiment is the same as shown for the previous (IRCR) section except that CMCR is calculated and reported. As time of dilution is allowed to progress, the CMCR rate increases (Figure 4.5) indicating a loss of inhibition. The CMCR rate is plotted against the calculated $[\mathrm{Pg}]$ (from Pg hydration kinetics) that corresponds to the time of dilution. The fitted $\mathrm{IC}_{50}$ is $12.9 \mu \mathrm{M} \pm 0.1 \mu \mathrm{M}$ (SE). The time of dilution axis is included as a reference and estimate only. The individual $\mathrm{pH}$ dependent prototropic forms present in this experiment are the same forms present in the concentration dependent experiment (Figure 4.3). Therefore, the form or forms responsible for the inhibited CMCR rates with increasing concentration are probably responsible for the increasing rate (with decreasing concentration) here. That is, the disappearing inhibition effect is most likely due to a decrease in concentration of an inhibiting Pg form. This result implies that one or more of the prototropic forms are responsible for the CMCR inhibition effect. Given that this experiment is performed in $\mathrm{pH} 7.4$ buffer, which minimizes the cationic form to $<1 \%$ (see Figure 4.7 ), the quinoidal base form or the ionized quinoidal base form (or both) are likely responsible for CMCR inhibition. 

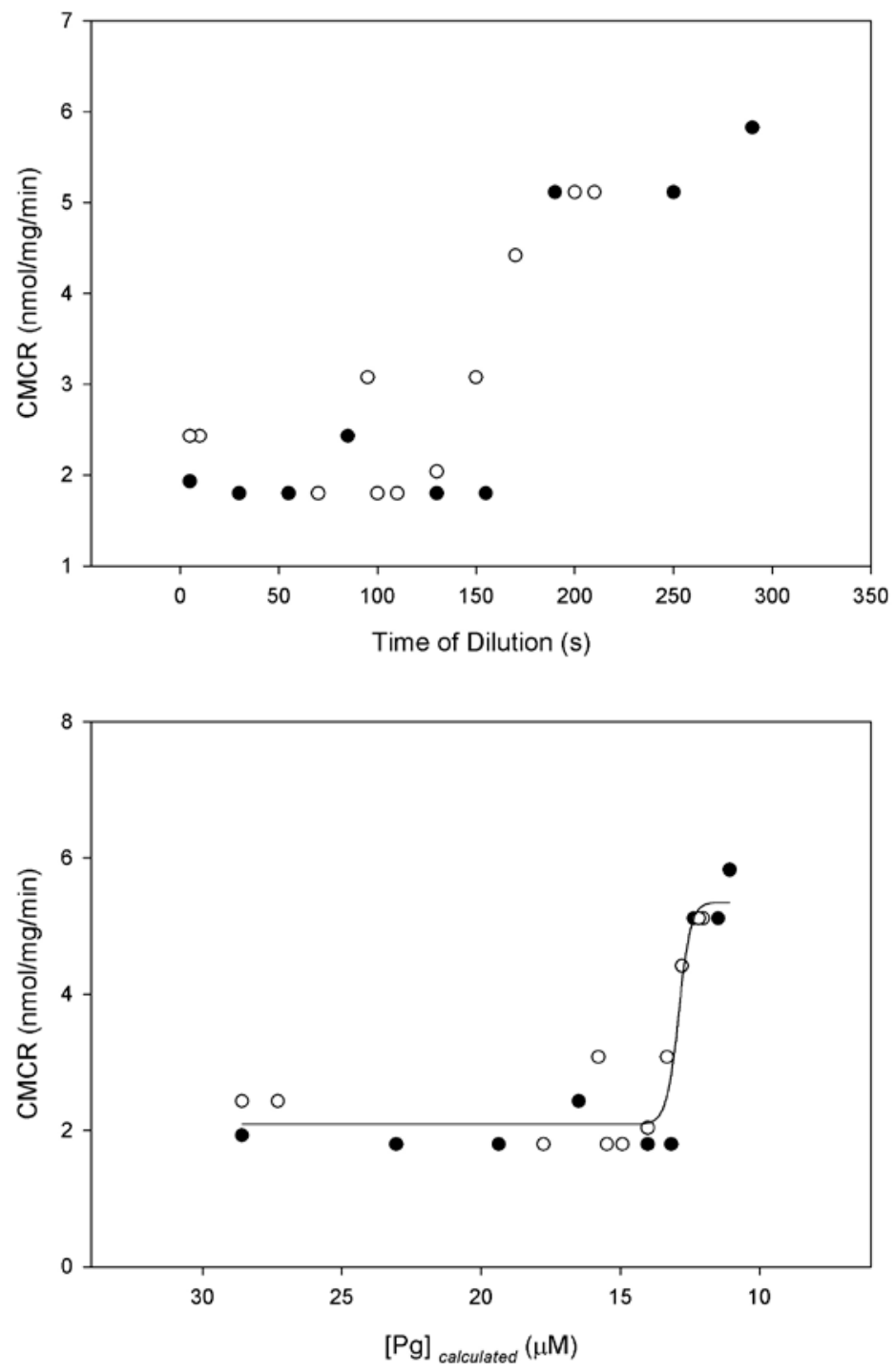

Figure 4.5 CMCR Inhibition by $30 \mu \mathrm{M}$ Pg Decreases with Respect to Time when Pre-diluted in a pH 5.8 Efflux Buffer

Top: CMCR vs TOD. Bottom: CMCR vs calculated [Pg] based on Pg's measured hydration kinetics (section 3.2.5). Data fit to a four parameter logistic curve - $\mathrm{IC}_{50}$ $=12.9 \mu \mathrm{M} \pm 0.1 \mu \mathrm{M} \mathrm{r}{ }^{2}=0.90$ (S.E. $\mathrm{n}=2$ ). Experiments performed in a $100 \mathrm{mM} \mathrm{KCl}$ 20mM PIPES efflux buffer at pH 7.4. $\sim 0.15 \mathrm{mg} / \mathrm{ml} \mathrm{sSR}+\sim 5 \mu \mathrm{M} \mathrm{CaCl}_{2}$ (premixed), $60 \mu \mathrm{M} \mathrm{MgCl} 2+30 \mu \mathrm{M}$ ATP (premixed). At uptake minimum $\left[\mathrm{Ca}^{2+}\right] \sim 1 \mu \mathrm{M}$ the indicated amount of $[\mathrm{Pg}]$ was added to the assay. $\mathrm{Pg}$ was pre-diluted into a $\mathrm{pH}$ 5.8 efflux buffer at $2 \mathrm{mM}$ (time $=0$ ). $2 \mathrm{mM}$ aqueous stock was then added to efflux assay to obtain $30 \mu \mathrm{M} \mathrm{Pg}$. 


\section{4 pH Dependent Modulation of $\mathrm{Ca}^{2+}$ Efflux by $\mathrm{Pg}$}

The results presented in section 4.2 and 4.3 strongly implies that one or more of the three prototropic forms as being the main modulating species for both IRCR stimulation and CMCR inhibition.

The species included in the prototropic group are the flavylium cation $\left(\mathrm{AH}^{+}\right)$, the quinoidal base $(A)$, and the ionized quinoidal base $\left(A^{-}\right)$with the specific mole fraction of each being $\mathrm{pH}$ dependent. The first $\mathrm{pKa}$ (experimental) and second pKa (calculated) of Pelargonidin are reported to be at $\mathrm{pH} 5.8$ and $\mathrm{pH} 7.1$ respectively (Borkowski et al. 2005). Figure 4.6 shows a calculated mole fraction diagram of Pelargonidin for the prototropic forms based on those $\mathrm{pK}$ values. At

pH 5.8 the calculated mole fractions of $\mathrm{AH}^{+}, \mathrm{A}$, and $\mathrm{A}^{-}$are $49 \%, 49 \%$, and $\sim 1 \%$ respectively. At pH 6.4, the mole fractions are 17\%, 70\%, and 13\% respectively. And at $\mathrm{pH} 7.4$, the mole fractions are $\sim 1 \%, 33 \%$, and $66 \% \%$ respectively (Figure 4.7).

The $\mathrm{pH}$ extremes tested here, $\mathrm{pH} 5.8$ and $\mathrm{pH} 7.4$, were chosen mainly due to the functionality limit of the sSR. Lastly, $\mathrm{pH} 6.4$ is chosen because it fit at the predicted maximum of $[\mathrm{A}]$ and the predicted minimum of $\left[\mathrm{AH}^{+}\right]$and $[\mathrm{A}-]$ (Figure 4.6). 


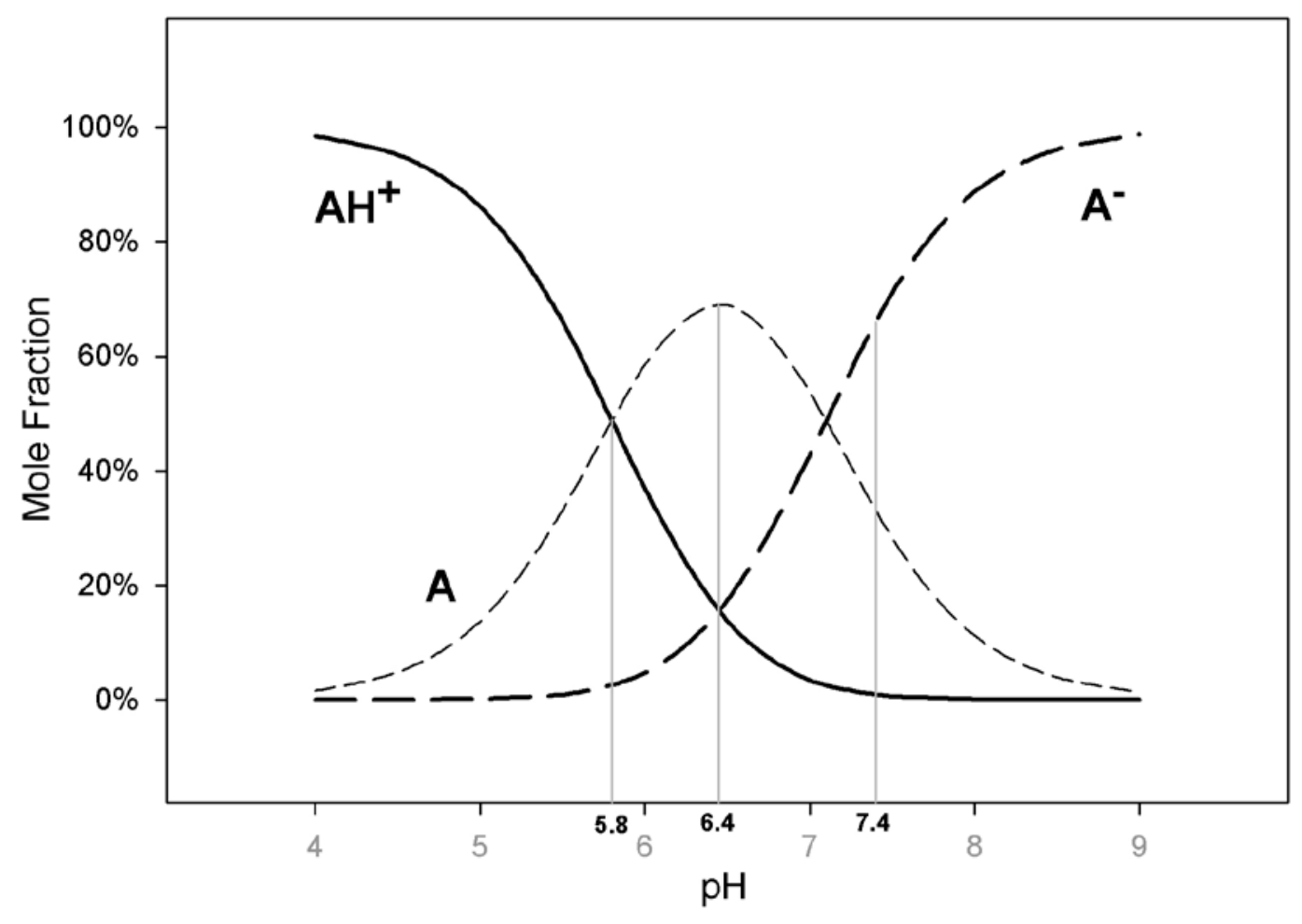

Figure 4.6 Reference Chart of the Mole Fractions of the Prototropic Forms of $\mathrm{Pg}$ vs $\mathrm{pH}$ Immediately After Dilution into an Aqueous Buffer

Chart shows the calculated mole fractions of the flavylium cation $\left(\mathrm{AH}^{+}\right)$, the quinoidal base $(A)$, and the ionized quinoidal base $\left(A^{-}\right)$of Pelargonidin vs $\mathrm{pH}$. First $\mathrm{pK}_{\mathrm{a} 1}=5.8$ and second $\mathrm{pK}_{\mathrm{a} 2}=7.1$ were taken from Borkowski et al. 2005. Efflux assay $\mathrm{pH}$ at 5.8, 6.4, and 7.4 are indicated for reference. 


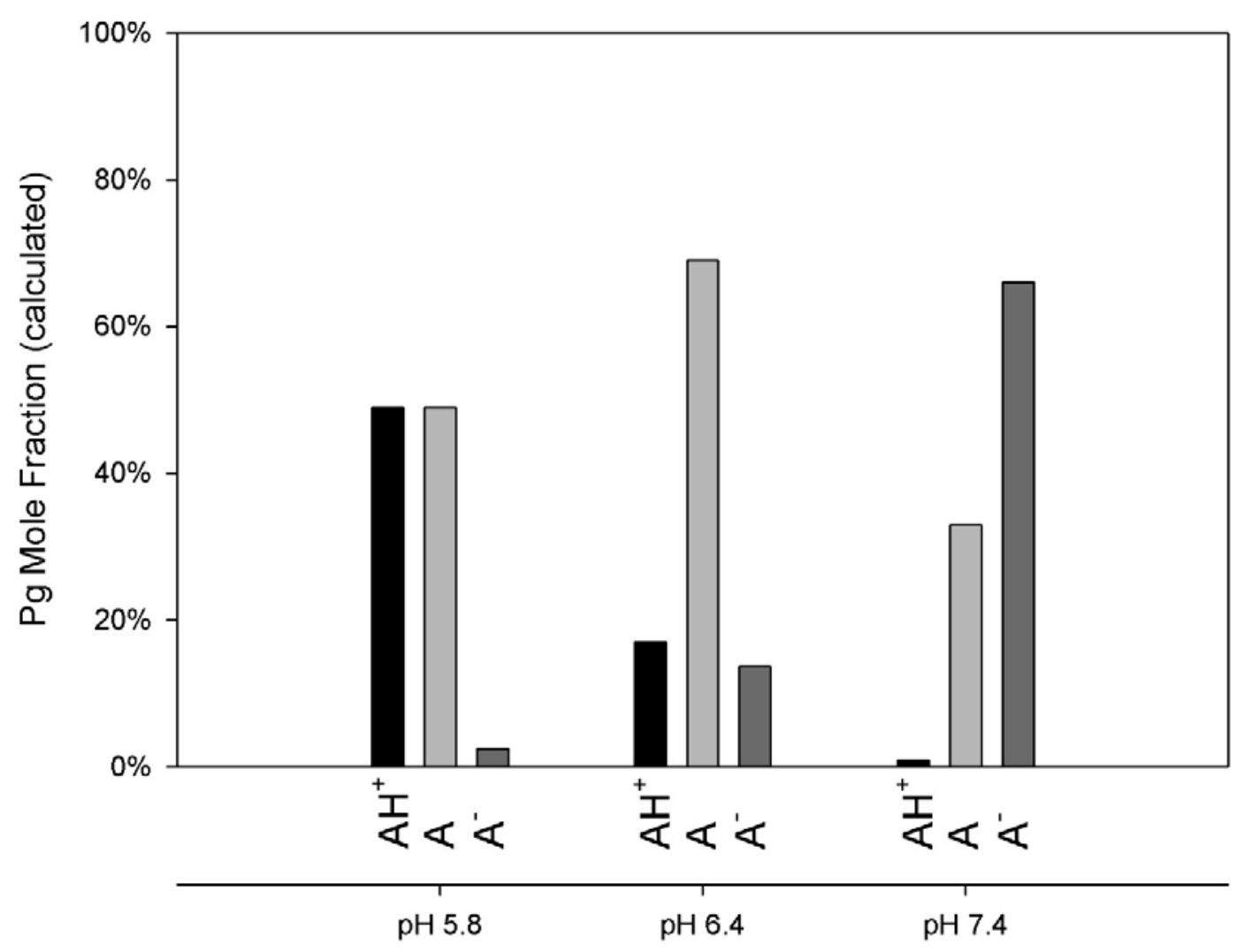

Figure 4.7 Calculated Mole Fractions of the Prototropic Forms of $\mathrm{Pg}$ vs $\mathrm{pH}$ Immediately After Dilution into an Aqueous Buffer

Chart shows the calculated mole fractions of $\mathrm{AH}^{+}, \mathrm{A}, \mathrm{A}^{-}$of Pelargonidin at $\mathrm{pH} 5.8$, 6.4 , and 7.4. First $\mathrm{pK}_{\mathrm{a} 1}=5.8$ and second $\mathrm{pK}_{\mathrm{a} 2}=7.1$ were taken from Borkowski et al. 2005. Data shown below.

\begin{tabular}{c|c|c|c|}
\multicolumn{1}{c}{} & \multicolumn{1}{c}{$\mathrm{AH}+$} & \multicolumn{1}{c}{$\mathrm{A}$} & $\mathrm{A}-$ \\
\cline { 2 - 4 } pH 5.8 & $49 \%$ & $49 \%$ & $2 \%$ \\
\cline { 2 - 4 } pH 6.4 & $17 \%$ & $70 \%$ & $13 \%$ \\
\cline { 2 - 4 } pH 7.4 & $1.00 \%$ & $33 \%$ & $66 \%$ \\
\cline { 2 - 4 } & & &
\end{tabular}




\subsection{1 pH Dependent IRCR by $30 \mu \mathrm{M} \mathrm{Pg}$}

A comparison between a control $(\mathrm{MeOH}+0.1 \% \mathrm{HCl}), 0.5 \mathrm{mM}$ caffeine, and $30 \mu \mathrm{M}$

$\mathrm{Pg}$ is made. Caffeine is utilized because the control has a very low (nearly zero) initial rate of efflux which can have limited use when making comparisons to a modulating compound. Additionally, caffeine is a well-known stimulator of the $\mathrm{CRC}$ that has a first $\mathrm{pKa} \sim 14$ and therefore will not ionize over the tested $\mathrm{pH}$ range. However, that doesn't preclude that the efficacy of caffeine stimulation of the $\mathrm{CRC}$ doesn't change over the tested $\mathrm{pH}$ range (due to $\mathrm{pH}$ dependent changes of the CRC itself).

As mentioned in Chapter 1 , the $\mathrm{CRC}$ is very sensitive to $\mathrm{pH}$. At low $\mathrm{pH}(<6)$, the $\mathrm{CRC}$ is in a near closed state and is resistant to stimulation. At high $\mathrm{pH}(>7.4)$, the $\mathrm{CRC}$ is in a relatively open state. Therefore, the comparison of the effects of $\mathrm{Pg}$ on the $\mathrm{CRC/sSR}$ across a $\mathrm{pH}$ range must be approached with caution. For reference, Figure 4.8 shows actual experimental traces and the relative difference of efflux kinetics for a control $(0.5 \% \mathrm{MeOH})$ experiment at $\mathrm{pH} 5.8,6.4$, and 7.4. 


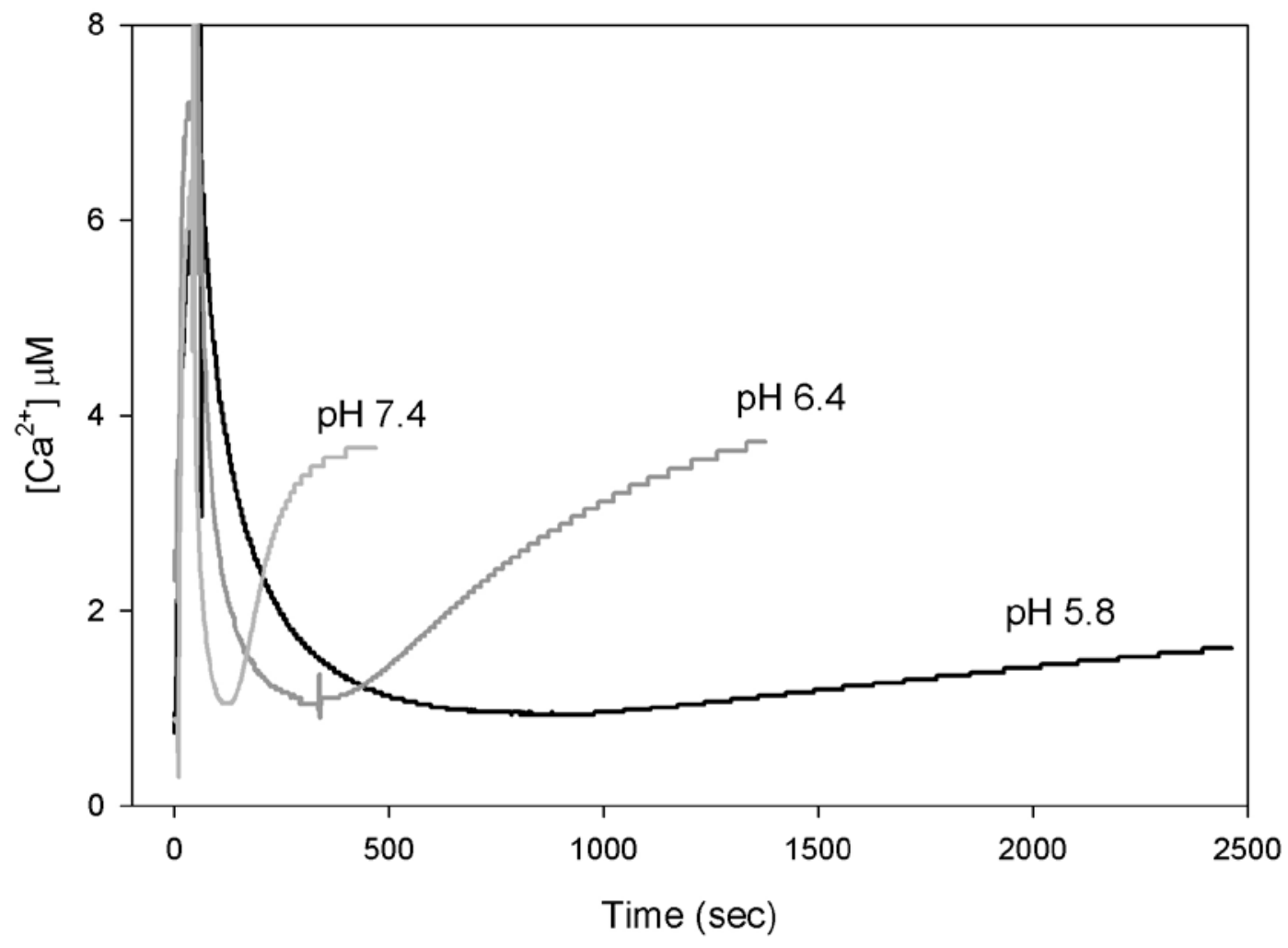

Figure 4.8 The Uptake and Efflux Kinetics of sSR Active Efflux Experiments are $\mathrm{pH}$ Dependent

Active efflux control experiments were performed in a $100 \mathrm{mM} \mathrm{KCl} 20 \mathrm{mM}$ PIPES efflux buffer at pH 5.8, 6.4, and 7.4. $\sim 0.15 \mathrm{mg} / \mathrm{ml} \mathrm{sSR}+\sim 5 \mu \mathrm{M} \mathrm{CaCl}_{2}$ (premixed), $5-60 \mu \mathrm{M} \mathrm{MgCl}_{2}+5-30 \mu \mathrm{M}$ ATP (premixed). At uptake minimum $\left[\mathrm{Ca}^{2+}\right] \sim 1 \mu \mathrm{M}$ $0.5 \% \mathrm{MeOH}$ was added to the assay. 
The result shown in Figure 4.9 shows the IRCR results for $0.5 \% \mathrm{MeOH}$ (control), $0.5 \mathrm{mM}$ caffeine, and $30 \mu \mathrm{M} \mathrm{Pg}$ at $\mathrm{pH} 5.8, \mathrm{pH} 6.4$, and $\mathrm{pH}$ 7.4. The IRCR for $\mathrm{MeOH}$ (black bars) increases with increasing $\mathrm{pH}$ confirming the $\mathrm{pH}$ dependent modulation of the CRC. The $0.5 \mathrm{mM}$ caffeine columns (light gray columns in each $\mathrm{pH}$ set) show a significant stimulation over the $\mathrm{pH}$ dependent increase of the control. Finally, the $30 \mu \mathrm{M} \mathrm{Pg}$ columns (dark gray columns in each pH set) also show a stimulation effect that increases with $\mathrm{pH}$. However, the level of IRCR stimulation is similar to that of $0.5 \mathrm{mM}$ caffeine at $\mathrm{pH} 5.8$ and $\mathrm{pH} 6.4$ but at $\mathrm{pH} 7.4$, stimulation is only $55 \%$ that of caffeine. Given the $\mathrm{pH}$ dependent complexity of $\mathrm{Pg}$, this could imply that $\mathrm{Pg}$ is losing its ability to stimulate IRCR at this (high) $\mathrm{pH}$ because of a loss of stimulating species (loss of $\mathrm{AH}^{+}$or $\mathrm{A}$ ) or because of an increase of an inhibiting form $\left(A^{-}\right)$. Since the comparison is made to caffeine, a look at it is also warranted. Even though caffeine isn't ionizing over this $\mathrm{pH}$ range, there is the possibility that the $\mathrm{pH}$ dependent changes of the $\mathrm{CRC}$ is altering (enhancing in this case) the efficacy of caffeine to stimulate IRCR. This data doesn't substantiate this possibility very well if one looks at the data with the $\mathrm{MeOH}$ IRCR rates normalized (Figure 4.10). Again, the rates for caffeine and Pg are comparable at $\mathrm{pH} 5.8$ and $\mathrm{pH}$ 6.4. At pH 7.4 the normalized caffeine IRCR rate is comparable to its normalized rate at $\mathrm{pH} 6.4$. If the efficacy of caffeine is enhanced when changing from $\mathrm{pH} 6.4$ to $\mathrm{pH} 7.4$, then one would expect the normalized rate to increase from that at $\mathrm{pH} 6.4$ which isn't apparent from the results presented. 


\subsection{2 pH Dependent CMCR by $30 \mu \mathrm{M} \mathrm{Pg}$}

It is important to note that there are two distinct changes in the time domain occurring that is distinct for each $\mathrm{pH}$. First, the duration of time required to get from the addition of $\mathrm{Pg}$ to the time point where the CMCR is calculated is decreasing with increasing $\mathrm{pH}$. Second, the rate of transformation of $\mathrm{Pg}$ is decreasing with increasing $\mathrm{pH}$. So, the estimated concentration of the $\mathrm{Pg}$ forms present at any given CMCR point must use the appropriate combination of the two time based factors. It is worth noting that the consideration of the $\mathrm{pH}$ and time factors listed above are significant if the effect of $\mathrm{Pg}$ on the SSR is reversible. That is, the modulating effect by $\mathrm{Pg}$ is caused by the concentration of the $\mathrm{Pg}$ forms present at the time of CMCR, not at the time Pg is added to the assay. The analysis presented here assumes a reversible process and therefore the loss of $[\mathrm{Pg}]$ with time is considered. This assumption is only supported by the fact that the effect of $\mathrm{Pg}$ on IRCR is transitory which may imply a reversible process. If the inhibition of CMCR by Pg is not reversible, then the impact of the incorrect assumption and analysis will result in an artificially low $\mathrm{IC}_{50}$ for $\mathrm{CMCR}$ modulation by $\mathrm{Pg}$. To determine if the effects of $\mathrm{Pg}$ are indeed reversible or not, other 


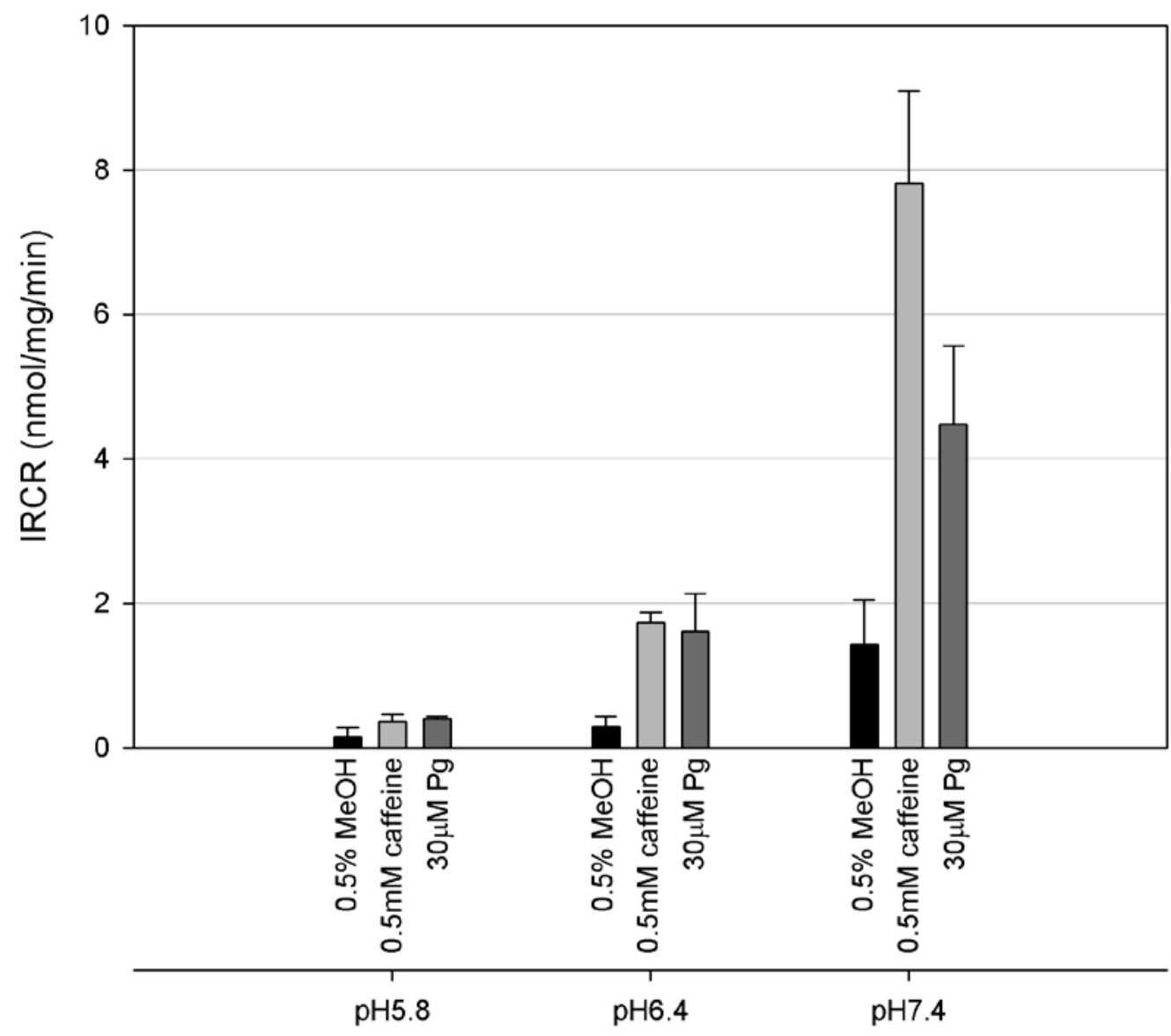

Figure 4.9 IRCR Stimulation of $\mathrm{Ca}^{2+}$ Efflux by $30 \mu \mathrm{M} \mathrm{Pg}$ and $0.5 \mathrm{mM}$ Caffeine vs $\mathrm{pH}$

Active efflux control experiments were performed in a $100 \mathrm{mM} \mathrm{KCl} 20 \mathrm{mM}$ PIPES efflux buffer at pH 5.8, 6.4, and 7.4. $\sim 0.15 \mathrm{mg} / \mathrm{ml} \mathrm{sSR}+\sim 5 \mu \mathrm{M} \mathrm{CaCl}$ (premixed), $5-60 \mu \mathrm{M} \mathrm{MgCl} 2+5-30 \mu \mathrm{M}$ ATP (premixed). At uptake minimum $\left[\mathrm{Ca}^{2+}\right] \sim 1 \mu \mathrm{M}$ either $0.5 \% \mathrm{MeOH}, 30 \mu \mathrm{M} \mathrm{Pg}$, or $0.5 \mathrm{mM}$ caffeine was added to the assay. Data shown below. $(\mathrm{n}=3 \pm \mathrm{SD})$. All rates below are in $\mathrm{nmol} / \mathrm{mg} / \mathrm{min}$.

\begin{tabular}{|c|c|c|c|}
\cline { 2 - 4 } \multicolumn{1}{c|}{} & $0.5 \% \mathrm{MeOH}$ & $0.5 \mathrm{mM}$ Caffeine & $30 \mu \mathrm{M} \mathrm{Pg}$ \\
\hline $\mathrm{pH} 5.8$ & $0.15 \pm 0.13$ & $0.36 \pm 0.11$ & $0.40 \pm 0.04$ \\
\hline $\mathrm{pH} 6.4$ & $0.30 \pm 0.14$ & $1.73 \pm 0.14$ & $1.61 \pm 0.52$ \\
\hline $\mathrm{pH} 7.4$ & $1.43 \pm 0.62$ & $7.81 \pm 1.28$ & $4.48 \pm 10.9$ \\
\hline
\end{tabular}




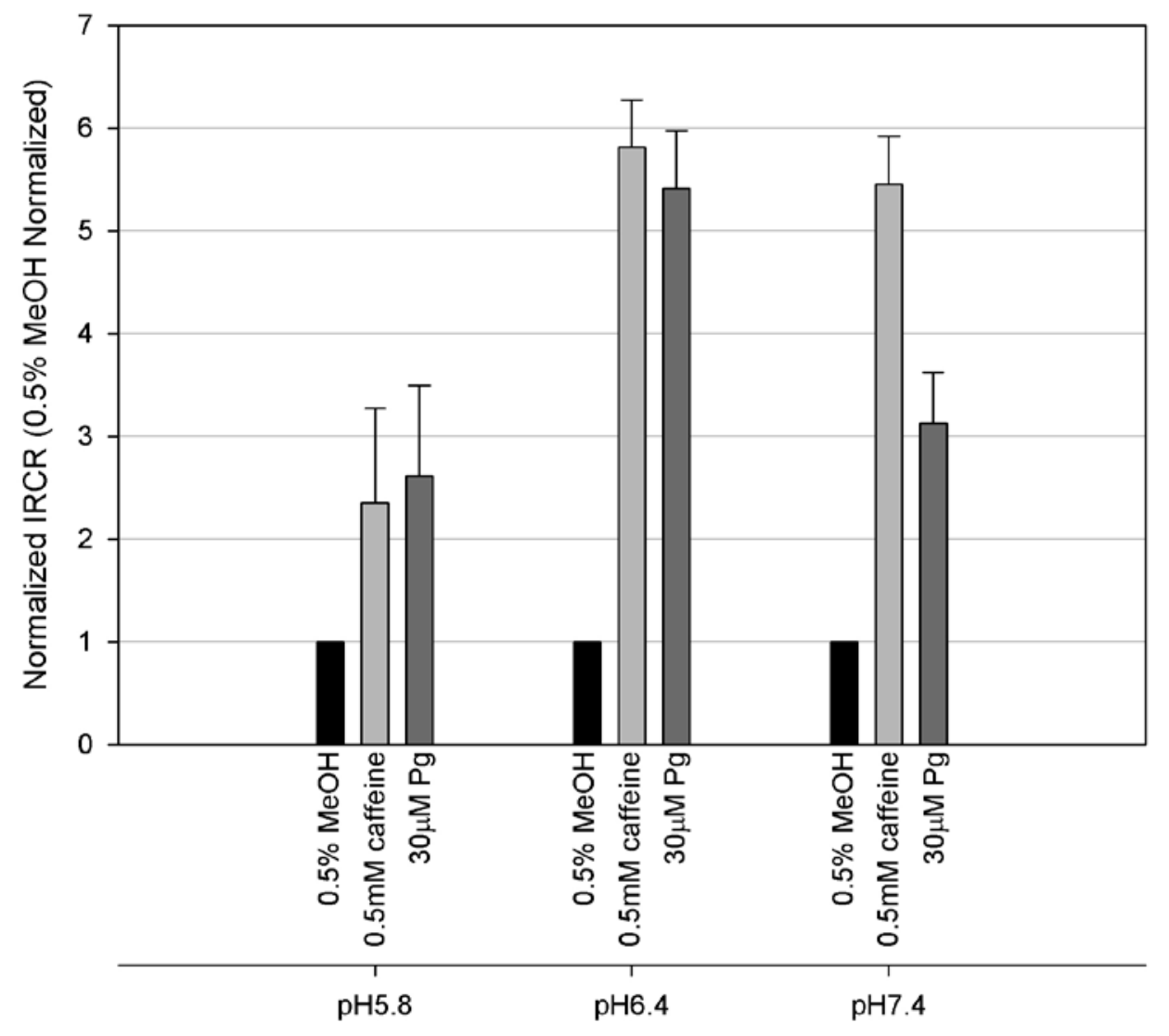

Figure 4.10 Control Normalized IRCR by $30 \mu \mathrm{M}$ Pg vs pH

Control normalized IRCR comparisons for $0.5 \% \mathrm{MeOH}+0.1 \% \mathrm{HCl}, 0.5 \mathrm{mM}$ caffeine, and $30 \mu \mathrm{M}$ at pH 5.8,6.4, and 7.4. Experiments were performed as noted in Figure 4.9. Data shown below.

\begin{tabular}{|c|c|c|c|}
\cline { 2 - 4 } \multicolumn{1}{c|}{} & $0.5 \% \mathrm{MeOH}$ & $0.5 \mathrm{mM}$ Caffeine & $30 \mu \mathrm{M} \mathrm{Pg}$ \\
\hline $\mathrm{pH} 5.8$ & 1 & $2.4 \pm 0.9$ & $2.6 \pm 0.9$ \\
\hline $\mathrm{pH} 6.4$ & 1 & $5.8 \pm 0.5$ & $5.4 \pm 0.6$ \\
\hline $\mathrm{pH} 7.4$ & 1 & $5.5 \pm 0.5$ & $3.1 \pm 0.5$ \\
\hline
\end{tabular}


experiments such as single channel work would need to be completed (but are not included here).

Figure 4.11 shows that the $\mathrm{CMCR}$ rate for the control increases with $\mathrm{pH}$ as expected. Caffeine also stimulates $\mathrm{CMCR}$ at $\mathrm{pH} 5.8$ and pH 6.4. At pH 7.4, the $\mathrm{CMCR}$ rate for $0.5 \mathrm{mM}$ caffeine is comparable to the $\mathrm{MeOH}$ control. $30 \mu \mathrm{M} \mathrm{Pg}$ stimulates CMCR on the same order as caffeine at $\mathrm{pH} 5.8$. However, at $\mathrm{pH} 6.4$ and $\mathrm{pH} 7.4, \mathrm{Pg}$ inhibits the $\mathrm{CMCR}$ rate significantly. Figure 4.12 shows the same data from Figure 4.11 as a percentage increase or decrease in CMCR rate compared to the control. Pg stimulates CMCR by $49 \%$ at $\mathrm{pH} 5.8$. CMCR is inhibited by $\mathrm{Pg}$ to $50 \%$ less at $\mathrm{pH} 6.4$ and to $58 \%$ less at $\mathrm{pH} 7.4$ with respect to the control. 


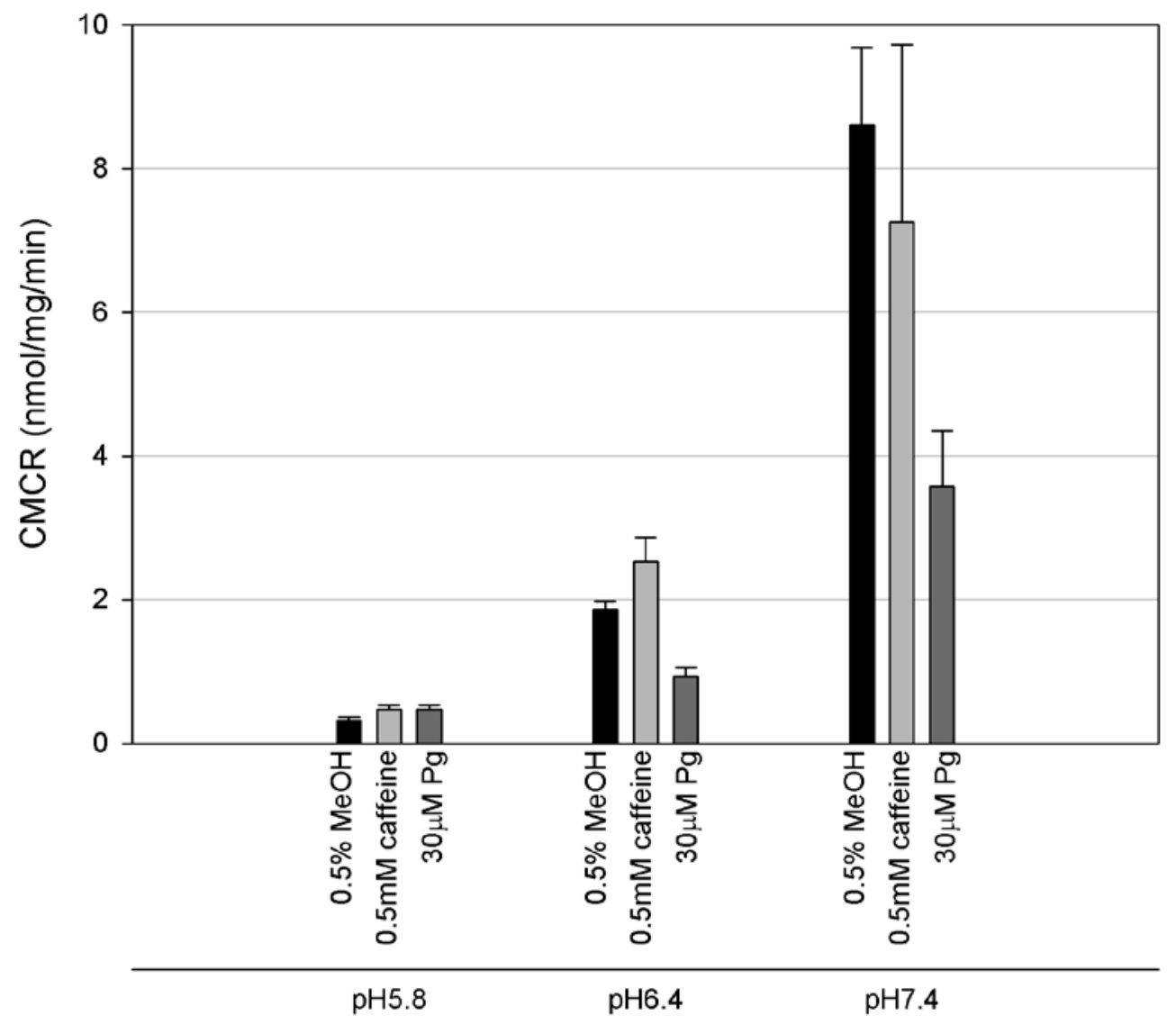

Figure 4.11 CMCR Modulation of $\mathrm{Ca}^{2+}$ Efflux by $30 \mu \mathrm{M} \mathrm{Pg}$ and $0.5 \mathrm{mM}$ Caffeine vs $\mathrm{pH}$

CMCR comparisons for $0.5 \% \mathrm{MeOH}+0.1 \% \mathrm{HCl}, 0.5 \mathrm{mM}$ caffeine, and $30 \mu \mathrm{M}$ at $\mathrm{pH}$ 5.8, 6.4, and 7.4. Experiments were performed in a $100 \mathrm{mM} \mathrm{KCl}, 20 \mathrm{mM}$ PIPES efflux buffer at the stated $\mathrm{pH}, 0.15 \mathrm{mg} / \mathrm{ml}$ crude $\mathrm{SSR}$ vesicles were actively loaded with $\sim 5 \mu \mathrm{M} \mathrm{Ca}^{2+}$ by $\mathrm{Ca}^{2+}$-ATPase activity with $5-60 \mu \mathrm{M} \mathrm{MgCl}_{2}+5-30 \mu \mathrm{M} \mathrm{ATP}$. At uptake minimum $\left[\mathrm{Ca}^{2+}\right] \sim 1 \mu \mathrm{M}$. $(\mathrm{n}=3 \pm \mathrm{SD})$. All rates below are in $\mathrm{nmol} / \mathrm{mg} / \mathrm{min}$.

\begin{tabular}{|c|c|c|c|}
\cline { 2 - 4 } \multicolumn{1}{c|}{} & $0.5 \% \mathrm{MeOH}$ & $0.5 \mathrm{mM}$ Caffeine & $30 \mu \mathrm{M} \mathrm{Pg}$ \\
\hline $\mathrm{pH} 5.8$ & $0.32 \pm 0.05$ & $0.47 \pm 0.06$ & $0.47 \pm 0.06$ \\
\hline $\mathrm{pH} 6.4$ & $1.86 \pm 0.11$ & $2.53 \pm 0.33$ & $0.93 \pm 0.12$ \\
\hline $\mathrm{pH} 7.4$ & $8.61 \pm 1.07$ & $7.26 \pm 2.47$ & $3.58 \pm 0.77$ \\
\hline
\end{tabular}




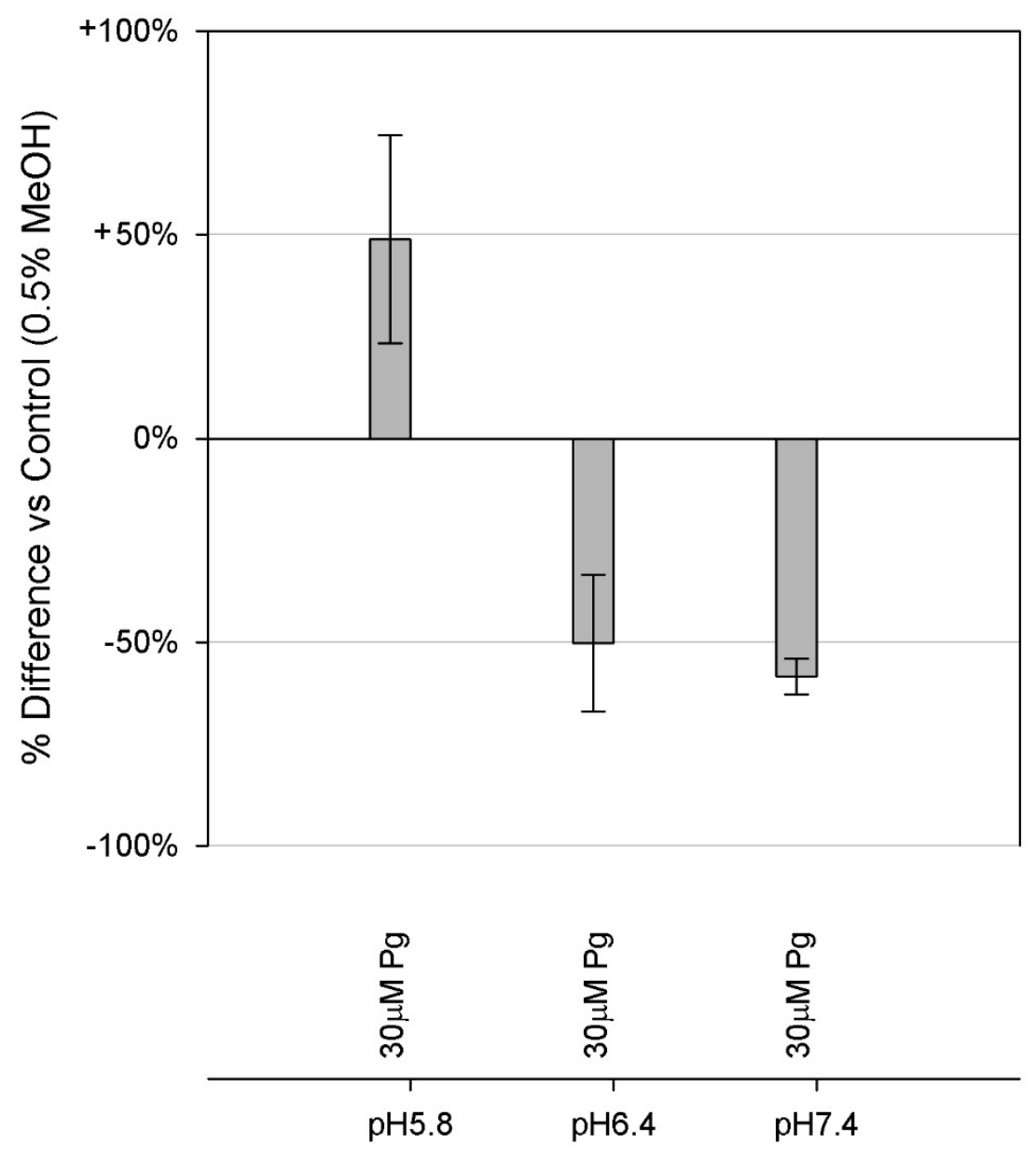

Figure $4.12 \%$ Difference of $30 \mu \mathrm{M}$ Pg Modulation of the CMCR Rate of $\mathrm{Ca}^{2+}$ Efflux with Respect to the $0.5 \% \mathrm{MeOH}$ control vs $\mathrm{pH}$

Data from Figure 4.11 represented as the \% Difference of $30 \mu \mathrm{M} \mathrm{Pg}$ Modulation of the CMCR Rate of $\mathrm{Ca}^{2+}$ Efflux with Respect to the $0.5 \% \mathrm{MeOH}$ control at pH 5.8 (49\% $\pm 26 \%)$, pH $6.4(-50 \% \pm 17 \%), \mathrm{pH} 7.4(-58 \% \pm 4 \%)$. 


\subsubsection{Comparison of Pg Effects on CMCR Efflux and the Relative Calculated Concentration of the Prototropic Forms of Pg}

As mentioned at the beginning of this section, this analysis assumes that the binding, and resulting modulation, of $\mathrm{Pg}$ to the $\mathrm{CRC}$ is a reversible process. To estimate the concentration of the three prototropic forms of $\mathrm{Pg}$ at the time that the CMCR is calculated, both the kinetics of transformation and the calculated mole fraction of the $\mathrm{Pg}$ forms at $\mathrm{pH} 5.8,6.8$, and 7.4 are considered.

The table at the bottom of Figure 4.13 lists the time duration between the point of $\mathrm{Pg}$ addition to the assay to the point at which the CMCR rate determined at each $\mathrm{pH}$. The '\%Pg Remaining' is calculated using the $\operatorname{CMCR}(\Delta t)$ data as the time variable in the equations, as measured and fitted, for $\mathrm{Pg}$ kinetics at each $\mathrm{pH}$ (Figure 3.5, Figure 3.6, and Figure 3.7). The 'Mole Fraction' data is taken from Figure 4.7. Finally, the 'Calculated [Pg form]' is the product of the initial Pg concentration $(30 \mu \mathrm{M})$, the Mole Fraction of each $\mathrm{Pg}$ form at that specific $\mathrm{pH}$, and the percent of $\mathrm{Pg}$ left at the time that the CMCR data point is taken (Equation 4.1).

$$
[\text { Pg form }]_{\text {calc. }}=[P g]_{\text {ini }} *\left\{\frac{[P g \text { form }]}{[P g]_{\text {ini }}}\right\} *\left\{\frac{[\text { Pg Remaining }]}{[P g]_{\text {ini }}}\right\}_{\text {time }=C M C R}
$$

\section{Equation 4.1}




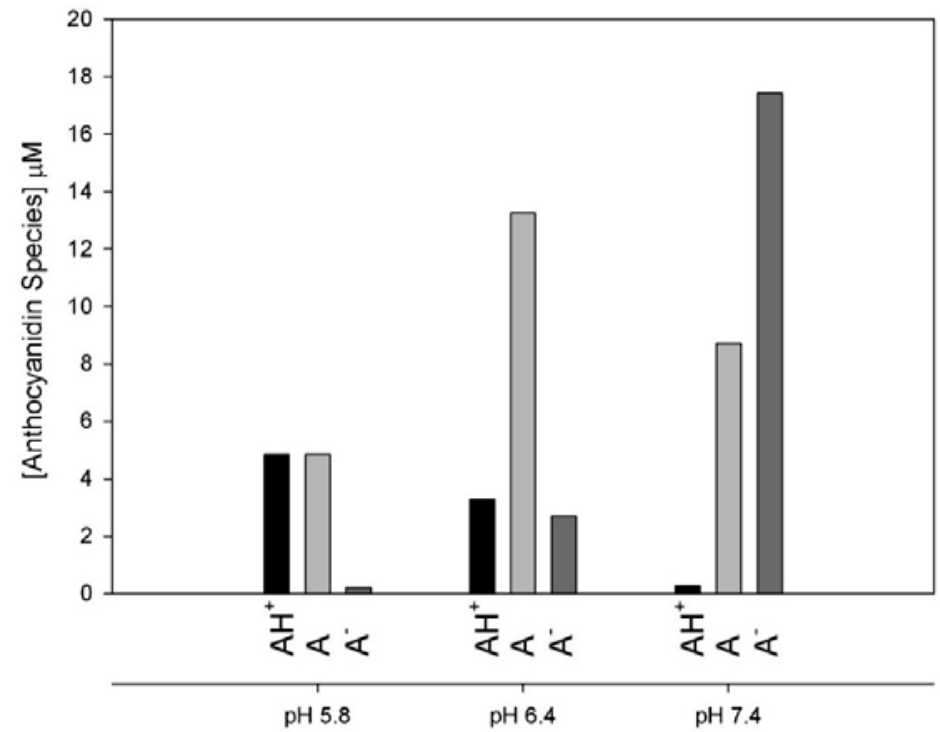

\begin{tabular}{|l|c|c|c|}
\cline { 2 - 4 } \multicolumn{1}{c|}{} & $\mathrm{pH} 5.8$ & $\mathrm{pH} 6.4$ & $\mathrm{pH} 7.4$ \\
\hline$[\mathrm{Pg}$ - initial] $\mu \mathrm{M}$ & 30 & 30 & 30 \\
\hline & & & \\
\hline $\mathrm{CMCR}(\Delta \mathrm{t}) \quad(\mathrm{sec})$ & 432 & 394 & 160 \\
\hline Std Deviation (sec) & 159 & 80 & 18 \\
\hline & & & \\
\hline$\% \mathrm{Pg}$ Remaining (Ave) & $33 \%$ & $64 \%$ & $87 \%$ \\
\hline Std Deviation & $4 \%$ & $2 \%$ & $1 \%$ \\
\hline & & & \\
\hline Mole Fraction of AH+ (calc.) & $49 \%$ & $17 \%$ & $1 \%$ \\
\hline Mole Fraction of A (calc.) & $49 \%$ & $69 \%$ & $33 \%$ \\
\hline Mole Fraction of A- (calc.) & $2 \%$ & $14 \%$ & $66 \%$ \\
\hline & & & \\
\hline & & & \\
\hline Calculated [AH+] $\mu \mathrm{M}$ & 5 & 3 & 0.3 \\
\hline Calculated [A] $\mu \mathrm{M}$ & 5 & 13 & 9 \\
\hline Calculated [A-] $\mu \mathrm{M}$ & 0.2 & 3 & 17 \\
\hline
\end{tabular}

Figure 4.13 Time Adjusted Concentration of the Pg Prototropic Forms at $\operatorname{CMCR}(\Delta \mathrm{t})$ vs $\mathrm{pH}$.

Top: Bar chart comparing the calculated $\left[\mathrm{AH}^{+}\right],[\mathrm{A}]$, and $\left[\mathrm{A}^{-}\right]$at each $\mathrm{pH}$ and at $\mathrm{CMCR}(\Delta \mathrm{t})$ with $30 \mu \mathrm{M}$ initial $\mathrm{Pg}$ concentration. .

Bottom: Data used to calculate $\left[\mathrm{AH}^{+}\right],[\mathrm{A}]$, and $\left[\mathrm{A}^{-}\right]$with $[\mathrm{Pg}]_{\mathrm{ini}}=30 \mu \mathrm{M} .(\mathrm{n}=3 \pm \mathrm{SD})$ 
The chart at the top of Figure 4.13 compares the calculated $\left[\mathrm{AH}^{+}\right],[\mathrm{A}]$, and $\left[\mathrm{A}^{-}\right]$ concentrations at each $\mathrm{pH}$ with an initial $[\mathrm{Pg}]$ of $30 \mu \mathrm{M}$. It is interesting to compare this data to Figure 4.7 which is the calculated mole fraction data at time of Pg addition into each buffer. Although the trends remain similar, the CMCR (time adjusted) data shows that the concentrations of the $\left[\mathrm{AH}^{+}\right]$and $[\mathrm{A}]$ forms at $\mathrm{pH} 5.8$ are significantly lower than the $[\mathrm{A}]$ and $\left[\mathrm{A}^{-}\right]$forms at $\mathrm{pH}$ 7.4. This is a direct result of the slower transformation kinetics of $\mathrm{Pg}$ at higher $\mathrm{pH}$. 


\subsection{Light Dependent Modulation of $\mathrm{Ca}^{2+}$ Efflux from sSR by Pg}

Arguably the most interesting property that $\mathrm{Pg}$ possesses with regards to its effect on the CRC is its effect when irradiated with white light. When irradiated, the CMCR inhibition shown in the previous sections is essentially nullified (Figure 4.14). That is, when irradiated, the CMCR rate increases to similar values as seem for the CMCR of the control.

\subsubsection{Light Dependent IRCR vs pH}

Figure 4.15 shows the $\mathrm{pH}$ dependent initial rate of efflux results for the $\mathrm{MeOH}$ (control) and $30 \mu \mathrm{M} \mathrm{Pg}$ as previously reported (two left most bars at each $\mathrm{pH}$ ). Additionally, the IRCR rate for $30 \mu \mathrm{M} \mathrm{Pg}(+\mathrm{h} v)$ that is irradiated with white light for the duration of the efflux phase is also shown. There isn't a significant difference between IRCR stimulation by Pg with or without irradiation. 


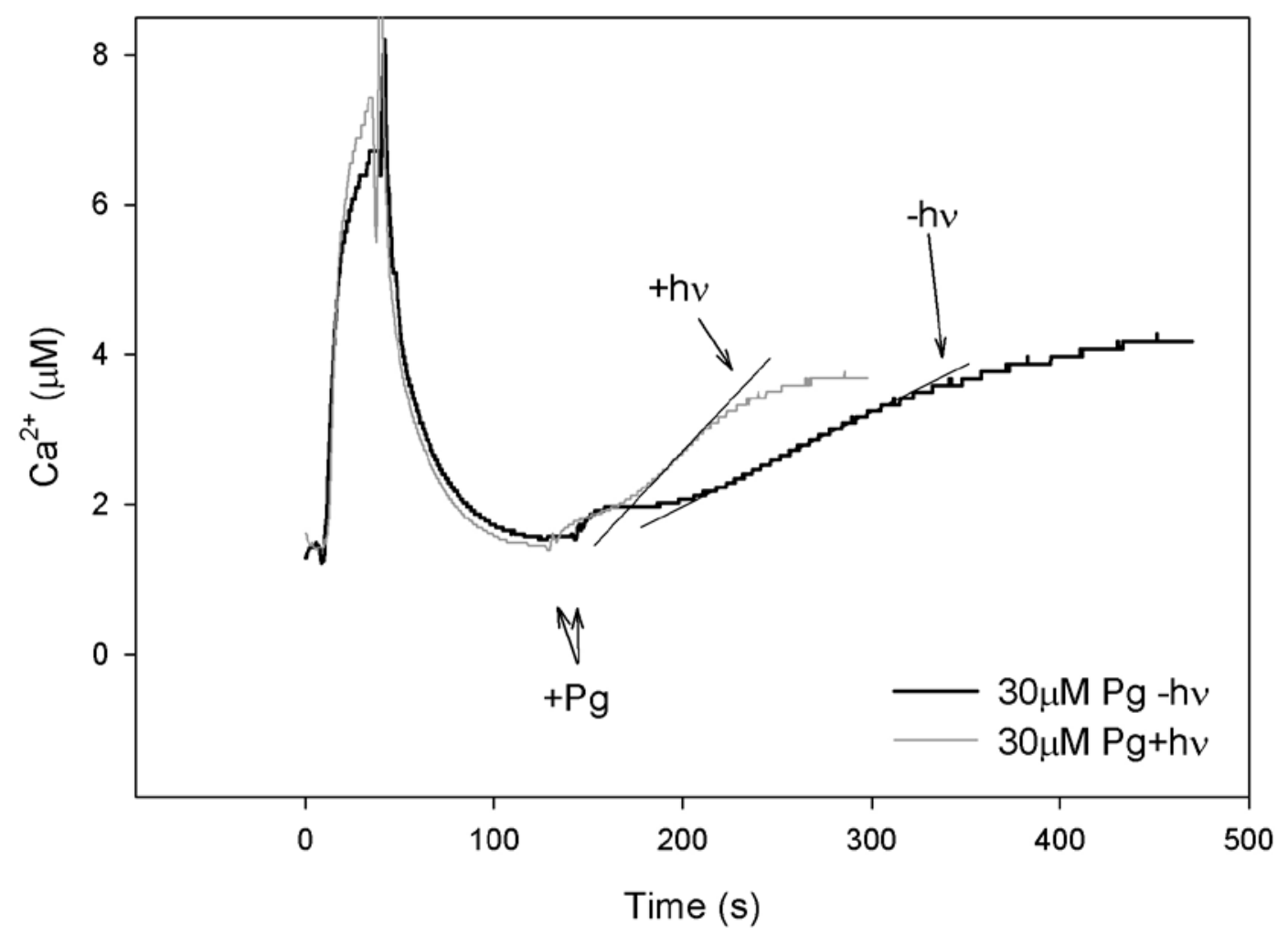

Figure 4.14 Irradiation with White Light Removes CMCR Inhibition by $30 \mu \mathrm{M} \mathrm{Pg}$ (Example Trace)

Active efflux control experiments were performed in a 100mM KCl 20mM PIPES efflux buffer at pH 7.4. $\sim 0.15 \mathrm{mg} / \mathrm{ml} \mathrm{sSR}+\sim 5 \mu \mathrm{M} \mathrm{CaCl} 2$ (premixed), $60 \mu \mathrm{M} \mathrm{MgCl}_{2}$ $+30 \mu \mathrm{M}$ ATP (premixed). At uptake minimum $\left[\mathrm{Ca}^{2+}\right] \sim 1 \mu \mathrm{M} 0.5 \% \mathrm{MeOH}$ was added to the assay. 


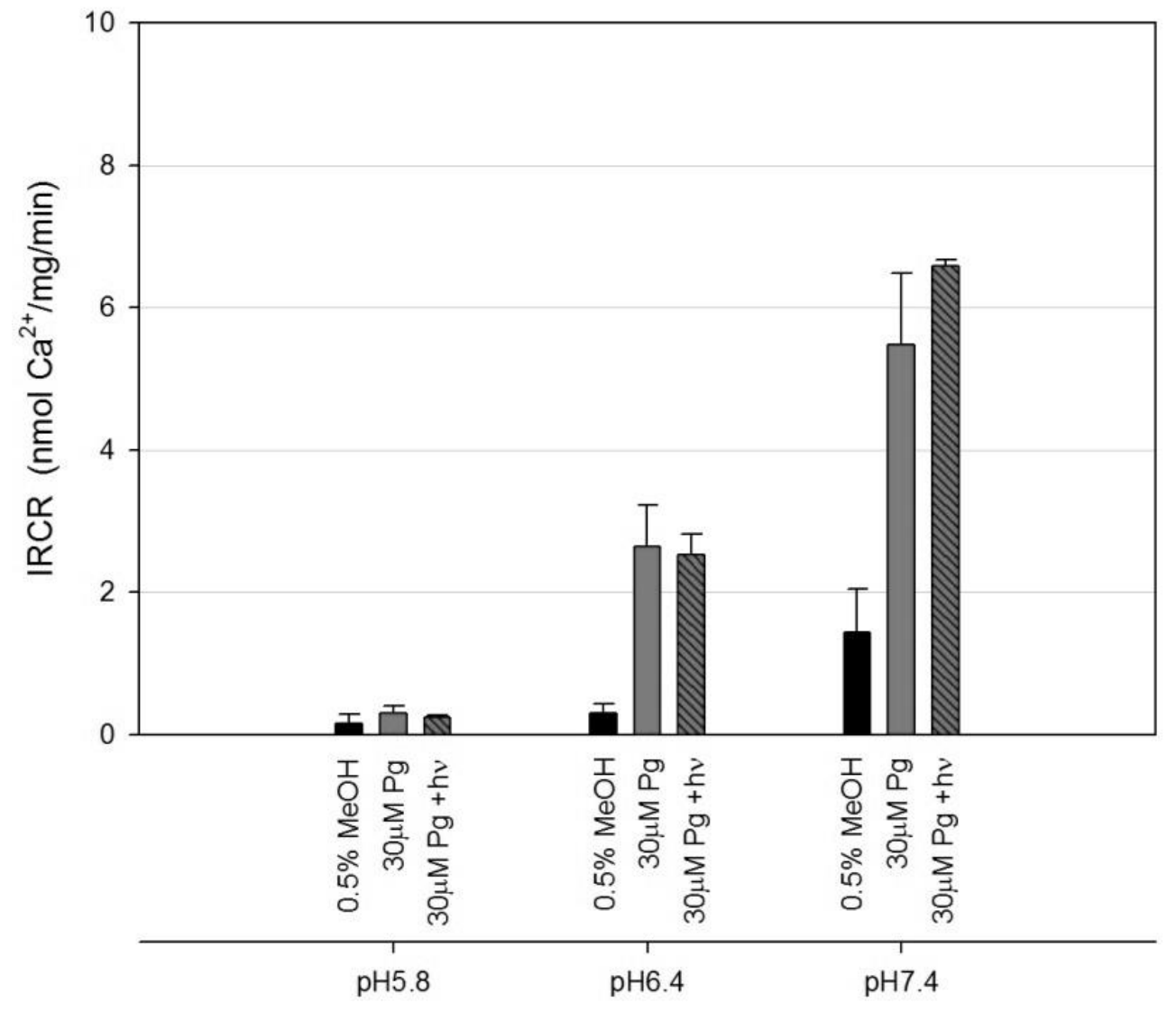

Figure 4.15 IRCR Modulation of Active $\mathrm{Ca}^{2+}$ Efflux by $30 \mu \mathrm{M} \mathrm{Pg}$ with and without Irradiation by White Light

Active efflux control experiments were performed in a $100 \mathrm{mM} \mathrm{KCl} 20 \mathrm{mM}$ PIPES efflux buffer at pH 7.4. $\sim 0.15 \mathrm{mg} / \mathrm{ml} \mathrm{sSR}+\sim 5 \mu \mathrm{M} \mathrm{CaCl} 2$ (premixed), $60 \mu \mathrm{M} \mathrm{MgCl}_{2}$ $+30 \mu \mathrm{M}$ ATP (premixed). At uptake minimum $\left[\mathrm{Ca}^{2+}\right] \sim 1 \mu \mathrm{M} 0.5 \% \mathrm{MeOH}$ or $30 \mu \mathrm{M}$ $\mathrm{Pg}$ was added to the assay. For thv experiments, light was turned on at the same time as the Pg was added. Data shown below. $(n=3 \pm S D)$. All rates below are in $\mathrm{nmol} / \mathrm{mg} / \mathrm{min}$.

\begin{tabular}{|c|c|c|c|}
\cline { 2 - 4 } \multicolumn{1}{c|}{} & $0.5 \% \mathrm{MeOH}$ & $30 \mu \mathrm{M} \mathrm{Pg}$ & $30 \mu \mathrm{M} \mathrm{Pg}+\mathrm{h} v$ \\
\hline $\mathrm{pH} 5.8$ & $0.15 \pm 0.13$ & $0.36 \pm 0.11$ & $0.40 \pm 0.04$ \\
\hline $\mathrm{pH} 6.4$ & $0.30 \pm 0.14$ & $1.73 \pm 0.14$ & $1.61 \pm 0.52$ \\
\hline $\mathrm{pH} 7.4$ & $1.43 \pm 0.62$ & $7.81 \pm 1.28$ & $4.48 \pm 1.09$ \\
\hline
\end{tabular}




\subsubsection{Light Dependent CMCR Rate of $\mathrm{Ca}^{2+}$ Efflux vs $\mathrm{pH}$}

Figure 4.16 shows the comparison of CMCR results for $30 \mu \mathrm{M} \mathrm{Pg}$ without and with irradiation vs the control. The $\mathrm{CMCR}$ efflux results for the $\mathrm{MeOH}$ (control) and $30 \mu \mathrm{M} \mathrm{Pg}$ are as shown as the two left most bars at each $\mathrm{pH}$ (black and light grey bars). The right most bars (dark grey) show the CMCR rate for $30 \mu \mathrm{M} \mathrm{Pg}$ that is irradiated with white light $(+\mathrm{h} v)$. Irradiation is started at the same time $\mathrm{Pg}$ is added to the assay. With irradiation, the CMCR rate returns to a value very comparable to the $\mathrm{MeOH}$ rate. There is even a slight increase in CMCR rates at pH 5.8 and pH 6.4 however the increases are small and a larger statistical data set would be needed for the stimulation result to be convincing. Similarly, the $\mathrm{CMCR}$ rate at $\mathrm{pH} 7.4$ is slightly less than the control (with the same reservation). 


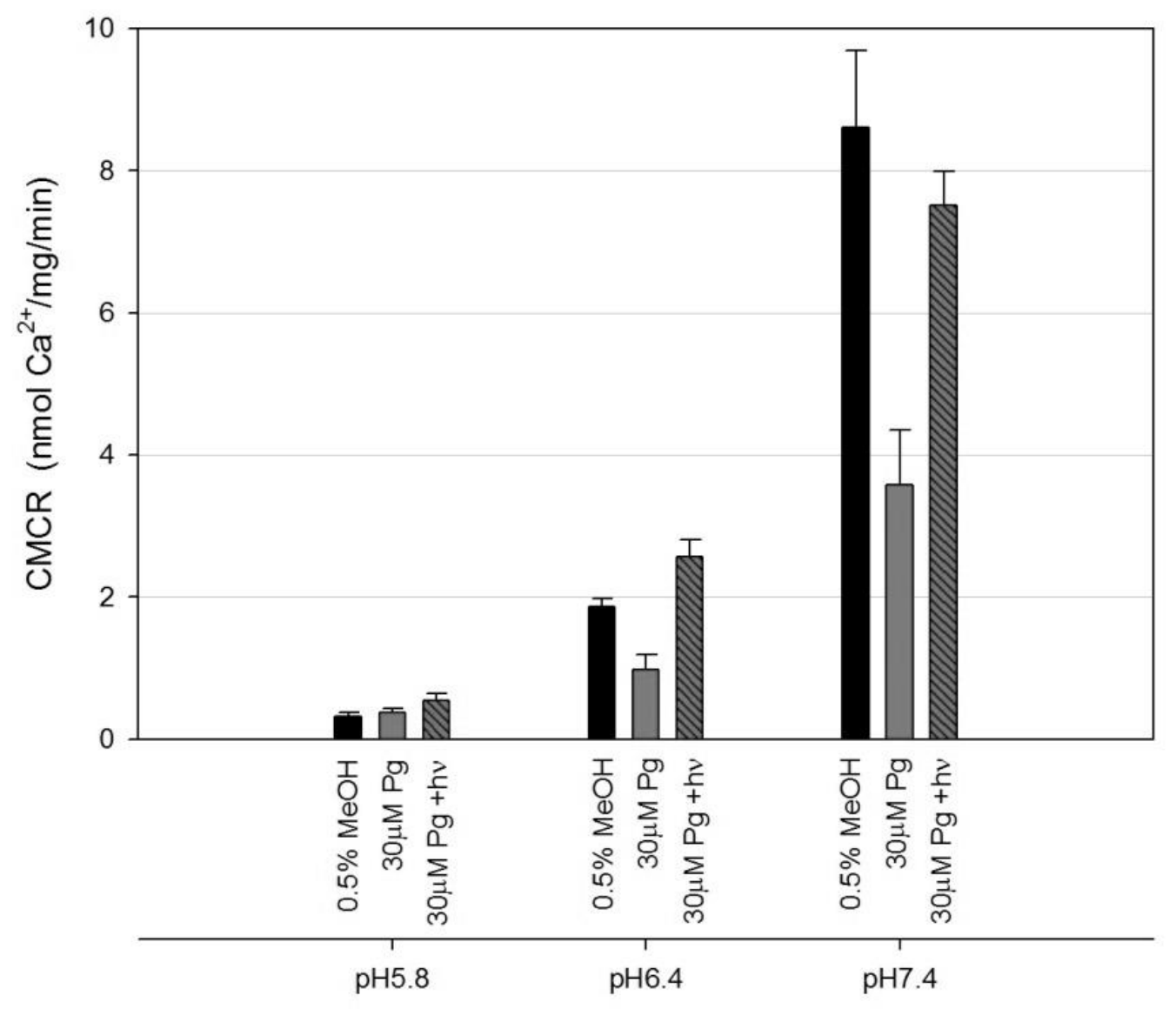

Figure 4.16 CMCR Modulation of Active $\mathrm{Ca}^{2+}$ Efflux by $30 \mu \mathrm{M} \mathrm{Pg}$ with and without Irradiation by White Light

Active efflux control experiments were performed in a $100 \mathrm{mM} \mathrm{KCl} 20 \mathrm{mM}$ PIPES efflux buffer at pH 7.4. $\sim 0.15 \mathrm{mg} / \mathrm{ml} \mathrm{sSR}+\sim 5 \mu \mathrm{M} \mathrm{CaCl}_{2}$ (premixed), $60 \mu \mathrm{M} \mathrm{MgCl}_{2}$ $+30 \mu \mathrm{M}$ ATP (premixed). At uptake minimum $\left[\mathrm{Ca}^{2+}\right] \sim 1 \mu \mathrm{M} 0.5 \% \mathrm{MeOH}$ or $30 \mu \mathrm{M}$ $\mathrm{Pg}$ was added to the assay. For thv experiments, light was turned on at the same time as the $\mathrm{Pg}$ was added. Data shown below. $(n=3 \pm S D)$. All rates below are in $\mathrm{nmol} / \mathrm{mg} / \mathrm{min}$.

\begin{tabular}{|c|c|c|c|}
\cline { 2 - 4 } \multicolumn{1}{c|}{} & $0.5 \% \mathrm{MeOH}$ & $30 \mu \mathrm{M} \mathrm{Pg}$ & $30 \mu \mathrm{M} \mathrm{Pg}+\mathrm{h} v$ \\
\hline $\mathrm{pH} 5.8$ & $0.32 \pm 0.05$ & $0.47 \pm 0.06$ & $0.47 \pm 0.06$ \\
\hline $\mathrm{pH} 6.4$ & $1.86 \pm 0.11$ & $2.53 \pm 0.33$ & $0.93 \pm 0.12$ \\
\hline $\mathrm{pH} 7.4$ & $8.61 \pm 1.07$ & $7.26 \pm 2.47$ & $3.58 \pm 0.77$ \\
\hline
\end{tabular}




\section{Discussion}

Pelargonidin has an interesting and complex modulating effect on sSR. In active efflux experiments performed at pH 7.4, it stimulates IRCR and inhibits CMCR in a concentration dependent manner over the concentrations assayed $(0.5 \mu \mathrm{M}-$ $45 \mu \mathrm{M})$.

It has been shown in this work that out of the several forms of Pelargonidin that exist in aqueous solution within the working physiological $\mathrm{pH}$ range of the $\mathrm{CRC}$, the colored prototropic forms including the flavylium cation, quiniodal base, and ionized quinoidal base, are responsible for the modulating effects on the CRC. This was confirmed with 'time of dilution' experiments where both the loss of IRCR stimulation and loss of CMCR inhibition corresponded with a concurrent loss of the colored forms of Pelargonidin. However, the modulating effects of the hemiketal and chalcone forms of Pelargonidin were not explicitly assayed for their possible modulating effects and therefore should not be discounted as possible CRC modulators.

The respective mole fractions of the prototropic forms responsible for modulation can be shifted with $\mathrm{pH}$. Experiments were performed at three different $\mathrm{pH}$ 's in an effort to isolate the different forms and their effects on modulation of $\mathrm{CRC} \mathrm{Ca}^{2+}$ efflux. The CRC's functional $\mathrm{pH}$ range didn't allow for the complete isolation of the individual colored forms of $\mathrm{Pg}$, however, a significant shift in the mole fractions of each of the three forms was achieved. Unfortunately, the form(s) 
responsible for stimulation of IRCR is difficult to confirm mainly because IRCR stimulation with persisted across all three pH's assayed. Even so, the result at $\mathrm{pH} 7.4$ does provide evidence that there is a $\mathrm{Pg}$ related $\mathrm{pH}$ dependent variable at play. The amount of stimulation by Pg decreases by $\sim 50 \%$ with respect to that of $0.5 \mathrm{mM}$ caffeine at $\mathrm{pH}$ 7.4. The difference in efficacy between caffeine and $\mathrm{Pg}$ across the $\mathrm{pH}$ jump from $\mathrm{pH} 6.4$ to $\mathrm{pH} 7.4$ could be explained by either an increase in the stimulation efficacy of caffeine or a decrease in stimulation efficacy of $\mathrm{Pg}$ (or possibly both). However, when the $\mathrm{pH}$ dependent IRCR data is normalized to the control, caffeine doesn't stimulate efflux any more at $\mathrm{pH} 7.4$ than at $\mathrm{pH} 6.4$ implying that it is not gaining efficacy. It should be noted that $1 \mathrm{mM}$ caffeine did significantly increase stimulation at $\mathrm{pH} 7.4$ indicating that the $\mathrm{CRC}$ isn't fully stimulated by $0.5 \mathrm{mM}$ caffeine (results not shown). So it seems probable that $\mathrm{Pg}$ is losing its stimulation ability or possibly gaining a competitive inhibitory nature (or both) with an increasing experimental $\mathrm{pH}$. The persistent IRCR stimulation with increasing $\mathrm{pH}$ may also be clouded due to a possible experimental design flaw. The stock solution of $\mathrm{Pg}$ is in acidified $\mathrm{MeOH}$ which stabilizes the cationic form. When Pg is added to the assay, it is being added as $\mathrm{AH}^{+}$. There will be a very short amount of time within the mixing time that the $\mathrm{AH}^{+}$ form could potentially interact with a fraction of the SSR prior to its deprotonating to the $A$ or $A^{-}$forms (irrespective of $\mathrm{pH}$ ). If real, this interaction could essentially minimize the buffer $\mathrm{pH}$ as an effective assay variable for $\mathrm{Pg}$ form isolation with regards to IRCR determination. This problem could be overcome by first pre- 
diluting Pg into the same efflux buffer with the same $\mathrm{pH}$ that is being assayed for efflux. This would theoretically establish the desired prototropic forms prior to addition to the efflux assay. Additional possible evidence for 'contamination' by $\mathrm{AH}^{+}$in the stock solution is the transient nature of the stimulation phase (see the $30 \mu \mathrm{M} P g$ trace in Figure 3.1) at the higher pH's that implies a transient, disappearing species such as $\mathrm{AH}^{+}$at high $\mathrm{pH}$. Stimulation at $\mathrm{pH} 5.8$ doesn't show the same transient IRCR stimulation characteristics like stimulation by Pg at the higher pH's. This may be due to the persistence (not disappearance) of a stimulating species at pH 5.8 (presence of flavylium cation), the lack of an inhibiting species at that $\mathrm{pH}$ (no ionized quinoidal base), or, possibly both have a part to play. Although it is difficult to specifically pin point the form of $\mathrm{Pg}$ that is stimulating IRCR, the general statement can be made that Pg stimulation, with respect to the control, is evident at all pH's but it is decreasing as the $\mathrm{pH}$ is increased.

Inhibition of CMCR efflux from the CRC is also concentration dependent. An increase in the $\mathrm{Pg}$ concentration causes a decrease in the CMCR rate (an increase in inhibition). Also similarly to the IRCR stimulation effects, the inhibition effects are also caused by the colored prototropic forms.

To isolate the prototropic forms responsible for stimulation and inhibition, the following argument can be made. CMCR is stimulated at pH 5.8 and inhibited at $\mathrm{pH}$ 6.4. At $\mathrm{pH}$ 5.8, the $\mathrm{AH}^{+}$and $\mathrm{A}$ forms exist with equal calculated 
concentrations of $\sim 5 \mu \mathrm{M}$ (Figure 4.13) but when jumping to $\mathrm{pH} 6.4$, the concentration of $\mathrm{AH}^{+}$is only slightly decreasing from $\sim 5 \mu \mathrm{M}$ to $\sim 3 \mu \mathrm{M}$ but $\mathrm{A}$ is significantly increasing from $\sim 5 \mu \mathrm{M}$ to $\sim 13 \mu \mathrm{M}$. That essentially rules out $\mathrm{A}$ as a stimulator which only leaves the option for it being inert or an inhibitor. For the same reason, $\mathrm{AH}^{+}$is identified as a stimulator. When jumping from $\mathrm{pH} 6.4$ to $\mathrm{pH}$ 7.4, CMCR inhibition increases slightly. Concurrently, the concentration of A decreases slightly from $13 \mu \mathrm{M}$ to $9 \mu \mathrm{M}$ and the concentration of $\mathrm{A}^{-}$increases significantly from $3 \mu \mathrm{M}$ to $17 \mu \mathrm{M}$. Therefore, $\mathrm{A}$ is, again, either inert or an inhibitor, and $A^{-}$is identified as a probable inhibitor.

\begin{tabular}{c|c|c|c|}
\multicolumn{1}{c}{} & \multicolumn{1}{c}{$\mathrm{AH}+$} & \multicolumn{1}{c}{$\mathrm{A}$} & \multicolumn{1}{c}{$\mathrm{A}-$} \\
\cline { 2 - 4 } Stimulating & $\mathrm{X}$ & & \\
\cline { 2 - 4 } Inert & & $\mathrm{X}$ & \\
\cline { 2 - 4 } Inhibiting & & $\mathrm{X}$ & $\mathrm{X}$ \\
\cline { 2 - 4 } & & &
\end{tabular}

Figure 5.1 Anthocyanidin Form vs. Proposed Modulator Type

The role of $A$ is a little less certain but seems to point toward one of four possibilities. First, it could be a weak stimulator. In this case it supplements the more potent stimulating effects of $\mathrm{AH}^{+}$at $\mathrm{pH} 5.8$ and doesn't significantly nullify the inhibiting effects of $\mathrm{A}^{-}$at $\mathrm{pH} 6.4$ and $\mathrm{pH}$ 7.4. Second, it could be a weak inhibitor. In this case it doesn't overpower the stimulating effects of $\mathrm{AH}^{+}$at $\mathrm{pH} 5.8$ and supports inhibition of $\mathrm{A}^{-}$at $\mathrm{pH} 6.4$ and $\mathrm{pH}$ 7.4. Third, $\mathrm{A}$ is a strong inhibitor but $\mathrm{AH}^{+}$is an even stronger stimulator and overpowers $\mathrm{A}$ at $\mathrm{pH}$ 5.8. The fourth 
possibility is that it is inert and has no effect. The A form doesn't seem to be a strong stimulator because if it was, then its effect should be more noticeable at $\mathrm{pH} 6.4$ where there is very little of the $A^{-}$form.

\subsection{Proposed Mechanisms of Stimulation and Inhibition}

You can't discuss the chemistry and reactivity of anthocyanidins without considering their antioxidant (cation radical scavenging) activity. The antioxidant activity of anthocyanidins increases with the increasing number of hydroxyl groups on the B ring. However, the antioxidant capability of Pelargonidin is not very good as compared to other anthocyanins and anthocyanidins due to the lack of a catechol or pyrogallo group on its B ring. Additionally, the scavenging activity of $\mathrm{Pg}$ was not $\mathrm{pH}$ dependent like other similar anthocyanidins were. Given that pelargonidin's effect on the CRC is shown in this work to have a pH dependence, the antioxidant activity of Pg doesn't seem to be a likely mechanism of CRC modulation by $\mathrm{Pg}$.

Another interesting and possible mechanism is ground state charge coupling where coupling between an electron donor (assigned to the $\mathrm{CRC}$ ) and the anthocyanidin electron acceptor occurs with a driving force being the transfer of charge from the donor to the acceptor. It this scenario, the excellent electron acceptor properties and charge coupling capability of the $\mathrm{AH}^{+}$form may be primarily responsible for stimulation of the $\mathrm{CRC}$ at lower $\mathrm{pH}$. At higher $\mathrm{pH}$, the 
better electron donor $A^{-}$form is bound to the $\mathrm{CRC}$ modulating site which forces an opposite charge shift and a resultant CRC inhibition effect. When $A^{-}$is excited (by irradiation), it becomes a better acid and therefore a better $\mathrm{e}^{-}$acceptor, the charge shifts back toward the excited form and inhibitory effect is removed.

This theory fits well with the current proposed CRC function proposed by the Abramson group. It also complements a possible mechanism for the inhibition of CMCR as well as the light dependent stimulation/loss of inhibition of CMCR.

However, the excited states of ionized quinoidal forms have not been studied nor substantiated by the literature so this is just a theory.

Another possible mechanism for the light dependent reaction is related to the photochomic behavior of synthetic and natural anthocyanins. At slightly acidic $\mathrm{pH}$, anthocyanins and related synthetics compounds will eventually transform to the low energy form, the trans-Chalcone. Numerous studies have shown that irradiation of the trans-Chalcone form will initiate photoisomerization back to the cis-Chalcone and Hemiketal forms eventually giving the prototropic forms depending on $\mathrm{pH}$. In the case of these experiments, the $\mathrm{pH}$ is sufficiently high that the back reaction is unfavored and probably does not have a role in the work presented here.

Yet another possible mechanism for the light dependent reaction is due to possible chalcone excited states. It has been reported by the Lima group that the two chalcone isomers of Malvin may have different excited state properties with 
respect to their acid-base equilibria (Lima et al. 1994) and therefore it is likely that other anthocyanins have similar properties. The amounts of Chalcone form in the work performed here are probably very small. Although the mole fraction of the colorless forms aren't specifically known for Pelargonidin, anthocyanidins generally have much more Hemiketal content than Chalcone content in equilibrium. This minimizes the potential for this mechanism as being relevant in this work.

\subsection{Closing Remarks}

Pelargonidin is a very unique modulator of the CRC. Never before has a compound been shown to have stimulating, inhibiting, and light dependent modulation effects on the CRC. Pelargonidin is different from most CRC modulators in that it exists as a mixture of forms that change with time and with $\mathrm{pH}$. Each of the very closely structured forms of Pg have different chemical properties and they also have correspondingly different effects on the CRC. This result in itself is very important and it supports the recently proposed CRC functional theory proposed by the Abramson group that electron donors and electron acceptors can have competing modulating effects on the $\mathrm{Ca}^{2+}$ transport properties of the CRC. 


\section{References}

Abramson, J. J, J. R Cronin, and G. Salama. 1988. "Oxidation Induced by Phthalocyanine Dyes Causes Rapid Calcium Release from Sarcoplasmic Reticulum Vesicles* 1." Archives of Biochemistry and Biophysics 263 (2): 245-55.

Abramson, J. J., E. Buck, G. Salama, J. E. Casida, and I. N. Pessah. 1988. "Mechanism of Anthraquinone-Induced Calcium Release from Skeletal Muscle Sarcoplasmic Reticulum." Journal of Biological Chemistry 263 (35): 18750.

Abramson, J.J., and G. Salama. 1988. "Sulfhydryl Oxidation and Ca2+ Release from Sarcoplasmic Reticulum." Mol.Cell Biochem. 82 (1-2): 81-84.

Abramson, Jonathan J., and Benjamin S. Marinov. 2012. "Method for Determining Redox Activity and Screening Compounds Based on Redox Activity."

Abramson, Jonathan J., and Guy Salama. 1988. "Sulfhydryl Oxidation and Ca2+ Release from Sarcoplasmic Reticulum." Molecular and Cellular Biochemistry 82 (1): 81-84. doi:10.1007/BF00242520.

Abramson, Jonathan J., and Guy Salama. 1989. "Critical Sulfhydryls Regulate Calcium Release from Sarcoplasmic Reticulum." Journal of Bioenergetics and Biomembranes 21 (2): 283-94. doi:10.1007/BF00812073.

Andersen, Øyvind M., and Kenneth R. Markham. 2006. Flavonoids: Chemistry, Biochemistry, and Applications. CRC Press.

Asen, S., R. N. Stewart, and K. H. Norris. 1972. "Co-Pigmentation of Anthocyanins in Plant Tissues and Its Effect on Color." Phytochemistry 11 (3): 1139-44. doi:10.1016/S0031-9422(00)88467-8.

Belevych, A. E, D. Terentyev, S. Viatchenko-Karpinski, R. Terentyeva, A. Sridhar, Y. Nishijima, L. D Wilson, et al. 2009. "Redox Modification of Ryanodine Receptors Underlies Calcium Alternans in a Canine Model of Sudden Cardiac Death." Cardiovascular Research.

Belevych, A. E, D. Terentyev, S. Viatchenko-Karpinski, R. Terentyeva, A. Sridhar, C. Rio, Y. Nishijima, C. Carnes, G. Billman, and S. Gyorke. 2008. "Abstract 1539: Redox-Modification of Ryanodine Receptor Underlies Sarcoplasmic Reticulum Luminal Calcium-Dependent Cardiac Alternans in a Canine Model of Sudden Cardiac Death." Circulation 118 (18 Supplement).

Belevych, A., Z. Kubalova, D. Terentyev, R. L Hamlin, C. A Carnes, and S. Gylörke. 2007. "Enhanced Ryanodine Receptor-Mediated Calcium Leak Determines Reduced Sarcoplasmic Reticulum Calcium Content in Chronic Canine Heart Failure." Biophysical Journal 93 (11): 4083-92.

Belevych, A., and D. Terentyev. 2010. "Redox Modification of Ryanodine Receptors in Cardiac Arrhythmia And Failure: A Potential Therapeutic Target." 
Boots, A. W, N. Kubben, G. R.M.M Haenen, and A. Bast. 2003. "Oxidized Quercetin Reacts with Thiols rather than with Ascorbate: Implication for Quercetin Supplementation." Biochemical and Biophysical Research Communications 308 (3): 560-65.

Borkowski, T., H. Szymusiak, A. Gliszczynska-Swiglo, I. M.C.M Rietjens, and B. Tyrakowska. 2005. "Radical Scavenging Capacity of Wine Anthocyanins Is Strongly pH-Dependent." J. Agric. Food Chem. 53 (14): 5526-34.

Brouillard, R., and B. Delaporte. 1977. "Chemistry of Anthocyanin Pigments. 2. Kinetic and Thermodynamic Study of Proton Transfer, Hydration, and Tautomeric Reactions of Malvidin 3-Glucoside." Journal of the American Chemical Society 99 (26): 8461-68.

Brouillard, R., and J. E Dubois. 1977. "Mechanism of the Structural Transformations of Anthocyanins in Acidic Media." Journal of the American Chemical Society 99 (5): 1359-64.

Brouillard, R., G. A. lacobucci, and J. G. Sweeny. 1982. "Chemistry of Anthocyanin Pigments. 9. UV-Visible Spectrophotometric Determination of the Acidity Constants of Apigeninidin and Three Related 3-Deoxyflavylium Salts." Journal of the American Chemical Society 104 (26): 7585-90.

Brouillard, R., G. Mazza, Z. Saad, A. M. Albrecht-Gary, and A. Cheminat. 1989. "The Co-Pigmentation Reaction of Anthocyanins: A Microprobe for the Structural Study of Aqueous Solutions." Journal of the American Chemical Society 111 (7): 2604-10. doi:10.1021/ja00189a039.

Cabrita, Luis, Torgils Fossen, and Oyvind M Andersen. 2000a. "Colour and Stability of the Six Common Anthocyanidin 3-Glucosides in Aqueous Solutions." Food Chemistry 68 (1): 101-7.

Cabrita, Luis, Torgils Fossen, and Øyvind M. Andersen. 2000b. "Colour and Stability of the Six Common Anthocyanidin 3-Glucosides in Aqueous Solutions." Food Chemistry 68 (1): 101-7. doi:10.1016/S03088146(99)00170-3.

Canada, A. T., E. Giannella, T. D. Nguyen, and R. P. Mason. 1990. "The Production of Reactive Oxygen Species by Dietary Flavonols." Free Radical Biology \& Medicine 9 (5): 441-49.

Dangles, O., G. Fargeix, and C. Dufour. 2000. "Antioxidant Properties of Anthocyanins and Tannins: A Mechanistic Investigation with Catechin and the 3', 4', 7-Trihydroxyflavylium Ion." Journal of the Chemical Society, Perkin Transactions 22000 (8): 1653-63.

Dangles, Olivier, Norio Saito, and Raymond Brouillard. 1993. "Anthocyanin Intramolecular Copigment Effect." Phytochemistry 34 (1): 119-24. doi:10.1016/S0031-9422(00)90792-1.

Davies, K.J., A.T. Quintanilha, G.A. Brooks, and L. Packer. 1982. "Free Radicals and Tissue Damage Produced by Exercise Three-Dimensional Visualization of FKBP12.6 Binding to an Open Conformation of Cardiac Ryanodine Receptor." Biochem.Biophys.Res.Commun. 107 (4): 11981205. 
Davies, M. J., and R. T. Dean. 1997. Radical-Mediated Protein Oxidation: From Chemistry to Medicine. Oxford University Press.

Dhalla, N S, L Golfman, S Takeda, N Takeda, and M Nagano. 1999. "Evidence for the Role of Oxidative Stress in Acute Ischemic Heart Disease: A Brief Review." The Canadian Journal of Cardiology 15 (5): 587-93.

Du, G. G, B. Sandhu, V. K Khanna, X. H Guo, and D. H MacLennan. 2002. "Topology of the $\mathrm{Ca} 2+$ Release Channel of Skeletal Muscle Sarcoplasmic Reticulum (RyR1)." Proceedings of the National Academy of Sciences of the United States of America 99 (26): 16725.

Dulhunty, A., C. Haarmann, D. Green, and J. Hart. 2000. "How Many Cysteine Residues Regulate Ryanodine Receptor Channel Activity? 1." Antioxid.Redox.Signal. 2 (1): 27-34.

Estevez, L., and R. A. Mosquera. 2008. "Molecular Structure and Antioxidant Properties of Delphinidin." The Journal of Physical Chemistry. A 112 (42): 10614.

Ferreira da Silva, Palmira, J. C Lima, F. H Quina, and A. L Macanita. 2004. "Excited-State Electron Transfer in Anthocyanins and Related Flavylium Salts." J. Phys. Chem. A 108 (46): 10133-40.

Ferreira da Silva, Palmira, João C. Lima, Adilson A. Freitas, Karina Shimizu, Antonio L. Maçanita, and Frank H. Quina. 2005. "Charge-Transfer Complexation as a General Phenomenon in the Copigmentation of Anthocyanins." The Journal of Physical Chemistry A 109 (32): 7329-38. doi:10.1021/jp052106s.

Fridovich, Irwin. 1978. "The Biology of Oxygen Radicals." Science 201 (4359). New Series: 875-80.

Galati, G., T. Chan, B. Wu, and P. J O'Brien. 1999. "Glutathione-Dependent Generation of Reactive Oxygen Species by the Peroxidase-Catalyzed Redox Cycling of Flavonoids." Chem. Res. Toxicol 12 (6): 521-25.

Graziani, Y., R. Chayoth, N. Karny, B. Feldman, and J. Levy. 1982. "Regulation of Protein Kinases Activity by Quercetin in Ehrlich Ascites Tumor Cells." Biochimica et Biophysica Acta (BBA)-General Subjects 714 (3): 415-21.

Guerra, L., E. Cerbai, S. Gessi, P. A Borea, and A. Mugelli. 1996. "The Effect of Oxygen Free Radicals on Calcium Current and Dihydropyridine Binding Sites in Guinea-Pig Ventricular Myocytes." British Journal of Pharmacology 118 (5): 1278.

Harborne, J. B., T. J. Mabry, and H. Mabry. 1975. The Flavonoids. London.

Harborne, J.B. 1967. Comparative Biochemistry of the Flavonoids. Academic Press, London.

He, X., Y. Liu, V. Sharma, R. T Dirksen, R. Waugh, S. S Sheu, and W. Min. 2003. "ASK1 Associates with Troponin T and Induces Troponin T Phosphorylation and Contractile Dysfunction in Cardiomyocytes." American Journal of Pathology 163 (1): 243. 
Hidalgo, C., and P. Donoso. 2008. "Crosstalk between Calcium and Redox Signaling: From Molecular Mechanisms to Health Implications." Antioxidants \& Redox Signaling 10 (7): 1275-1312.

Higuchi, Y., K. Otsu, K. Nishida, S. Hirotani, H. Nakayama, O. Yamaguchi, Y. Matsumura, H. Ueno, M. Tada, and M. Hori. 2002. "Involvement of Reactive Oxygen Species-Mediated NF-[kappa] B Activation in TNF[alpha]-Induced Cardiomyocyte Hypertrophy." Journal of Molecular and Cellular Cardiology 34 (2): 233-40.

Hodnick, W. F, F. S Kung, W. J Roettger, C. W Bohmont, and R. S Pardini. 1986. "Inhibition of Mitochondrial Respiration and Production of Toxic Oxygen Radicals by Flavonoids:: A Structure-Activity Study." Biochemical Pharmacology 35 (14): 2345-57.

Hodnick, W. F, E. B MllosavljeviC, J. H Nelson, and R. S Pardini. 1988. "Electrochemistry of Flavonoids:: Relationships between Redox Potentials, Inhibition of Mitochondrial Respiration, and Production of Oxygen Radicals by Flavonoids." Biochemical Pharmacology 37 (13): 2607-11.

Hoshino, Tsutomu, Ushino Matsumoto, and Toshio Goto. 1980. "Evidences of the Self-Association of Anthocyanins I. Circular Dichroism of Cyanin Anhydrobase." Tetrahedron Letters 21 (18): 1751-54. doi:10.1016/S00404039(00)77827-0.

Hoshino, Tsutomu, Ushino Matsumoto, and Toshio Goto. 1981. "Self-Association of Some Anthocyanins in Neutral Aqueous Solution." Phytochemistry 20 (8): 1971-76. doi:10.1016/0031-9422(81)84047-2.

Huikuri, H. V, A. Castellanos, and R. J Myerburg. 2001. "Sudden Death due to Cardiac Arrhythmias." New England Journal of Medicine 345 (20): 1473.

Jurd, L. 1963. "Anthocyanins and Related Compounds. I. Structural Transformations of Flavylium Salts in Acidic Solutions." The Journal of Organic Chemistry 28 (4): 987-91.

Jurd, L. 1964. "Anthocyanins and Related Compounds. III. Oxidation of Substituted Flavylium Salts to 2-Phenylbenzofurans." The Journal of Organic Chemistry 29 (9): 2602-5.

Jurd, L., and T. A. Geissman. 1963. "Anthocyanins and Related Compounds. II. Structural Transformations of Some Anhydro Bases." The Journal of Organic Chemistry 28 (9): 2394-97.

Jurd, L., and A. C. Waiss. 1965. "Anthocyanins and Related compounds-VI Flavylium Salt—phloroglucinol Condensation Products." Tetrahedron 21 (6): 1471-83.

Kalckar, HM. 1947. Methods in Enzymology, Vol. 3. New York, Academic Press.

Kaldas, M. I, U. K Walle, H. van der Woude, J. E.M McMillan, and T. Walle. 2005. "Covalent Binding of the Flavonoid Quercetin to Human Serum Albumin." J. Agric. Food Chem 53 (10): 4194-97.

Kaplan, P., E. Babusikova, J. Lehotsky, and D. Dobrota. 2003. "Free RadicalInduced Protein Modification and Inhibition of Ca 2+-ATPase of Cardiac 
Sarcoplasmic Reticulum." Molecular and Cellular Biochemistry 248 (1): 41-47.

Khatri, J. J, C. Johnson, R. Magid, S. M Lessner, K. M Laude, S. I Dikalov, D. G Harrison, H. J Sung, Y. Rong, and Z. S Galis. 2004. "Vascular Oxidant Stress Enhances Progression and Angiogenesis of Experimental Atheroma." Circulation 109 (4): 520.

Kim, D. H., S. T. Ohnishi, and N. Ikemoto. 1983. "Kinetic Studies of Calcium Release from Sarcoplasmic Reticulum in Vitro." Journal of Biological Chemistry 258 (16): 9662.

Kourie, J. I. 1998. "Interaction of Reactive Oxygen Species with Ion Transport Mechanisms." American Journal of Physiology- Cell Physiology 275 (1): C1.

Lee, Eun Hui, Gerhard Meissner, and Do Han Kim. 2002. "Effects of Quercetin on Single Ca2+ Release Channel Behavior of Skeletal Muscle." Biophysical Journal 82: 1266-77.

Lehnart, S. E, X. H.T Wehrens, P. J Laitinen, S. R Reiken, S. X Deng, Z. Cheng, D. W Landry, K. Kontula, H. Swan, and A. R Marks. 2004. "Sudden Death in Familial Polymorphic Ventricular Tachycardia Associated with Calcium Release Channel (ryanodine Receptor) Leak." Circulation 109 (25): 3208. Lima, J. C., Parvin Danesh, Paulo Figueiredo, Fernando S. Pina, and António Maçanita. 1994. "Excited States of Anthocyanins: The Chalcone Isomers of Malvidin 3,5-Diglucoside." Photochemistry and Photobiology 59 (4): 412-18. doi:10.1111/j.1751-1097.1994.tb05057.x.

MacLennan, D. H, C. C. Yip, G. H. Iles, and P. Seeman. 1973. "Isolation of Sarcoplasmic Reticulum Proteins." In Cold Spring Harbor Symposia on Quantitative Biology, 37:469.

Marinov, B. S, R. O Olojo, R. Xia, and J. J Abramson. 2007. "Non-Thiol Reagents Regulate Ryanodine Receptor Function by Redox Interactions That Modify Reactive Thiols." Antioxidants \& Redox Signaling 9 (5): 609-21.

Martonosi, A., and R. Feretos. 1964a. "Sarcoplasmic Reticulum I. THE UPTAKE OF CA++ BY SARCOPLASMIC RETICULUM FRAGMENTS." Journal of Biological Chemistry 239 (2): 648-58.

Martonosi, A., and R. Feretos. 1964b. "Sarcoplasmic Reticulum II. CORRELATION BETWEEN ADENOSINE TRIPHOSPHATASE ACTIVITY AND CA++ UPTAKE." Journal of Biological Chemistry 239 (2): 659-68.

Metodiewa, D., A. K Jaiswal, N. Cenas, E. Dickancaité, and J. Segura-Aguilar. 1999. "Quercetin May Act as a Cytotoxic Prooxidant after Its Metabolic Activation to Semiquinone and Quinoidal Product." Free Radical Biology and Medicine 26 (1-2): 107-16.

Moopanar, Terence R, and David G Allen. 2005. "Reactive Oxygen Species Reduce Myofibrillar Ca2+ Sensitivity in Fatiguing Mouse Skeletal Muscle at $37^{\circ} \mathrm{C}$." The Journal of Physiology 564 (1): 189-99. doi:10.1113/jphysiol.2005.083519. 
Moreira, Paulo F., Leticia Giestas, Chang Yihwa, Carolina Vautier-Giongo, Frank H. Quina, Antonio L. Maçanita, and João C. Lima. 2003. "Ground- and Excited-State Proton Transfer in Anthocyanins: From Weak Acids to Superphotoacids." The Journal of Physical Chemistry A 107 (21): 4203-10. doi:10.1021/jp027260i.

Noda, Y., T. Kaneyuki, A. Mori, and L. Packer. 2002. "Antioxidant Activities of Pomegranate Fruit Extract and Its Anthocyanidins: Delphinidin, Cyanidin, and Pelargonidin." J. Agric. Food Chem 50 (1): 166-71.

Ogawa, Y, S Harigaya, S Ebashi, and KS Lee. 1971. "Sarcoplasmic Reticulum: Calcium Uptake and Release Systems in Muscle." Methods in Pharmacology 1: 327-46.

Pina, F., M. J Melo, A. J Parola, M. Maestri, and V. Balzani. 1998. "pH-Controlled Photochromism of Hydroxyflavylium lons." CHEMISTRY-WEINHEIMEUROPEAN JOURNAL- 4: 2001-7.

Quina, F. H, A. A Freitas, A. L Maçanita, P. F da Silva, and J. C Lima. 2006. "The (photo) Chemistry of Anthocyanins." The SpectrumA A 19 (3): 18.

Rice-Evans, Catherine A, Nicholas J Miller, and George Paganga. 1996. "Structure-Antioxidant Activity Relationships of Flavonoids and Phenolic Acids." Free Radical Biology and Medicine 20 (7): 933-56.

Robinson, Gertrude Maud, and Robert Robinson. 1931. "A Survey of Anthocyanins. I." Biochemical Journal 25 (5): 1687-1705.

Satue-Gracia, M. T, M. Heinonen, and E. N Frankel. 1997. "Anthocyanins as Antioxidants on Human Low-Density Lipoprotein and Lecithin- Liposome Systems." J. Agric. Food Chem 45 (9): 3362-67.

Schafer, F. Q, and G. R Buettner. 2001. "Redox Environment of the Cell as Viewed through the Redox State of the Glutathione Disulfide/glutathione Couple." Free Radical Biology and Medicine 30 (11): 1191-1212.

Sekher Pannala, A., T. S Chan, P. J O'Brien, and C. A Rice-Evans. 2001. "Flavonoid B-Ring Chemistry and Antioxidant Activity: Fast Reaction Kinetics." Biochemical and Biophysical Research Communications 282 (5): 1161-68.

Sekher Pannala, Ananth, Tom S Chan, Peter J O'Brien, and Catherine A RiceEvans. 2001. "Flavonoid B-Ring Chemistry and Antioxidant Activity: Fast Reaction Kinetics." Biochemical and Biophysical Research Communications 282 (5): 1161-68.

Sen, C. K, and L. Packer. 2000. "Thiol Homeostasis and Supplements in Physical Exercise." American Journal of Clinical Nutrition 72 (2): 653S.

Sharma, S., J. V Adrogue, L. Golfman, I. Uray, J. Lemm, K. Youker, G. P Noon, O. H. Frazier, and H. Taegtmeyer. 2004. "Intramyocardial Lipid Accumulation in the Failing Human Heart Resembles the Lipotoxic Rat Heart." The FASEB Journal 18 (14): 1692.

Trimm, J. L., G. Salama, and J. J. Abramson. 1986. "Sulfhydryl Oxidation Induces Rapid Calcium Release from Sarcoplasmic Reticulum Vesicles." Journal of Biological Chemistry 261 (34): 16092. 
Van Acker, S. A. 1996. "Structural Aspects of Antioxidant Activity of Flavonoids." Free Radical Biology and Medicine 20 (3): 331-42.

Van Acker, S. A., M. J. De Groot, D. J. Van den Berg, M. N. Tromp, K. G DonnéOp, W. J. Van der Vijgh, and A. Bast. 1996. "A Quantum Chemical Explanation of the Antioxidant Activity of Flavonoids." Chemical Research in Toxicology 9 (8): 1305.

Vanacker, S., M. Tromp, G. Haenen, W. J. F. Vandervijgh, and A. Bast. 1995. "Flavonoids as Scavengers of Nitric Oxide Radical." Biochemical and Biophysical Research Communications 214 (3): 755-59.

Vaya, J., and M. Aviram. 2001. "Nutritional Antioxidants Mechanisms of Action, Analyses of Activities and Medical Applications." Current Medicinal Chemistry-Immunology, Endocrine \&\# 38; Metabolic Agents 1 (1): 99-117.

Wada, M., H. Kido, K. Ohyama, T. Ichibangase, N. Kishikawa, Y. Ohba, M. N. Nakashima, N. Kuroda, and K. Nakashima. 2007. "Chemiluminescent Screening of Quenching Effects of Natural Colorants against Reactive Oxygen Species: Evaluation of Grape Seed, Monascus, Gardenia and Red Radish Extracts as Multi-Functional Food Additives." Food Chemistry 101 (3): 980-86.

Xu, L., J. P Eu, G. Meissner, and J. S Stamler. 1998. "Activation of the Cardiac Calcium Release Channel (ryanodine Receptor) by Poly-S-Nitrosylation." Science 279 (5348): 234.

Ye, Yanping, Daniel Yaeger, Laura J Owen, Jorge O Escobedo, Jialu Wang, Jeffrey D Singer, Robert M Strongin, and Jonathan J Abramson. 2012. "Designing Calcium Release Channel Inhibitors with Enhanced Electron Donor Properties: Stabilizing the Closed State of Ryanodine Receptor Type 1." Molecular Pharmacology 81 (1): 53-62. doi:10.1124/mol.111.074740.

Yeh, Y. H, R. Wakili, X. Y Qi, D. Chartier, P. Boknik, S. Kaab, U. Ravens, P. Coutu, D. Dobrev, and S. Nattel. 2008. "Calcium-Handling Abnormalities Underlying Atrial Arrhythmogenesis and Contractile Dysfunction in Dogs with Congestive Heart Failure." Circulation: Arrhythmia and Electrophysiology 1 (2): 93.

Zable, Anthony C, Terence G Favero, and Jonathan J Abramson. 1997. "Glutathione Modulates Ryanodine Receptor from Skeletal Muscle Sarcoplasmic Reticulum. EVIDENCE FOR REDOX REGULATION OF THE Ca2+ RELEASE MECHANISM." J. Biol. Chem. 272 (11): 7069-77.

Zima, A. V, and L. A Blatter. 2006. "Redox Regulation of Cardiac Calcium Channels and Transporters." Cardiovascular Research 71 (2): 310. 